\title{
Chapter 7 \\ Ecotoxicological Impacts of Micro- and Nanoplastics in Terrestrial and Aquatic Environments
}

\author{
Tânia Gomes, Agathe Bour, Claire Coutris, Ana Catarina Almeida, \\ Inger Lise Bråte, Raoul Wolf, Michael S. Bank, and Amy L. Lusher
}

\begin{abstract}
Plastic pollution is a widespread environmental problem that is currently one of the most discussed issues by scientists, policymakers and society at large. The potential ecotoxicological effects of plastic particles in a wide range of organisms have been investigated in a growing number of exposure studies over the past years. Nonetheless, many questions still remain regarding the overall effects of microplastics and nanoplastics on organisms from different ecosystem compartments, as well as the underlying mechanisms behind the observed toxicity. This chapter provides a comprehensive literature review on the ecotoxicological impacts of microplastics and nanoplastics in terrestrial and aquatic organisms in the context of particle characteristics, interactive toxicological effects, taxonomic gradients and with a focus on synergies with associated chemicals. Overall, a total of 220 references were reviewed for their fulfilment of specific quality criteria (e.g. experimental design, particle characteristics, ecotoxicological endpoints and findings), after which 175 were included in our assessment. The analysis of the reviewed studies
\end{abstract}

T. Gomes $(\bowtie) \cdot$ A. C. Almeida · I. L. Bråte · R. Wolf · A. L. Lusher

Section of Ecotoxicology and Risk Assessment, Norwegian Institute for Water Research

(NIVA), Oslo, Norway

e-mail: tania.gomes@niva.no; ana.catarina.almeida@niva.no; inger.lise.nerland@niva.no; raoul.wolf@niva.no; Amy.Lusher@niva.no
A. Bour
Department of Biological and Environmental Sciences, University of Gothenburg,
Gothenburg, Sweden
e-mail: agathe.bour@bioenv.gu.se
C. Coutris
Division of Environment and Natural Resources, Norwegian Institute of Bioeconomy
Research (NIBIO), Ås, Norway
e-mail: claire.coutris@nibio.no
M. S. Bank
Institute of Marine Research, Bergen, Norway
University of Massachusetts Amherst, Amherst, MA, USA
e-mail: Michael.Bank@hi.no; mbank@eco.umass.edu 
revealed that organisms' responses were overall influenced by the physicochemical heterogeneity of the plastic particles used, for which distinct differences were attributed to polymer type, size, morphology and surface alterations. On the other hand, little attention has been paid to the role of additive chemicals in the overall toxicity. There is still little consistency regarding the biological impacts posed by plastic particles, with observed ecotoxicological effects being highly dependent on the environmental compartment assessed and specific morphological, physiological and behavioural traits of the species used. Nonetheless, evidence exists of impacts across successive levels of biological organization, covering effects from the subcellular level up to the ecosystem level. This review presents the important research gaps concerning the ecotoxicological impacts of plastic particles in different taxonomical groups, as well as recommendations on future research priorities needed to better understand the ecological risks of plastic particles in terrestrial and aquatic environments.

\subsection{Introduction}

Plastic particles are a widespread environmental problem and possibly an important human health issue that has recently garnered significant interest from scientists, policymakers, natural resource managers, media entities and the public (Prata et al. 2021; Thompson et al. 2004). The complexity of plastic pollution follows a dynamic environmental cycle (Bank and Hansson 2019, 2021), which involves bidirectional fluxes across different ecosystem compartments including the atmosphere, hydrosphere, biosphere as well as terrestrial environments (Vince and Hardesty 2017; Windsor et al. 2019). There has been an outburst of research into plastic pollution in recent years, with research focusing on sources, presence and transport in the environment (as presented in other chapters in this volume - e.g. Bank and Hansson 2021; Kallenbach et al. 2021; Lundebye et al. 2021). Despite this, many questions remain regarding the ecotoxicology of plastic particles and their overall effect on wild populations of biota from different ecosystem compartments (de Sá et al. 2018; Galloway et al. 2017; GESAMP 2020; Law and Thompson 2014; Prakash et al. 2020; VKM 2019).

Many of the challenges related to understanding the ecotoxicological consequences of plastic particles are inherently linked to their complex nature as environmental contaminants (Rochman et al. 2019). Microplastics are made up of different polymers and additives which can influence their impact on living organisms. Furthermore, microplastics can originate from many different sources. Some are specifically designed (primary microplastics), whereas others are formed through the breakdown of larger plastics (secondary microplastics) (Cole et al. 2011). The terminologies used to describe plastic particles can also hold significant weight in terms of how data is interpreted. Microplastics are most commonly defined by their size, being less than $5 \mathrm{~mm}$ (GESAMP 2019), although definitions used across different research fields introduce inconsistencies, especially with reference to their 
lower size limit (Hartmann et al. 2019). For the purpose of this chapter, we kept the definitions of microplastics as $<5 \mathrm{~mm}$ in size (GESAMP 2019), even though much of the ecotoxicological data presented involved particles $<1 \mathrm{~mm}$ in size. The lower size limit of microplastics is here defined as $1 \mu \mathrm{m}$, following the definition set by Hartmann et al. (2019) in reference to nanoplastics $(1-1000 \mathrm{~nm})$.

A wide array of impacts and toxic effects have been reported for both microplastics and nanoplastics, and as a brief example, several studies have examined the direct and indirect effects of a broad range of size fractions on a range of different species. Effects observed include impacts on reproduction, population dynamics, oxidative stress, ingestion, physiology, feeding behaviour, metabolic and hepatic functions, as well as interactions with other contaminants (e.g. Anbumani and Kakkar 2018; Haegerbaeumer et al. 2019; Kögel et al. 2020). However, the extent to which the available data is useful to interpret consequences across different biological levels (cellular-organ-individual-population; Galloway et al. 2017) has been called into question (VKM 2019).

The potential risks of micro- and nanoplastics to the environment and biota health have been the subject of several recent reviews and risk assessments by international authorities including (i) the European Food Safety Authority (EFSA), Panel on Contaminants in the Food Chain (CONTAM) on the presence of nano- and microplastics in food (EFSA CONTAM Panel 2016); (ii) a technical paper from the Food and Agriculture Organization of the United Nations (FAO) on the status of knowledge on microplastics related to fisheries and aquaculture (Lusher et al. 2017); (iii) a scientific perspective on microplastics in nature and society (SAPEA 2019); (iv) an updated knowledge summary built on the foundations of the previous three reports (VKM 2019); and (v) an ecological and human health risk assessment conducted by the Joint Group of Experts on the Scientific Aspects of Marine Environmental Protection (GESAMP 2020). During the VKM systematic assessment (VKM 2019), publications were judged based on a set of criteria to assess their quality, and those with poor quality were excluded. The accepted papers were used to attempt conceptual human and environmental risk assessments; however, many uncertainties and knowledge gaps were identified. One of the most significant limitations was that nano- and microplastics were treated as one entity, ignoring their physicochemical heterogeneity (Rochman et al. 2019). There was also a disproportionate representation between different species and different environmental compartments (marine, brackish, freshwater, terrestrial), which hampered the understanding of impacts in specific ecosystems. Much of the information available focused on species which are routinely used in standard test guidelines developed by the Organization for Economic Cooperation and Development (OECD) and the International Organization for Standardization (ISO).

Here we provide an overview and synthesis of microplastic and nanoplastic ecotoxicology (2012 - August 2019) in the context of particle characteristics (e.g. polymer type, morphology, size fractions), interactive toxicological effects, taxonomic gradients and with a focus on other potential synergies with associated chemical compounds. The specific objectives of this chapter are to (1) synthesize the literature and scientific consensus regarding the ecotoxicity of microplastics and 
nanoplastics and their potential relationships with other chemical compounds; (2) evaluate the effects of microplastic and nanoplastic concentrations, polymer type, size and morphology, experimental design, exposure time and pathways on ecotoxicological endpoints; (3) identify critical data and knowledge gaps in microplastic and nanoplastic toxicity research; and (4) suggest approaches and guidelines for addressing the most pressing questions and for advancing microplastic and nanoplastic ecotoxicity research.

\subsection{Methods Used for Review Process}

\subsubsection{Overall Review Process}

A comprehensive assessment of available published peer-reviewed literature was conducted up to August 2019 using the Web of Science, ScienceDirect, Scopus, PubMed and Google Scholar databases. The search was based on a combination of keyword terms, such as microplastic, nanoplastic, effects, toxicity, specific phylum/ sub-phylum and specific target organisms (e.g. fish, crustaceans, bivalves, etc.), in any topic, title or keywords. Additional targeted searches were conducted from references included in relevant peer-reviewed articles (including review papers), as well as relevant reports overlooked by the search engines used. Of the identified references, only those focusing on studies reporting ecotoxicological effects were retained for further analysis. Studies only describing ingestion and egestion of plastic particles without reporting toxicity assessment were excluded from the collected literature. The ingestion of nano- and microplastics by biota has been described in previous review articles (e.g. Collard et al. 2019; Wang et al. 2019b, 2020). Particles $>5 \mathrm{~mm}$ were not included in this assessment. An overview of the review process can be found in Fig. 7.1.

\subsubsection{Extraction and Compilation of Data}

A total of 220 references containing relevant ecotoxicity data were selected for review, after which the following information was extracted and compiled in an EXCEL spreadsheet for subsequent analysis: (i) experimental design, (ii) group of organisms, (iii) particles used, (iv) ecotoxicological endpoints and (v) publication information.

In terms of experimental design, the information extracted was categorized according to (i) exposure time, as described by authors and converted into days; (ii) particle concentration, in mass and/or particle number; (iii) exposure regime, static, semi-static or flow-through; (iv) replication, as number of independent replicate experiments or number of replicate exposure vessels; (v) use of controls, negative 


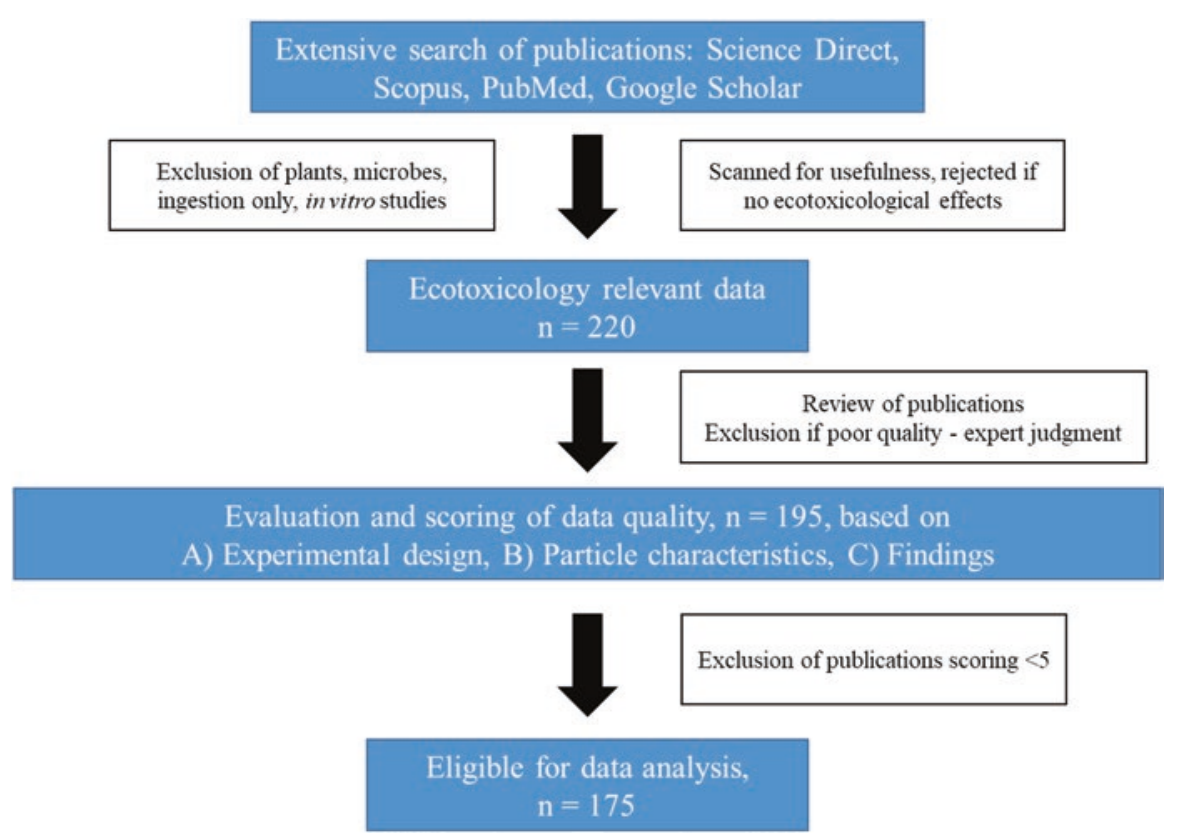

Fig. 7.1 Schematics on the literature review search of references containing relevant ecotoxicity data regarding micro- and nanoplastics

control (no plastic, only exposure media), additive/preservative control (e.g. tween 20, $\mathrm{NaNO}_{3}$ ), particle control (kaolin, clay, etc.) or chemical control (co-exposure with other contaminants); (vi) confirmation of test concentration, nominal versus measured; (vii) exposure route, water, sediment/soil, food (e.g. inert pellets), prey (food chain) or others; and (viii) additional information, not included in the previous categories.

The types of organisms used in the studies reviewed were divided into the following taxonomic groups: Annelida, Arthropoda, Chordata, Cnidaria, Echinodermata, Mollusca, Nematoda, Phytoplankton and Rotifera. For each group, the following information was extracted: (i) taxonomic class; (ii) species, full Latin name; (iii) developmental stage, egg, embryo, larvae, juvenile, adult and others; (iv) feeding strategy, filter feeder, deposit feeder, scavenger, suspension feeder, predator or others; (v) supply of food during exposure; (vi) environmental compartment, freshwater, seawater or soil/sediment; (vii) replication, number of organisms per endpoint determination; and (viii) ingestion, checked, yes or no. Toxicity studies on higher plants, bacteria and in vitro were not included in this review.

For information on the particles used, the following categories were chosen as the most representative in terms of physicochemical characteristics: (i) polymer type; (ii) particle morphology, spheres, fibres, fragments (same as irregular), pellets or others if missing; (iii) surface modification, plain, $\mathrm{COOH}, \mathrm{NH}_{2}$, others or not specified; (iv) particle size; (v) co-exposure/mixture, yes or no in case of spiking 
with chemicals; (vi) chemical details, chemical name and concentration used; (vii) characterization, only by the supplier and/or additional by the authors; and (viii) others, additional information on particles, e.g. fluorescence, density, etc. In terms of particle type, the following list of polymer types was used to classify the particles used in the selected studies, which include the main groups of polymer materials reported in PlasticsEurope (2019): polyethylene (PE), polyethylene terephthalate (PET), polystyrene (PS), polypropylene (PP), polyvinylchloride (PVC), polyamide (PA), acrylonitrile butadiene styrene (ABS), nylon, polycarbonate (PC), polyhydroxy butyrate (PHB), polylactic acid (PLA), polymethylmethacrylate (PMMA), polyoxymethylene (POM), styrene acrylonitrile (SAN), phenylurea-formaldehyde (PUF), proprietary polymer as well as not specified (NS). High- and low-density PE were not differentiated but included in an overall PE group. To assess the impact of particle size (i.e. nanoplastic versus microplastic), one or more of the following size categories were used: $<0.05 \mu \mathrm{m}, 0.05-0.099 \mu \mathrm{m}, 0.1-0.99 \mu \mathrm{m}, 1-9 \mu \mathrm{m}, 10-19 \mu \mathrm{m}$, 20-49 $\mu \mathrm{m}, 50-99 \mu \mathrm{m}, 100-199 \mu \mathrm{m}, 200-500 \mu \mathrm{m}$ and $>500 \mu \mathrm{m}$.

The effects reported were categorized following the levels of biological organization as suggested by Galloway et al. (2017): subcellular (e.g. enzyme activity, gene expression, oxidative damage), cellular (e.g. apoptosis, membrane stability), organ (e.g. histology, energetic reserves), individual (e.g. mortality, growth), population (e.g. reproduction, larval development) and ecosystem (e.g. behaviour, ecosystem function, community shifts). In cases where a large amount of data was generated in a specific study, detailed information on biological endpoints was also recorded, such as gene and protein expression data, enzymatic activities, histopathology effects, etc. Presence or absence of significant effects were recorded as yes or no, followed by the direction of the effect recorded as up (induction) and down (inhibition). Whenever disclosed, the ECx (concentration showing a $\mathrm{x} \%$ effect), NOEC (no observed effect concentration) and LOEC (lowest observed effect concentration) values were also recorded.

Within the selected references, descriptions of experiments using different experimental conditions (e.g. time of exposure and concentration), two or more species (e.g. life stages and route of exposure) or particles with different characteristics (e.g. polymer type, size, morphology) were considered as individual records and added as separate entries in the data matrix. For example, whenever the size distribution for a given particle spanned more than one of the defined size categories, multiple entries were recorded, each corresponding to a size category. If a study included more than one species, a separate record was added for each species, each one with multiple entries dependent of the varying treatments used by the authors. Accordingly, the number of studies and corresponding entries presented in the results section represent the number of interactions of the classification criteria recorded for each reference, and not the total number of publications reviewed.

After revision of the 220 references collected, 25 were excluded due to poor quality in one or more of the classification criteria used. Examples were poor experimental design, lack of information on particles used or particle characterization, inadequate data representation or conclusions not supported by data. The exclusion of these 25 references was based on expert judgement, and data entries pertaining to 
these references were removed from the data matrix. The data matrix can be made available upon demand.

\subsubsection{Evaluation and Scoring of Data Quality}

The 195 references considered of acceptable quality were further evaluated and given a quality score based on the criteria presented in earlier publications. This was to ensure that the highest quality data generated through ecotoxicological studies was also the data that had the most impact in this analysis. Evaluation criteria were divided in three groups, experimental design, particle characterization and findings, as detailed in Table 7.1 (based on Connors et al. 2017; VKM 2019). Specifically:

- "Experimental design" included the use of reference controls and chemical controls, as well as replication within the test system. Maximum score $=3$.

Table 7.1 Evaluation criteria used to score data quality of reviewed references (based on Connors et al. 2017; VKM 2019)

\begin{tabular}{|c|c|c|}
\hline Criteria & Description & Scoring definition \\
\hline \multirow[t]{3}{*}{$\begin{array}{l}\text { Experimental } \\
\text { design }(0-3)\end{array}$} & $\begin{array}{l}\text { Use of reference } \\
\text { controls }\end{array}$ & $\begin{array}{l}\text { Use of reference particles other than plastic (e.g. kaolin, } \\
\text { sand, etc.) }\end{array}$ \\
\hline & $\begin{array}{l}\text { Use of chemical } \\
\text { controls }\end{array}$ & $\begin{array}{l}\text { Applies to vector studies only, where the particles are } \\
\text { spiked with one or more chemicals, or when further } \\
\text { characterization was carried out and results indicate the } \\
\text { presence of chemicals on the particles. Otherwise, } 1 \\
\text { point should be automatically attributed }\end{array}$ \\
\hline & $\begin{array}{l}\text { Replication in test } \\
\text { system }\end{array}$ & $\begin{array}{l}\text { Exposure replication of minimum 3; total number of } \\
\text { individuals: Depends on the endpoint }\end{array}$ \\
\hline \multirow[t]{5}{*}{$\begin{array}{l}\text { Characterization } \\
(0-5)\end{array}$} & Particle size & $\begin{array}{l}\text { Concentration range of particles used determined by } \\
\text { authors (e.g. DLS, particle counter, etc.) }\end{array}$ \\
\hline & Particle charge & $\begin{array}{l}\text { Applies for nanoparticles only. If microparticles are } \\
\text { used, } 1 \text { point should be automatically attributed }\end{array}$ \\
\hline & $\begin{array}{l}\text { Polymer } \\
\text { confirmation }\end{array}$ & $\begin{array}{l}\text { Confirmation of polymer used in exposure system (e.g. } \\
\text { FT-IR) }\end{array}$ \\
\hline & $\begin{array}{l}\text { Chemical } \\
\text { characterization }\end{array}$ & $\begin{array}{l}\text { Applies for studies using spiked particles, particles } \\
\text { obtained from the grinding of consumer goods, } \\
\text { deployed particles, industrial particles (e.g. nurdles). } \\
\text { Only in the case of particles obtained from a "trusted" } \\
\text { supplier (e.g. Cospheric, sigma, etc.) and said to be } \\
\text { "pristine", } 1 \text { point should be automatically attributed }\end{array}$ \\
\hline & $\begin{array}{l}\text { Test concentration } \\
\text { confirmation }\end{array}$ & $\begin{array}{l}\text { Test concentration measured in exposure system and not } \\
\text { nominal concentration used }\end{array}$ \\
\hline Findings $(0-1)$ & $\begin{array}{l}\text { Conclusions } \\
\text { supported by the } \\
\text { results }\end{array}$ & $\begin{array}{l}\text { Accurate interpretation of the results without conjecture } \\
\text { beyond experimental design }\end{array}$ \\
\hline
\end{tabular}




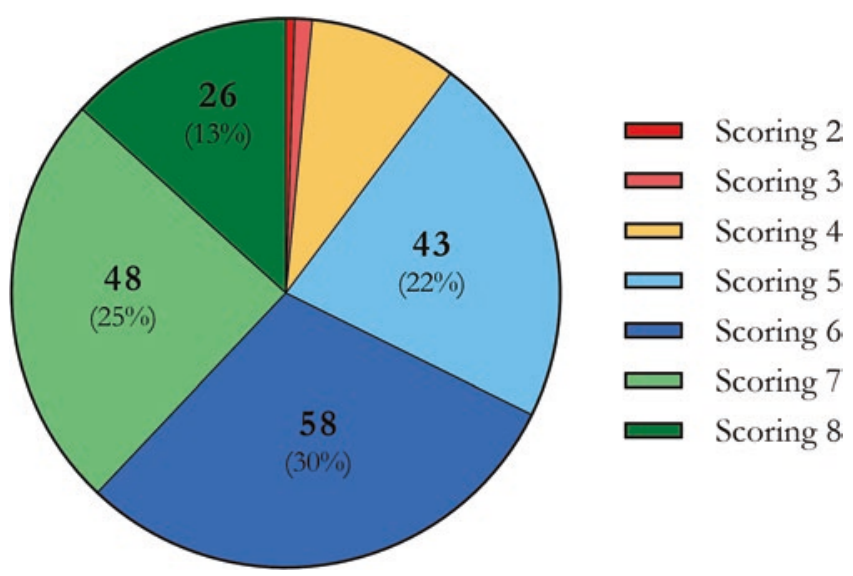

Fig. 7.2 Scoring of the 195 reviewed references. The number and $\%$ of references are only presented for those scored with 5 or more points

- "Particle characterization" included the reporting of particle size, particle charge, polymer confirmation, chemical characterization and confirmation of the test concentration. Maximum score $=5$.

- "Findings" included the assessment of whether the conclusions were supported by the results. Maximum score $=1$.

For each time a criterion was met, 1 point was attributed, and references were categorized based on a quality score out of 9 . References that scored 4 or less were excluded from further analysis and corresponding data entries removed from the data matrix. Of the 195 references scored, 20 were eliminated due to low score, in which 17 papers scored 4 points, 2 papers scored 3 points and 1 paper scored 2 points. None of the papers scored either 1 or 9 points (Fig. 7.2).

\subsubsection{Treatment of Extracted Data}

Species sensitivity distributions (SSDs) were fitted for three relevant exposure routes: water exposure, sediment/soil exposure and food exposure. Ecotoxicity data for terrestrial, freshwater and marine compartments and species were extracted and summarized for use in the SSD model fitting. Information on polymer types and size classes were combined, and for this reason, studies using fibres were excluded from the SSDs. Ecotoxicity endpoints were limited to individual and population levels (Burns and Boxall 2018; Connors et al. 2017), and only NOECs and EC $_{50}$ values were included. When only acute NOEC or $\mathrm{EC}_{50}$ data was available, chronic NOEC values were extrapolated as proposed by Posthuma et al. (2019). When multiple NOEC values were available for the same species, the geometric mean of the NOECs was used to summarize the information. To allow the comparison of 
ecotoxicological data from studies reporting different dose metrics, mass-based concentrations were converted to $\mathrm{mg}$ per litre $(\mathrm{mg} / \mathrm{L})$ and particle-based concentrations converted to particles per litre (particles/L). In the case of studies where particles were added via sediment/soil or via food, concentrations were converted to $\mathrm{mg}$ per $\mathrm{kg}(\mathrm{mg} / \mathrm{kg})$ of sediment/soil or food and particles per $\mathrm{kg}$ (particle $/ \mathrm{kg}$ ) of sediment or food. As several studies only reported concentrations in either mass or particle number, two SSDs were created per exposure route. Studies where none of the above dose metrics were employed were excluded from the SSD fitting. The SSDs were realized as Bayesian distributional regression models assuming a lognormal data distribution (Ott 1990). All modelling was performed using statistical programming language $\mathrm{R}$ ( $\mathrm{R}$ Core Team 2020) and its add-on package brms (Bürkner 2017, 2018). A total of 10,000 posterior draws were used to characterize each SSD. Where applicable, the value indicating the concentration at which 5\% of the species are affected (hazard concentration, $\mathrm{HC}_{5}$ ) was extracted from the posterior draws and summarized as average and $95 \%$ credible interval.

\subsection{Results and Discussion}

A key issue in understanding how microplastics and nanoplastics interact with the surrounding environment is their dynamic nature. The physicochemical properties of the parent material, including density, morphology, charge and size, are likely to influence particles' physical behaviour in the environment, fate (e.g. presence in the water column or in sediments), potential to adsorb environmental contaminants (e.g. Trojan horse effect), bioavailability and potential toxicological impacts on organism health (e.g. de Sá et al. 2018; Galloway et al. 2017; Haegerbaeumer et al. 2019; Kögel et al. 2020). The extensive literature review carried out showed that the responses of organisms to particle exposure were mostly dependent on particle characteristics as polymer type, size, morphology and surface alterations. However, it is possible that other factors were driving the observed impacts, as, for example, the presence of additive chemicals associated with the plastic particles, which are rarely considered in studies. A special emphasis has therefore been given to particle size, with a higher consensus in terms of increased internalization for smaller sized particles than larger ones and thus higher potential for toxic effects. A variety of experimental designs have been used to evaluate the effects of nanoplastics and microplastics in organisms, in which exposure time and particle concentration seem to be determinant for the induction of toxicity. Nonetheless, the observed effects were highly dependent on the environmental compartment assessed, in combination with specific morphological, physiological and behavioural traits of the species used, as, for example, developmental stage, trophic level and feeding strategy.

In terms of ecotoxicological effects, there is still little consensus regarding the biological impacts posed by plastic particles, as well as a limited understanding on the underlying toxic mechanisms causing the observed effects. This limited knowledge on mechanistic toxicity data also makes it difficult to understand and 
distinguish physical from chemical toxicological effects of plastic particles. And even though it is quite clear from wider literature that large particles (e.g. macroplastics) cause visible effects at the organism level (Kühn et al. 2015; Rochman 2015), the direct and indirect physiological effects of the smaller plastic particles remain elusive. Based on this review, effects were found at different levels of biological organization in a range of organisms. However, many of these studies used standard ecotoxicity approaches based on OECD or ISO guidelines that do not consider effects at the lower levels of biological organization such as cellular or subcellular mechanisms, which may be more sensitive and have a higher impact on the physiological traits of organisms, especially in the long term. To a small degree, some of the reviewed studies highlighted that the combination of nanoplastics and microplastics with organic and inorganic contaminants also modify and potentiate their toxicity towards biological systems. Nonetheless, the effects of chemical additives present in plastic particles are also understudied, and it is still not clear if the presence of these additives rather than the polymeric composition of particles are the main driver of the adverse effects reported in organisms. Based on the 175 publications reviewed, a more general and detailed report of the main factors influencing particle toxicity towards the different groups of organisms are presented in the sections below.

\subsubsection{General Overview of Information Extracted from Reviewed Publications}

\subsubsection{Polymer Type, Morphology, Surface and Size}

Within the 175 reviewed publications, the most commonly used polymer type was PS (90 studies, 51\%), followed by PE (62 studies, 35\%), PVC (17 studies, 10\%) and PET (11 studies, 6\%). The remaining polymer types (acrylonitrile butadiene styrene [ABS], nylon, polyamide [PA], polycarbonate [PC], polyhydroxybutyrate [PHB], polylactic acid [PLA], poly(methyl methacrylate) [PMMA], polyoxymethylene $[\mathrm{POM}]$, polypropylene [PP], styrene acrylonitrile resin [SAN]) were used in less than $5 \%$ in the reviewed studies. The use of PS and PE as polymers of choice in exposure studies is consistent with the most commonly found polymers in the environment, as PS, PE and PP are typically retrieved from surface waters and sediments (e.g. Koelmans et al. 2019 and references therein). Given that polymer type can influence the fate and behaviour of particles within test systems, in particular density and presence of chemical additives (e.g. Gallo et al. 2018), other polymers should be comprehensively assessed in order to build up knowledge regarding how their composition influence toxicity towards organisms.

Despite the prevalence of fragments, fibres and films in environmental samples due to degradation of larger pieces of plastic (see Burns and Boxall 2018; Kooi and Koelmans 2019; Phuong et al. 2016), the majority of studies focused on spherical particles (106 studies, 61\%), with only 40 studies looking at the impacts of 
fragments/irregular particles (23\%) and even less focusing on the effects of fibres (13 studies, 7\%). The main reason for the use of spherical particles is that they are easier to produce than the other morphological types (e.g. fibres, fragments, foams), especially in terms of sufficient quantity within a certain size range. The irregular and non-standardized morphology of these particles also make them more difficult to characterize and track during exposure experiments, which results in poorly comparable ecotoxicity data. Nonetheless, irregularly shaped particles resulting from the fragmentation of larger plastic items or materials containing synthetic polymers as fibres have a higher environmental relevance and should be used more often in effects studies, especially in terms of increasing ecological relevance for advancing quantitative data to assess environmental risks.

Among the reported surface alterations, plain/pristine particles were used in 163 publications out of the 175 (93\%) studies reviewed. Of all the particles reported with surface alterations, the majority was for PS, with PS-COOH and PS- $\mathrm{NH}_{2}$ in the nano-size range being the most commonly used (10\% and 9\%, respectively). Particle surface chemistry, i.e. chemical groups and surface charge, was one of the main properties driving the behaviour of particles in the aquatic environment - this is particularly true for smaller sized particles - especially when it comes to stability, aggregation, mobility and sedimentation (e.g. Mudunkotuwa and Grassian 2011). In fact, particle surface charge, more so than polymer composition, has been suggested as the main driver behind behaviour and consequent toxicity of smaller sized plastics (Lowry et al. 2012; Nel et al. 2009). Even though functionalized particles are commonly used as surrogates for naturally altered particles, their prevalence in the environment has been questioned. The presence of negatively charged PS-COOH has been suggested as widespread in the environment, although there is very little information on its fate in different environmental compartments. Similarly, the presence of PS- $\mathrm{NH}_{2}$ as a plastic degradation product in the environment has not yet been fully recognized/determined (Besseling et al. 2014).

An overview of the number of studies per particle type and size class is presented in Fig. 7.3. Of the size classes tested, most studies used particles smaller than those that can be detected with confidence in environmental matrices $(<100 \mu \mathrm{m}$, e.g. (de Ruijter et al. 2020)). Sixty-five of the reviewed studies used particles with sizes in the range $1-9 \mu \mathrm{m}(37 \%)$, followed by 43 studies with size in the range $20-49 \mu \mathrm{m}$ (25\%), 36 studies with sizes in the range $50-99 \mu \mathrm{m}(21 \%)$ and 34 studies with sizes in the range $10-19 \mu \mathrm{m}(19 \%)$. As for smaller size ranges, $39 \%$ of the reviewed publications used particles $<1 \mu \mathrm{m}$ (total 69 studies), with a predominance of particles within $0.1-0.99 \mu \mathrm{m}$. Regarding fibres, the size ranges used were between 362 and $3000 \mu \mathrm{m}$ in length and 41 and $3000 \mu \mathrm{m}$ in diameter. In terms of size distribution per polymer type, for PS and PMMA a higher focus has been given to particles $<10 \mu \mathrm{m}$, especially for PS in the nano-range size, as seen in Fig. 7.3. This is the opposite of $\mathrm{PE}$, as well as the remaining polymers reported, where most particles used have a size range $>1 \mu \mathrm{m}$. Most of the studies comparing the effects of both nanoplastics and microplastics of the same polymer composition reported size-dependent effects, with an increase in toxicity with decreasing particle size (e.g. Jeong et al. 2016, 2017; Lee et al. 2013; Lei et al. 2018a; Snell and Hicks 2011). Nonetheless, this 


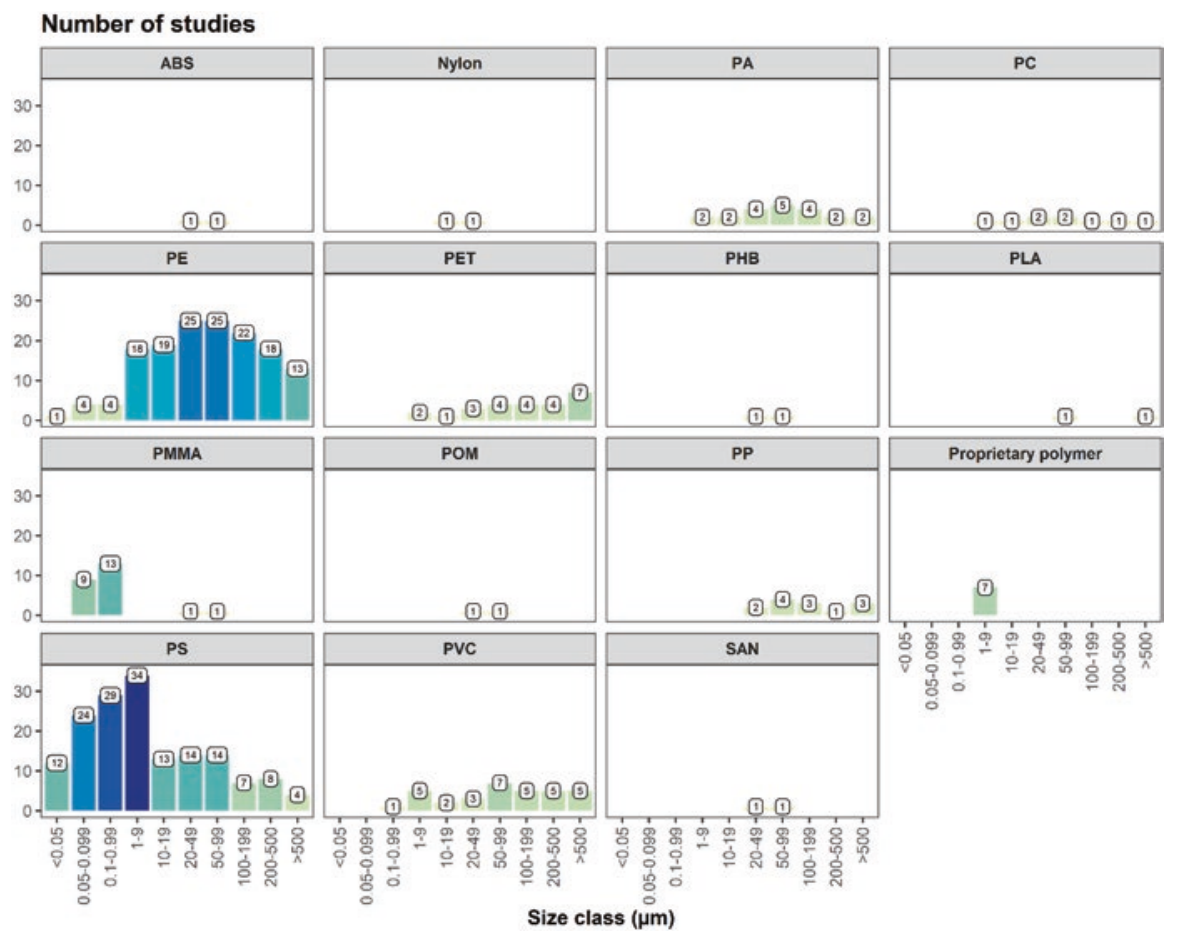

Fig. 7.3 Overview of the number of studies per particle type and size class. Note: There can be more than one size class within a study for a specific particle. See Methods Sect. 7.2.2. for more information on how particle size was categorized. $A B S$ acrylonitrile butadiene styrene, $P A$ polyamide, $P C$ polycarbonate, $P E$ polyethylene, $P E T$ polyethylene terephthalate, $P H B$ polyhydroxy butyrate, $P L A$ polylactic acid, $P M M A$ polymethylmethacrylate, $P O M$ polyoxymethylene, $P P$ polypropylene, $P S$ polystyrene, $P V C$ polyvinylchloride, $S A N$ styrene acrylonitrile

size-toxicity correlation seems to be species and phyla dependent. Irrespective of the potentially higher adverse effects imposed by smaller sized particles in organisms, their detection in different environmental compartments and resulting uncertainties in terms of natural concentrations remain an ongoing analytical challenge. Nonetheless, their presence in the environment as a consequence of fragmentation and degradation of plastic debris is widely accepted, having been proven under laboratory conditions (e.g. Lambert and Wagner 2016) and where their occurrence in the North Atlantic subtropical gyre has also been suggested (Ter Halle et al. 2017).

Even though particle ingestion and egestion were not considered in this review chapter, the selective size ingestion of micro- and nanoplastics has been reported for a range of aquatic organisms (e.g. bivalves, Ward et al. 2019). Accordingly, the size distribution of microplastics and nanoplastics used in ecotoxicological studies need to be appropriate for the species used, as this may influence exposure and particleorganism interactions. 


\subsubsection{Experimental Conditions}

Standard test protocol guidelines commonly used in toxicity testing of chemicals are not always suitable for testing of particles (e.g. Hermsen et al. 2018). Accordingly, ecotoxicity testing of nano- and microplastics often require modifications in experimental design to address specific particle behaviour and/or characteristics, leading to a lack of standardization. The lack of standardized test protocols for plastic particles results in a multiplicity of experimental conditions, which limits consistency and result comparison and interpretation (Connors et al. 2017; VKM 2019).

Considering the absence of consistent particle quantification in the environment in size ranges as small as those commonly used in ecotoxicological studies (PaulPont et al. 2018), the use of the so-called environmentally relevant doses of plastic particles also remains a challenge. Concentration range and units expressed in either mass or particle number are two of the main issues that have been highlighted related to the dosing of plastic particles in exposure systems. More than half of the publications reviewed reported particle concentrations in mass (minimum $7 \times 10^{-7}$ $\mathrm{mg} / \mathrm{L}$ to maximum $12,500 \mathrm{mg} / \mathrm{L}$ ), with the most commonly used concentration range of $1-100 \mathrm{mg} / \mathrm{L}$ (organisms exposed via water, $72 \%$ of studies). As for particle mass used in exposures via food (17\% of studies) or sediment/soil (10\% and 7\% of studies, respectively), concentrations varied from $7 \times 10^{5}$ to $100 \mathrm{mg} / \mathrm{kg}$ food (most common $4000,12,000,100,000 \mathrm{mg} / \mathrm{kg}$ food) and $4 \times 10^{5}$ to $1 \mathrm{mg} / \mathrm{kg}$ sediment $/ \mathrm{soil}$ (most common 1000 to $50,000 \mathrm{mg} / \mathrm{kg}$ sediment/soil). Few studies reported concentrations in terms of particle number, with concentrations ranging from 1 to $8 \times 10^{15}$ particles/L, 16 to $23 \times 10^{7}$ particles $/ \mathrm{kg}$ sediment $/$ soil and $3 \times 10^{5}$ to $1 \times 10^{8}$ particles $/ \mathrm{kg}$ food. Therefore, it seems that the nano- and microplastics used in the reviewed publications have been tested in numbers several orders of magnitude higher than those currently detected in the natural environment. This is particularly true for the small sized plastics within a wide range of polymer types, where realistic concentrations are rarely available for sizes $>10 \mu \mathrm{m}$ and not available for sizes $<10 \mu \mathrm{m}$ (for more information on environmental data on plastic contamination, check Litter Database webpage: http://litterbase.awi.de/litter). In addition, the failure to provide particle concentrations in both mass and number complicates the comparison of effect data across published studies, confounding the ability to reach precise conclusions over exposure and risk.

Exposure time is another important aspect related to varying experimental conditions used in nano- and microplastic ecotoxicological studies. The most commonly used exposure times in the reviewed studies were $48 \mathrm{~h}$ (27\% studies), $24 \mathrm{~h}$ (18\% studies), $96 \mathrm{~h}$ (17\% studies) and $72 \mathrm{~h}$ (14\% studies). These exposure durations are within those recommended in ecotoxicity guidelines for acute testing (e.g. OECD and ISO). In these tests, model organisms are normally exposed to high concentrations of a test compound over a short period of time, after which effect endpoints such as mortality or development are commonly assessed. Even though several of these studies showed evidence of deleterious effects at high concentrations, there are still knowledge gaps - which are hidden by the present focus in acute ecotoxicological testing, relating to limited environmental relevance. As exposure 
concentration and duration are two major parameters influencing toxicity, results based on short-term and high exposure concentrations make it difficult to extrapolate data to a more realistic scenario of exposure to low concentrations over a long period of time. One of the main gaps in the reviewed studies was the underrepresentation of long-term exposures at environmentally relevant concentrations and their consequent long-term effects at the organism and ecosystem levels (e.g. chronic exposure, whole life cycle, multi-generational effects). Long-term (or chronic) studies on the effects of nano- and microplastics were mostly carried out for 28 and 21 days ( $11 \%$ studies each), followed by 14 days (10\% studies). Only a very small percentage of studies have used an exposure period higher than 28 days, with only 4 studies looking at ecotoxicological effects above 3 months of exposure (maximum 240 days, i.e. 8 months). Long-term exposures carried out over more than 1 life stage or whole organism's lifespan allow to focus on population-relevant adverse endpoints (e.g. reproduction), as well as other sublethal effects that might constitute more reliable endpoints for risk assessment and are therefore urgently needed.

\subsubsection{Organisms Used in Ecotoxicological Studies}

When it comes to environmental compartments, most test organisms used were from the marine environment $(61 \%)$, followed by freshwater $(31 \%)$ and terrestrial $(8 \%)$ compartments, as presented in Fig. 7.4. Only 1 study reported the use of brackish organisms (1\%). This highlights that the effects of nano- and microplastics on terrestrial and freshwater ecosystems have been understudied and deserve further attention (e.g. Adam et al. 2019; Haegerbaeumer et al. 2019; Horton et al. 2017; Strungaru et al. 2019). These knowledge gaps are of particular concern, especially when terrestrial and freshwater environments are considered the main sources and transport pathways of plastic particles to the marine environment. Given that many

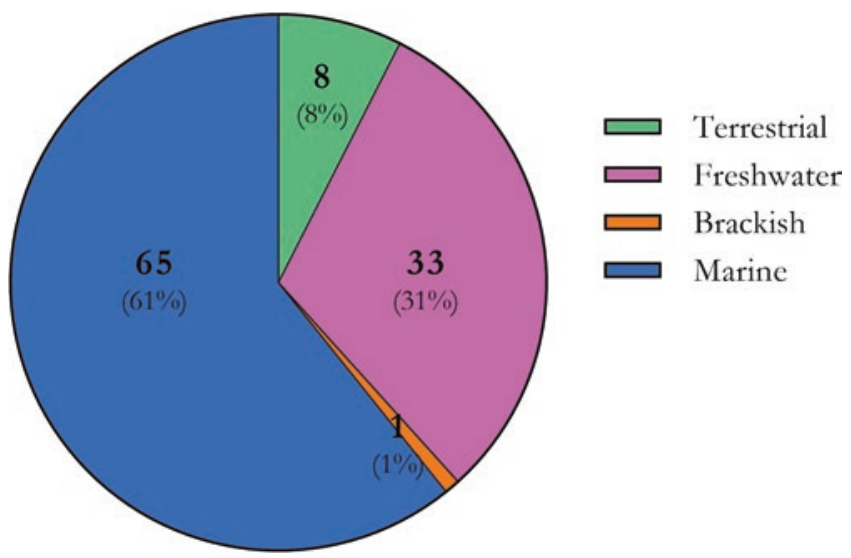

Fig. 7.4 Number of species (total of 107) from each environmental compartment used in the reviewed references 
plastic particles are used and disposed on land, terrestrial environments will be subject to extensive pollution by particles of varying characteristics at high concentrations, making terrestrial organisms at high risk of exposure. As for freshwater organisms, these will be directly affected by terrestrial runoff and other anthropogenic sources (e.g. wastewater treatment discharge, sewage sludge application), potentially containing high levels of plastic particles, as well as other associated contaminants (Adam et al. 2019; Horton et al. 2017 and references therein).

At the phylum level, Arthropoda was the most studied (34\%, 59 publications), followed by Chordata (23\%, 41 publications), Mollusca (21\%, 36 publications), Phytoplankton (14\%, 25 publications), Annelida (9\%, 16 publications), Cnidaria and Echinodermata (2\% each, 4 publications), Rotifera (2\%, 3 publications) and finally Nematoda (1\%, 1 publication). The freshwater crustacean Daphnia magna (17\% overall studies) was the most studied species, followed by the marine mussel Mytilus galloprovincialis and the freshwater zebrafish Danio rerio (both with 6\% of overall studies). In terms of developmental stage, most of the studies assessed effects in adult organisms ( $42 \%, 73$ studies total) and a small percentage used juveniles or neonates (both with 14\%, 25 studies). Very few studies have looked at whole cycle assessments, $3 \%$ of the total of reviewed publications, and those that did were only directed towards arthropods. In terms of feeding strategy, $32 \%$ of the species used were filter feeders, followed by photosynthetic organisms (21\%), predators $(17 \%)$, detritivores (10\%), grazers (9\%), scavengers (8\%) and deposit feeders $(5 \%)$. Only one herbivore and one microbivore were used.

Even though the organisms used in the reviewed publications have different roles in terrestrial and aquatic food webs, there is still a lack of studies conducted on organisms other than fish, small crustaceans and bivalves. Specifically, more studies on the effects of nano- and microplastics on organisms that are the basis of aquatic food chains should be conducted (e.g. planktonic species). These species have critical roles in ecosystem balance and might be at highest risk of exposure due to their feeding strategies and relative position in the water column. Moreover, small plastic particles are easily confused as food and ingested by planktonic species, thus serving as a route of transfer to secondary and tertiary consumers in food chains (Botterell et al. 2018). In addition, soil- and sediment-dwelling organisms are of major importance, as soil/sediment is considered the main sink for contaminants in the environment, increasing the likelihood of synergistic effects of plastic particles with other environmental contaminants (Adam et al. 2019; Horton et al. 2017 and references therein). Furthermore, targeted studies on species other than those commonly used in OECD and ISO guidelines should also be conducted, as the toxicological and mechanistic effect data on these species might not provide sufficient information into impacts on other ecologically relevant species. The same can be said in terms of transferring knowledge from marine to freshwater or terrestrial environment. Given the differences in habitat, physiological traits and feeding mechanisms, it is not clear as to what extent ecotoxicological effects on marine organisms can be applied to freshwater and terrestrial species within the same taxonomical group and vice versa. 


\subsubsection{Levels of Biological Organization}

Most of the reviewed studies focused on the effects of nano- and microplastics at the individual level (133 studies, 40\%), followed by the subcellular level (78 studies, $23 \%)$. The population level has been addressed in 45 studies (14\%), ecosystem in $33(10 \%)$, closely followed by the organ level with 30 studies (9\%). Only 13 studies (4\%) analysed effects at the cellular level. Within the individual endpoints, growth and mortality were the most studied (74 and 73 studies, respectively), while at the subcellular level, effects looking at alterations in gene expression (41 studies) were the most frequent, followed by oxidative stress (26 studies) and enzymatic activities (24 studies). Within population-related endpoints, the most determined were reproduction (21 studies) and larval development (16 studies). Within ecosystem, 29 studies looked at behaviour and 22 looked at community shifts. As for organ level, most studies (17) looked at histopathological alterations, followed by nine studies looking at energy reserves. At the cellular level, eight studies looked at membrane stability, five at cell size and four at both cell number and cell complexity. When looking at the number of studies categorized by environmental compartment (Fig. 7.5), the majority of the studies for both freshwater and marine environments

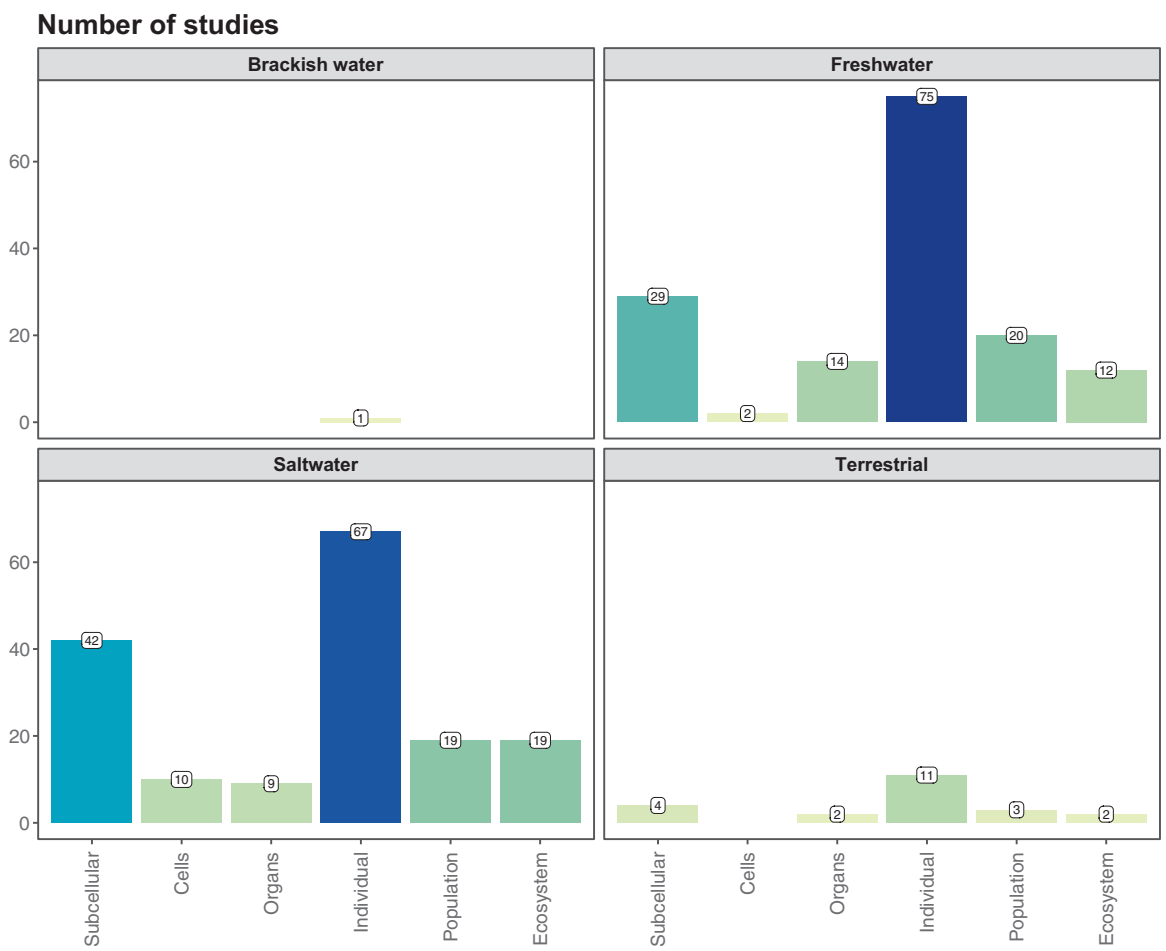

Fig. 7.5 Number of studies categorized by level of biological organization per environmental compartment 
covered endpoints at the individual level (75 and 72 studies, respectively), followed by effects at the subcellular level ( 29 and 42 studies, respectively). Impacts at the individual and cellular levels were also the most determined in terrestrial organisms (ten and 4 studies, respectively), while only one study covered individual endpoints in the brackish environment. Studies on effects at the cellular level were less common in freshwater and marine environments (two and ten studies, respectively), while no studies addressed this level of biological organization in terrestrial and brackish environments.

\subsubsection{Ecotoxicological Effects}

While a range of ecotoxicological effects caused by plastic particle exposure have been documented across several groups of organisms, there are still distinct research gaps concerning effects of both nano- and microplastics in specific taxonomical groups. In the following paragraphs, particle characteristics, exposure conditions and consequent ecotoxicological effects will be described for each taxonomical group considered in the present review: Phytoplankton, Cnidaria, Nematoda, Rotifera, Arthropoda, Annelida, Mollusca, Echinodermata and Chordata.

\subsubsection{Phytoplankton}

Phytoplankton include unicellular organisms such as microalgae that are at the bottom of the aquatic food chain. Small disruptions of microalgae populations due to exposure to plastic particles may lead to serious repercussions at the ecosystem level, being thus imperative to characterize the risks/effects of plastic particles on this taxonomical group (Prata et al. 2019). Phytoplankton were evenly represented from marine and freshwater environments in the reviewed studies (12 and 13 studies, respectively). Exposure studies included 21 different species belonging to 8 different classes (Bacillariophyceae, Chlorodendrophyceae, Chlorophyceae, Coscinodiscophyceae, Cyanophyceae, Dinophyceae, Prymnesiophyceae and Trebouxiophyceae). The most used class was Chlorophyceae (14 studies). Raphidocelis subcapitata, previously named as Pseudokirchneriella subcapitata, was the most used species with four studies. Six other species (Chaetoceros neogracile, Chlamydomonas reinhardtii, Chlorella pyrenoidosa, Dunaliella tertiolecta, Scenedesmus obliquus and Skeletonema costatum) had two studies each, while the remaining had only one publication.

A total of 7 different polymers were used across the 25 reviewed studies, with PS as the most studied polymer (15 studies). Five studies used PE, four used PVC, two used PP, while PMMA, proprietary polymer and PUF were represented by one study each. Most studied PS spheres $(\mathrm{n}=12)$, while only two used PVC spheres. Regarding size, eight studies used PS particles ranging between 0.05 and $0.099 \mu \mathrm{m}$, and four used PS particles between 1 to $9 \mu \mathrm{m}$ and 0.1 to $0.99 \mu \mathrm{m}$. There were two 
studies on PE particles between 50 and $99 \mu \mathrm{m}$ and PVC particles between 1 and $9 \mu \mathrm{m}$. In terms of particle surfaces, plain PS particles $(\mathrm{n}=7$ studies $)$ were the most used, followed by PS-COOH $(n=6)$ and PS- $-\mathrm{NH}_{2}(\mathrm{n}=5)$.

All phytoplankton publications addressed effects at the individual level, with $60 \%$ reporting effects. Growth was the most common endpoint (24 studies, 21 with effects), followed by pigment content ( 9 studies, 7 with observed effects), photosynthesis and photosynthetic performance (8 studies, 7 with effects) and chlorophyll a content (1 study with significant effects) (Baudrimont et al. 2020; Bellingeri et al. 2019; Bergami et al. 2017; Besseling et al. 2014; Bhargava et al. 2018; Canniff and Hoang 2018; Casado et al. 2013; Chae et al. 2018; Gambardella et al. 2018; Garrido et al. 2019; González-Fernández et al. 2019; Lagarde et al. 2016; Liu et al. 2019; Long et al. 2017; Luo et al. 2019; Mao et al. 2018; Nolte et al. 2017; Prata et al. 2018; Sendra et al. 2019; Seoane et al. 2019; Thiagarajan et al. 2019; Zhang et al. 2017; Zhao et al. 2019; Zhu et al. 2019). At the cellular level, effects on membrane stability (four studies, three with effects), cell complexity (three studies, all with effects) and cell size (four studies, three with effects) were addressed in marine and freshwater species (González-Fernández et al. 2019; Liu et al. 2019; Mao et al. 2018; Sendra et al. 2019; Seoane et al. 2019). Nine studies looked at several effects at the subcellular level, including oxidative stress (six studies, all observing effects), lipid peroxidation (three studies, two with effects), reactive oxygen species (ROS) formation (one study, no effects), neutral lipid content (one study with effects), protein content (two studies with effects), DNA damage (one study with effects) and gene expression (one study with effects) (Bellingeri et al. 2019; González-Fernández et al. 2019; Lagarde et al. 2016; Liu et al. 2019; Mao et al. 2018; Sendra et al. 2019; Seoane et al. 2019; Thiagarajan et al. 2019; Zhu et al. 2019). Only one publication studied effects at the ecosystem level, such as bacteria concentration and community shifts, with effects only reported for the latter (González-Fernández et al. 2019).

Overall, phytoplankton growth does not seem to be greatly impacted by microor nanoplastic exposure, for which little or no effects were reported for both freshwater and marine species. However, deleterious effects were seen at concentrations considered high. The lowest concentration at which effects on growth were reported was $0.001 \mathrm{mg} / \mathrm{L}$ for $D$. tertiolecta exposed to PS spheres ( $72 \mathrm{hrs,} \mathrm{size} \mathrm{range} 0.1$ to $0.99 \mu \mathrm{m}$ ), even though complete growth inhibition was not achieved (Gambardella et al. 2018). In this study, a dose-dependent growth inhibition was observed in exposed microalgae and associated with the use of energy sources in detoxification processes, such as the generation of extracellular polysaccharides (Gambardella et al. 2018). Of the 25 reviewed studies, only 2 reported $\mathrm{EC}_{50}$ values for PS nanoplastics: an $\mathrm{EC}_{50}$ value of $12.97 \mathrm{mg} / \mathrm{L}$ was recorded for the marine microalgae D. tertiolecta (size range $0.05-0.099 \mu \mathrm{m}$ ) (Bergami et al. 2017), while $\mathrm{EC}_{50}$ of $0.58 \mathrm{mg} / \mathrm{L}$ and $0.54 \mathrm{mg} / \mathrm{L}$ were obtained for freshwater microalga $P$. subcapitata (polyethyleneimine PS with different size ranges of $0.05-0.099$ and $0.1-0.99 \mu \mathrm{m}$, respectively) (Casado et al. 2013). For sublethal effects, the consensus is that toxicity in microalgae was influenced by size and surface chemistry of particles, with nanoplastics exerting stronger impairment than their micro-sized counterparts (e.g. 
Bergami et al. 2017; Seoane et al. 2019; Zhang et al. 2017). PS nanoplastics, size range $0.05-0.99 \mu \mathrm{m}$, were found to induce oxidative stress in the form of ROS formation (PS-NH ${ }_{2}$ and plain PS (González-Fernández et al. 2019; Sendra et al. 2019)), result in effects on protein and neutral lipid content, affect membrane stability, cause DNA damage (plain PS (Sendra et al. 2019)), decrease pigment content including chlorophyll a (PS, PS- $\mathrm{NH}_{2}$ and PS-COOH (Besseling et al. 2014; González-Fernández et al. 2019; Sendra et al. 2019)), alter cell size and complexity (PS-NH $\mathrm{NH}_{2}$ and plain PS (González-Fernández et al. 2019; Sendra et al. 2019)) as well

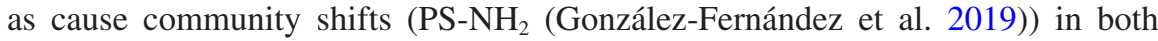
freshwater and marine microalgae. Furthermore, positively charged PS- $\mathrm{NH}_{2}$ have been shown to have higher interaction and toxicity than negatively charged PS-COOH and plain PS due to increased adhesion onto algal surfaces, with particle charge being recognized as the cause for the increased severity (Bergami et al. 2017; Chae et al. 2018; Nolte et al. 2017).

Overall, ecotoxicological data obtained for microalgae demonstrated that exposure to nano- or microplastics caused a variety of cellular and biochemical effects, from altered expression of genes involved in metabolic pathways, to photosynthetic impairment and growth inhibition (e.g. Lagarde et al. 2016; Mao et al. 2018). The toxicity observed to microalgae seems to be dependent of many factors including particle size (Zhang et al. 2017), polymer type (Lagarde et al. 2016), surface chemistry (González-Fernández et al. 2019; Seoane et al. 2019), particle concentration (Mao et al. 2018), exposure time, as well as targeted species (Long et al. 2017). Nonetheless, the environmental relevance and toxicity mechanisms of nano- and microplastics in microalgae remain unclear. This is mostly due to the determination of growth inhibition as the most common toxicological endpoint, in which the exposure duration is too short, and it is not possible to clearly discriminate between direct toxic effects and indirect physical effects caused by particles. Limitations in the use of this method have also been highlighted in studies using nanomaterials, mostly related to particle interference with algal growth quantification techniques (i.e. measurement chlorophyll a fluorescence) due to a shading effect (Handy et al. 2012). The presence of particles in suspension can cause shading either by reducing the access of algae to light or by obstructing the fluorescence signal from the algae to the fluorescent detector. This shading effect will impact the accuracy of the measured fluorescence response, leading to an underestimation of chlorophyll a quantification, thereby overestimating the overall toxic effect (Farkas and Booth 2017). In view of the important role that phytoplankton have in aquatic food webs, there is a need to develop better toxicological assays/endpoints with increased sensitivity that are able to reveal underlying toxic effects of plastic particles.

\subsubsection{Cnidaria}

The group Cnidaria is composed of aquatic organisms with basic body forms, swimming medusae or sessile polyps, that inhabit both the freshwater and the marine environments, even though more predominant in the latter. Examples of cnidarians 
are sea anemones, corals and jellyfish. The cnidarians used in the reviewed publications were all coral species and exclusively from the marine environment. Nine species were represented across four studies, all from the class Anthozoa. Pocillopora damicornis was the only species used in more than one study. The eight other species (Acropora formosa, A. humilis, A. millepora, Montastraea cavernosa, Orbicella faveolata, Pocillopora verrucosa, Porites cylindrica, P. lutea) were all used in single studies. All Cnidaria species investigated were filter feeders and were exposed to particles via water. Most studies were carried out on polyps (two studies).

Four studies have been carried out on Cnidaria investigating irregular fragments and beads composed of two polymer types. PE was used in three of the four studies (Hankins et al. 2018; Reichert et al. 2018; Syakti et al. 2019), while only one study used PS (Tang et al. 2018). Two studies used PE fragments (Reichert et al. 2018; Syakti et al. 2019), one used PE beads (Hankins et al. 2018), and the remaining study did not specify the morphology of PS particles used (Tang et al. 2018). In terms of size, one study focused on the smallest size category, 0.1 to $0.99 \mu \mathrm{m}$ (Jia Tang et al. 2018); PE fragments were studied in the size range 20-49 $\mu \mathrm{m}$ (Reichert

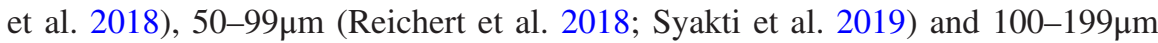
(Reichert et al. 2018; Syakti et al. 2019); and one study used the size range 200-500 $\mu \mathrm{m}$ (Syakti et al. 2019). PE beads were investigated in the size ranges 50-99 $\mu \mathrm{m}, 100-199 \mu \mathrm{m}, 200-500 \mu \mathrm{m}$ and $>500 \mu \mathrm{m}$ during a single study (Hankins et al. 2018).

The subcellular level was studied in one publication reporting effects on enzymatic activity and gene expression (Tang et al. 2018). At the individual level, two studies investigated and reported bleaching (Reichert et al. 2018; Syakti et al. 2019); one study investigated and reported effects on mucus production, tissue necrosis and growth (Reichert et al. 2018); one study investigated and reported mortality and tissue necrosis (Syakti et al. 2019); and one study investigated calcification but did not observe any effects (Hankins et al. 2018). Only one publication studied community shifts, although no effects were observed on symbiont density or symbiont chlorophyll content (Tang et al. 2018). Bleaching was the most common endpoint, with both studies detecting effects. No studies were found at the population level.

Regarding concentrations and particle size, only a single concentration (50 mg/L) and size $(1-9 \mu \mathrm{m})$ was used to investigate subcellular-level effects (Tang et al. 2018). The effects of PS on enzymatic activity were investigated, where alterations in superoxide dismutase, alkaline phosphatase, catalase and glutathione S-transferase activity were observed throughout exposure. No effects were observed for phenoloxidase activity.

The reported effects at the individual level ranged from exposure to $50 \mathrm{mg} / \mathrm{L}$ to $150 \mathrm{mg} / \mathrm{L}$. Exposure to PE fragments increased mortality, bleaching and necrosis in A. formosa after 2 days of exposure at 50,100 and $150 \mathrm{mg} / \mathrm{L}$ (size range 50 to $500 \mu \mathrm{m}$ (Syakti et al. 2019)), as well as in A. humilis, A. millepora, P. cylindrica, A. humilis, $P$. verrucosa and $P$. damicornis after 28 -day exposure at $100 \mathrm{mg} / \mathrm{L}$ (size range 20 to $100 \mu \mathrm{m}$ (Reichert et al. 2018)). Growth was also impaired across these species, but this was dependent on the size of particles used in the exposure. Mucus production only appeared to be affected in P. lutea also exposed to PE fragments 
(100 mg/L, size range 20-100 $\mathrm{mm}$ ) (Reichert et al. 2018). At the ecosystem level, the only observed effect was a community shift in chlorophyll content symbiont at 12-hr exposure to PS $50 \mathrm{mg} / \mathrm{L}$ (Tang et al. 2018).

\subsubsection{Nematoda}

Nematodes, also called roundworms, are unsegmented worms found in almost every terrestrial and aquatic habitat. Only a single study addressed the effect of microplastics on nematodes (Judy et al. 2019). The nematode Caenorhabditis elegans, which lives in the pore water of soils, was exposed to fragments larger than $500 \mu \mathrm{m}$, produced by shredding consumer products (Judy et al. 2019). The exposure scenarios used organisms at the adult stage, exposed through contact with the soil solution, implying both dermal and trophic exposure to microplastics.

The effects of a single high concentration ( $5 \mathrm{~g} / \mathrm{kg}$ soil dry weight) of three polymer types (PE, PET, PVC) were assessed at the individual level (mortality and reproduction), after various contact time between soil and plastics ( 0,3 and 9 months). Increased mortality was only observed for PET incubated in soil for 3 months, while decreased reproduction was only observed for PVC incubated in soil for 9 months (Judy et al. 2019).

\subsubsection{Rotifera}

Rotifers are organisms that are bilaterally symmetrical and have a microscopic size and unsegmented soft body, with a common distribution in both the freshwater and marine environments. As main components of zooplankton, these small organisms have an important ecological role in aquatic ecosystems. This taxonomic group was only represented by a single marine species, Brachionus plicatilis. Two developmental stages of $B$. plicatilis were used in exposure studies, neonates (Gambardella et al. 2018; Manfra et al. 2017) and nauplii (Beiras et al. 2018), both exposed via water. All studies investigated the effect of microplastic spheres, either composed of PS (Beiras et al. 2018; Gambardella et al. 2018) or PE (Manfra et al. 2017). In terms of size, two studies looked at particles $<0.05 \mu \mathrm{m}$ (Gambardella et al. 2018; Manfra et al. 2017), one study looked at particles 0.05-0.099 $\mu \mathrm{m}$ (Manfra et al. 2017), and one study looked at 1-9 $\mu \mathrm{m}$ sized particles (Beiras et al. 2018). Two studies described the surface of the particles, Gambardella et al. (2018) used plain PS spheres, and Manfra et al. (2017) looked at both $\mathrm{COOH}$ and $\mathrm{NH}_{2}$ coated PS spheres.

All publications looked at individual-level effects, specifically mortality. No studies assessed subcellular or population-level effects and only one study considered ecosystem-level effects, specifically alterations in swimming speed (Gambardella et al. 2018). Neonates exposed to PS-NH $\mathrm{NH}_{2}$ spheres $(0.001-50 \mathrm{mg} / \mathrm{L})$ exhibited significant mortality only when concentrations exceeded $10 \mathrm{mg} / \mathrm{L}$ (Manfra et al. 2017). On the other hand, PS-COOH spheres did not induce any effect at the 
same concentrations (Manfra et al. 2017). In another study, nauplii exposed to PE spheres were only significantly affected after $48 \mathrm{hrs}$ of exposure, when concentrations exceeded $1 \mathrm{mg} / \mathrm{L}$ (Beiras et al. 2018). Finally, PS spheres $(<0.05 \mu \mathrm{m})$ only affected the swimming speed of neonates after $48-\mathrm{hr}$ exposure $(0.001-10 \mathrm{mg} / \mathrm{L})$ (Gambardella et al. 2018).

\subsubsection{Arthropoda}

Arthropoda is the largest group of the animal kingdom, which includes invertebrate organisms that have an exoskeleton, a segmented body and jointed appendages. Arthropods are widely represented in every environmental compartment and include crustaceans, insects, isopods and amphipods, among others. Most of the studies conducted with Arthropoda ( 39 of 57) were in the freshwater environment, followed by 16 studies in the marine environment, 3 studies in terrestrial and only 1 in the brackish environment. Twenty-nine Arthropoda species from 5 classes, Branchiopoda, Entognatha, Hexanauplia, Insecta and Malacostraca, were studied: Acartia tonsa, Amphibalanus amphitrite, Artemia franciscana, Asellus aquaticus, Calanus finmarchicus, Calanus helgolandicus, Carcinus maenas, Centropages typicus, Ceriodaphnia dubia, Chironomus tepperi, Corophium volutator, Daphnia galeata, Daphnia magna, Daphnia pulex, Echinogammarus marinus, Eriocheir sinensis, Folsomia candida, Gammarus fossarum, Gammarus pulex, Hyalella azteca, Idotea emarginata, Lobella sokamensis, Nephrops norvegicus, Palaemonetes pugio, Parvocalanus crassirostris, Platorchestia smithi, Porcellio scaber, Talitrus saltator and Tigriopus fulvus. Fifteen of the species were Malacostraca, while there was only one study on Insecta (Chironomus tepperi; Ziajahromi et al. 2018). Daphnia magna was by far the most used species ( $\mathrm{n}=29$ publications), followed by Artemia franciscana ( $\mathrm{n}=4$ publications). Overall, 14 species were from the marine environment, 11 from freshwater, 3 terrestrial and 1 from brackish water.

Most of the Arthropoda species were filter/suspension feeders (6 species in 35 studies). Nine studies used eight detritivores species, seven studies included seven grazer species, and four studies used four scavenger species. Deposit feeders (two species), filter feeders (one species) and grazer and detritivores (one species) were represented by two publications each. Only one publication studied a predator species, Eriocheir sinensis. Most studies were carried out on adults (27 studies) and neonates ( 23 studies), while juveniles ( 7 studies), nauplii (6 studies), larvae ( 2 studies) and 1-week-old organisms (1 study) were less studied. Five publications studied the whole cycle of D. magna and D. pulex. Filter/suspension feeders and predators were exposed via water (37 studies). On the other hand, detritivores were exposed via water (three studies), sediment (two studies), soil (two studies) and food (two studies). Grazers were also exposed via water (five studies), sediment and food, and deposit feeders were exposed via water and sediment. Lastly, scavenger organisms were only exposed via food (four studies).

Fourteen polymer types were studied using Arthropoda, in a total of 57 publications. PS was the most studied polymer, followed by PE (31 and 14 studies, 
respectively). PET was represented by five publications, while PA, PMMA and PP had four each. Proprietary polymer and PVC had three and two studies, respectively. All the other particle types (ABS, nylon, PC, PHB, POM and SAN) were represented by one study each. Most of the studies used spheres (30 and 11 using PS and PE, respectively), while the remaining particle shapes had less than 5 studies each. Regarding size, PS particles between $1-9 \mu \mathrm{m}, 0.1-0.99 \mu \mathrm{m}$ and $0.05-0.099$ were used in 13, 12 and 10 publications, respectively. Seven studies used PE particles between 20 and $49 \mu \mathrm{m}$. The remaining size classes were used in five or less studies. ABS, PC, PHB, POM and SAN were only studied within the size range 20 to $49 \mu \mathrm{m}$. Regarding particle surface, PS-COOH was the most studied with seven publications, followed by PS plain and PS- $\mathrm{NH}_{2}$ with six studies each, all particles within the nano-scale. Particles with other surface modifications were used in five or less publications each.

Effects at the individual level (51 studies, corresponding to $89 \%$ of studies) were the most commonly determined in arthropods, followed by effects at the population (18 studies, $32 \%$ of studies) and subcellular, ecosystem and organ levels (11, 7 and 5 studies, corresponding to $19 \%, 12 \%$ and $9 \%$ of studies). When comparing the different levels of biological organization, the percentage of reported effects was comparable to those reporting no effects. Gene expression was the most common endpoint determined within the subcellular level (Bergami et al. 2017; Fadare et al. 2019; Gambardella et al. 2017; Heindler et al. 2017; Imhof et al. 2017; Lin et al. 2019b; Liu et al. 2018, 2019; Tang et al. 2019; Yu et al. 2018; Zhang et al. 2019), followed by enzymatic activity and neurotoxicity (Gambardella et al. 2017; Lin et al. 2019b; Yu et al. 2018) as well as oxidative stress (Lin et al. 2019b; Yu et al. 2018; Zhang et al. 2019). Energy reserves (Cole et al. 2019; Cui et al. 2017; Kokalj et al. 2018; Weber et al. 2018) and alterations in hepatosomatic index (Yu et al. 2018) were the endpoints targeted at the organ level. At the individual level, mortality (Au et al. 2015; Beiras et al. 2018; Bergami et al. 2016, 2017; Besseling et al. 2014; Bhargava et al. 2018; Blarer and Burkhardt-Holm 2016; Booth et al. 2016; Bosker et al. 2019; Bruck and Ford 2018; Canniff and Hoang 2018; Casado et al. 2013; Cole et al. 2015; Cui et al. 2017; Fadare et al. 2019; Gambardella et al. 2017; Gerdes et al. 2019; Gray and Weinstein 2017; Hämer et al. 2014; Horton et al. 2018; Imhof et al. 2017; Jemec et al. 2016; Kim et al. 2017; Kokalj et al. 2018; Lin et al. 2019b; Liu et al. 2018; Ma et al. 2016; Mattsson et al. 2017; Nasser and Lynch 2016; Ogonowski et al. 2016; Pacheco et al. 2018; Redondo-Hasselerharm et al. 2018; Rehse et al. 2016, 2018; Rist et al. 2017; Tang et al. 2019; Tosetto et al. 2016; Ugolini et al. 2013; Vicentini et al. 2019; Weber et al. 2018; Wu et al. 2019a; Yu et al. 2018; Zhang et al. 2019, p. 201; Ziajahromi et al. 2017) and growth (Au et al. 2015; Bergami et al. 2016; Besseling et al. 2014; Bruck and Ford 2018; Cole et al. 2019; Gerdes et al. 2019; Hämer et al. 2014; Imhof et al. 2017; Jemec et al. 2016; Kokalj et al. 2018; Liu et al. 2019; Ogonowski et al. 2016; Pacheco et al. 2018; Redondo-Hasselerharm et al. 2018; Rist et al. 2017; Jinghong Tang et al. 2019; Vicentini et al. 2019; Weber et al. 2018; Welden and Cowie 2016; Yu et al. 2018; Zhao et al. 2015; Zhu et al. 2018; Ziajahromi et al. 2017) were the most studied, alongside feeding behaviour (Blarer and Burkhardt-Holm 2016; Bruck and Ford 
2018; Cole et al. 2013, 2019; Hämer et al. 2014; Kokalj et al. 2018; Ogonowski et al. 2016; Redondo-Hasselerharm et al. 2018; Rist et al. 2017; Straub et al. 2017; Watts et al. 2015; Weber et al. 2018; Welden and Cowie 2016; Zhu et al. 2018), development (Blarer and Burkhardt-Holm 2016; Ma et al. 2016; Straub et al. 2017), energy reserves (Watts et al. 2015; Welden and Cowie 2016), respiration rate (Cole et al. 2015) and gut microbial diversity (Zhu et al. 2018). Endpoints related to population level included alterations in reproductive output (Au et al. 2015; Besseling et al. 2014; Bosker et al. 2019; Canniff and Hoang 2018; Cole et al. 2015; Cui et al. 2017; de Felice et al. 2019; Heindler et al. 2017; Imhof et al. 2017; Liu et al. 2019; Ogonowski et al. 2016; Pacheco et al. 2018; Rist et al. 2017; Vicentini et al. 2019; Zhu et al. 2018; Ziajahromi et al. 2017, 2018), followed by larval development (Ziajahromi et al. 2018) and population size (Heindler et al. 2017). At the ecosystem level, only alterations in behaviour (e.g. swimming activity, phototactic response, distance and acceleration) were recorded upon exposure (Booth et al. 2016; Chae et al. 2018; de Felice et al. 2019; Frydkjær et al. 2017; Gambardella et al. 2017; Kim and An 2019; Lin et al. 2019b; Tosetto et al. 2016).

From the terrestrial species included in the ecotoxicological assessments reviewed, effects on feeding behaviour, growth, gut microbial diversity and reproduction were seen for $F$. candida in response to PVC $(1000 \mathrm{mg} / \mathrm{kg}$ soil, size range $80-250 \mu \mathrm{m})(Z h u$ et al. 2018). These effects were attributed to changes in soil structure due to the presence of microplastics that led to alterations in feeding behaviour and capacity to find high-quality food, thus influencing nutrient absorption (Zhu et al. 2018). Similar findings were found for L. sokamensis exposed to PE (1000 mg/ $\mathrm{kg}$ soil, size range $20-49 \mu \mathrm{m})$ and PS (4, 8 and $1000 \mathrm{mg} / \mathrm{kg}$ soil, size ranges $0.1-0.99$, 20-49 and 200-500 $\mu \mathrm{m}$ ) (Kim and An 2019). In this study, springtails showed altered behaviour in response to microplastic movement into soil bio-pores, at lower concentrations and size ranges than those reported for $F$. candida (4 and $8 \mathrm{mg} / \mathrm{kg}$ soil for PS $0.1-0.99 \mu \mathrm{m}$ compared to $1000 \mathrm{mg} / \mathrm{kg}$ soil PVC $80-250 \mu \mathrm{m})$. Both studies highlight that the behaviour of plastic particles in soil does not only affect the behaviour of soil-dwelling organisms and lead to high adverse effects (e.g. impaired growth and reproduction), but their presence can also have wider implications for effective management of soils (Kim and An 2019; Zhu et al. 2018).

Several biological endpoints have been determined in freshwater arthropods in response to both nano- and microplastics, with toxicity being dependent on polymer type (e.g. Au et al. 2015), particle size (e.g. de Felice et al. 2019), surface chemistry (e.g. Lin et al. 2019b) and time of exposure (e.g. Liu et al. 2019). As mentioned previously, the crustacean Daphnia sp. was the most used organism to assess the ecotoxicological effects of plastic particles via water exposure, for which acute and chronic toxicity has been reported for different particles. Adverse effects including mortality (LOEC 0.005 mg/L, PS spheres 10-19 $\mu \mathrm{m}$ (P. Zhang et al. 2019)), abnormal development (adults LOEC $0.1 \mathrm{mg} / \mathrm{L}$ and offsprings LOEC $5 \mathrm{mg} / \mathrm{L}$, PS spheres 0.05-0.099 $\mu \mathrm{m}$ (Liu et al. 2019 and Cui et al. 2017, respectively)), swimming behaviour (LOEC $1 \mathrm{mg} / \mathrm{L}$ for PE fragments $10-19 \mu \mathrm{m}$, PS spheres $0.1-0.99 \mu \mathrm{m}$ and PS-NH ${ }_{2}$ 0.05-0.099 $\mu \mathrm{m}$ (Frydkjær et al. 2017; Lin et al. 2019b)) and reproductive output (LOEC $0.02 \mathrm{mg} / \mathrm{L}$, proprietary polymer 1-9 $\mu \mathrm{m}$ (Pacheco et al. 2018)) were 
the most commonly described. In terms of sediment exposure, the effects of PE at environmentally relevant concentration (500 particles $/ \mathrm{kg}$ sediment, size range 1-49 $\mu \mathrm{m}$ ) were evaluated using the chironomid C. tepperi (Ziajahromi et al. 2018) after 5 and 10 days of exposure. The authors reported that exposure to PE negatively affected the survival, growth (i.e. body length and head capsule) and emergence of chironomids, with the observed effects being strongly dependent on particle size.

Ecotoxicological studies of marine arthropods showed that smaller sized plastic particles had a stronger impact, with surface chemistry playing a significant role for the effects seen. This is the case of A. franciscana exposed to PS nanoplastics with different surface alterations, for which the lowest LOECs for different endpoints were recorded. Also, when comparing the long-term toxicity of PS-COOH and PS- $\mathrm{NH}_{2}$ (size range 0.05-0.099 $\mu \mathrm{m}$ ), Bergami et al. (2017) observed a concentrationdependent mortality in brine shrimp after 14 days, with the latter showing a higher impact $\left(\mathrm{EC}_{50}=0.83 \mathrm{mg} / \mathrm{L}\right)$. In addition, alteration in genes involved in moulting were also recorded at the lowest concentration tested of $0.01 \mathrm{mg} / \mathrm{L}$, further suggesting that the disruption of larval moulting and energy metabolism may play a role in the toxicity of nanoplastics towards arthropods. In another study by Gambardella et al. (2017), short-term exposure of A. franciscana and A. amphitrite to PS nanoplastics (size range $0.1-0.99 \mu \mathrm{m})$ at low concentrations $(0.001$ to $10 \mathrm{mg} / \mathrm{L}$ ) did not affect survival but impacted swimming behaviour, increased expression of catalase and inhibited acetylcholinesterase activity in exposed organisms. As only sublethal effects were observed, the authors highlight that behavioural responses seem to be more sensitive than mortality in plastic toxicity assessments, especially after shortterm exposure.

Arthropoda was the most heterogeneous of the taxonomical groups assessed, including a wide range of species belonging to the terrestrial and aquatic compartments with different developmental stages and feeding strategies. Several effects covering different levels of biological organization were reported, with impacts on feeding behaviour, growth, development, reproduction and lifespan being highlighted as the most significant. These findings emphasize the need to perform longterm exposures covering whole cycle assessments to fully understand the magnitude and consequences of plastic particles to the aquatic environment. This is particularly important for species belonging to zooplankton, an important food source for secondary consumers, as these represent a possible route by which plastic particles could enter food chains and be transferred up the trophic levels. In addition, a significant impact on the lifespan of these organisms might have serious consequences in the balance of aquatic ecosystems (Botterell et al. 2018).

\subsubsection{Annelida}

The Annelida group is composed of segmented worms, such as earthworms, lugworms and leeches. Annelids can be found in all types of habitat, and one of their most important ecological roles is reworking of soils and sediments. The terrestrial environment was represented by nine studies (covering three species) and the 
marine environment by seven studies (also covering three species). The marine environment was represented by three species belonging to the Polychaeta class: Arenicola marina (five studies), Hediste diversicolor (one study) and Perinereis aibuhitensis (one study). The terrestrial environment was represented by three species of the Clitellata class: Eisenia fetida (five studies), Lumbricus terrestris (three studies) and Eisenia andrei (one study). All but one of the studies (where life stage was not specified) used adult organisms. In the terrestrial environment, soil was spiked with microplastics in eight out of nine studies, the remaining study using spiked food (leaf litter). However, both dermal and trophic exposure can be expected from these two exposure scenarios, due to constant burrowing and feeding activity of the earthworms. For the aquatic environment, spiked sediment was also the main exposure scenario (six out of seven studies), with only one study using spiked water.

The most studied polymer type was PE (nine studies, Besseling et al. 2017; Huerta Lwanga et al. 2016; Judy et al. 2019; Prendergast-Miller et al. 2019; Rillig et al. 2017; Rodríguez-Seijo et al. 2017; Rodríguez-Seijo et al. 2018a, b; Wang et al. 2019a), followed by PS (five studies, Besseling et al. 2013; Cao et al. 2017; Leung and Chan 2018; Van Cauwenberghe et al. 2015; Wang et al. 2019a), PVC (four studies, Browne et al. 2013; Gomiero et al. 2018; Judy et al. 2019; Wright et al. 2013) and PET (one study, Judy et al. 2019). The morphology of the particles was not always provided by the authors, but when it was the case, spheres and fragments were the most common shapes, each covered by six studies. Interestingly in one study, characterization by scanning electron microscopy revealed that particles sold as spheres were in fact flakes (Cao et al. 2017). Overall, particles ranging from below $1 \mu \mathrm{m}$ to $5 \mathrm{~mm}$ were studied, with most studies focusing on particles above $100 \mu \mathrm{m}$ (12 out of 16 studies). When particles were prepared in the laboratory, the lowest and largest particle sizes were not always provided (e.g. Huerta Lwanga et al. 2016). None of the 16 studies on Annelida reported any surface characterization or functionalization.

The individual level was assessed in all 16 studies on annelids, followed by subcellular ( 9 studies), ecosystem (6 studies) and population (3 studies) levels. Only one study covered effects at the cellular and organ level. At the individual level, mortality and growth were the most studied endpoints (both covered by 10 studies), although being the least affected endpoints across species, environmental compartments, polymer types and sizes. Mortality was never observed, except in one study with PS flakes at environmentally irrelevant concentrations ( 5 and $20 \mathrm{~g} / \mathrm{kg}$ soil dry weight). Growth was rarely affected, and only at environmentally irrelevant concentrations for pristine plastic particles (from $10 \mathrm{~g} / \mathrm{kg}$ PS flakes and from $4 \mathrm{~g} / \mathrm{kg} \mathrm{PE}$ spheres).

The lowest concentrations inducing effects at the subcellular level were observed for exposure to PE fragments (size classes 200-500 and $>500 \mu \mathrm{m}$ ), which increased protein, lipid and polysaccharide contents in earthworms at $62 \mathrm{mg} / \mathrm{kg}$, decreased catalase activity at $125 \mathrm{mg} / \mathrm{kg}$ and increased lipid peroxidation at $250 \mathrm{mg} / \mathrm{kg}$

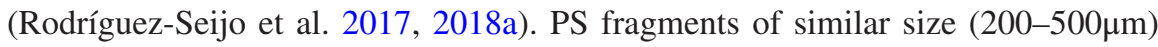
were found to increase peroxidase activity in earthworms at $10 \mathrm{~g} / \mathrm{kg}$ (the lowest concentration tested by Wang et al. 2019a). In marine annelids, PVC fragments 
$(100-199 \mu \mathrm{m})$ induced inflammation at $5 \mathrm{~g} / \mathrm{kg}$ (the lowest concentration tested by Wright et al. (2013)).

At the ecosystem level, negative results were most frequently reported, e.g. no avoidance of PE fibres $(40 \times 400 \mu \mathrm{m})$ at up to $10 \mathrm{~g} / \mathrm{kg}$ (Prendergast-Miller et al.

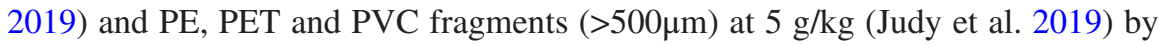
earthworms and no effect of PE spheres (particle size distribution ranging from $<50 \mu \mathrm{m}$ to $>100 \mu \mathrm{m}$ ) at up to $12 \mathrm{~g} / \mathrm{kg}$ on burrow formation by earthworms (Huerta Lwanga et al. 2016). The only effects seen were on the feeding activity of marine

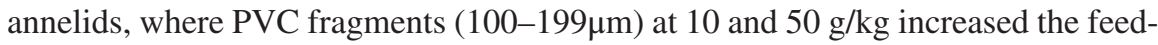
ing activity of Arenicola marina (Wright et al. 2013).

Overall, the data on the ecotoxicological effects of plastic particles on Annelida is very limited but seem to suggest a moderate to low risk to these organisms. One of the reasons could be linked to the ecological traits of annelids, adapted to continuously ingest vast amounts of non-nutritious particles, through their burrowing and feeding activities. It should also be noted that the absence of avoidance behaviour and detrimental effects on annelids make them efficient vectors of plastic particles not only to their predators but also to the whole ecological compartment, due to their intense bioturbation activity.

\subsubsection{Mollusca}

The Mollusca group includes several ecologically and commercially important filter feeders (e.g. mussels and clams) that due to their habitat and feeding behaviour are likely to encounter plastic particles of varying sizes. Most of the studies for Mollusca focused on marine species ( 29 studies, 13 species), followed by freshwater ( 6 studies, 4 species) and terrestrial species (a single study, 1 species). The 17 species belonged to 2 classes, Bivalvia and Gastropoda: Abra nitida, Achatina fulica, Corbicula fluminea, Crassostrea gigas, Dreissena polymorpha, Ennucula tenuis, Meretrix meretrix, Mytilus edulis, Mytilus galloprovincialis, Mytilus sp., Ostrea edulis, Perna perna, Perna viridis, Pinctada margaritifera, Potamopyrgus antipodarum, Scrobicularia plana and Sphaerium corneum. The most commonly studied species was the mussel M. galloprovincialis (in 11 studies). Most of the species used were filter feeding (13 species in 33 studies), followed by grazer species (2 species in 2 studies), while only 1 study used deposit feeders ( 2 species). Most studies were carried out on adults (28 studies), with 7 studies using larvae, 4 studies embryos, 2 studies gametes and 1 study juveniles. Filter-feeding organisms were exposed mainly via water (28 studies) and 1 via water plus muddy sediment. For these organisms, two studies used exposure via food and two studies via sediment. The deposit feeders were exposed via sediment, while the grazers via food and soil.

For Mollusca, 36 studies looked at the effects of 9 different polymers, with PS being the most studied polymeric material (total 20 studies). Overall, 12 studies used PE and 4 studies used PVC and PET. There were two studies for PLA and two for proprietary polymer, while all the other polymers (PA, PC and PP) only had one 
study each. Most of the studies were performed with PS spheres $(n=14)$, followed by PE and PS fragments (eight and three studies, respectively). Two studies used PET fibres and spheres of proprietary polymer, while the remaining morphologies only had one study each. Regarding size, the highest number of studies (12 in total) used PS particles between 1 and $9 \mu \mathrm{m}$. Studies with PE particles used size ranges of

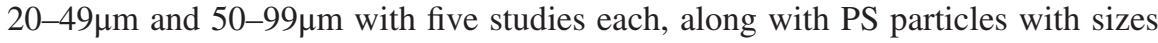
$0.1-0.99 \mu \mathrm{m}, 20-49 \mu \mathrm{m}$ and $20-49 \mu \mathrm{m}$. All the other particle size distributions had less than five studies each. Only studies using PS particles reported particle surface information, for which four studies used PS- $\mathrm{NH}_{2}$, three studies used plain and $\mathrm{COOH}$ and one used PS with sulphate groups, where all particles were within the nano-scale. Most of the reviewed studies only reported effects for particles above $1 \mu \mathrm{m}$, with only a small number showing impacts with particles within nano-range, more specifically PS and PE. This is the reflection of the size-dependent threshold commonly associated with the particle-selection feeding behaviour characteristic of most of the species included in this taxonomical group (Van Cauwenberghe and Janssen 2014; Wegner et al. 2012).

In terms of levels of biological organization, effects at the subcellular (23 studies, with 18 reporting effects) and individual level (22 studies, with 12 reporting effects) were the most studied. There was only one study at an ecosystem level (reporting effects) but 11 analysing effects at the population level (7 with observed effects). Overall, 11 studies analysed effects on organs (with 6 reporting effects) and 7 in cells (6 reporting effects). The most studied endpoint was related to impacts in feeding behaviour (15 studies), with 9 reporting significant effects related to filtration and ingestion rate, absorption and assimilation efficiency (Capolupo et al. 2018; Cole and Galloway 2015; Gardon et al. 2018; Green 2016; Guilhermino et al. 2018; Oliveira et al. 2018; Revel et al. 2019; Rist et al. 2016, 2019; Rochman et al. 2017; Santana et al. 2018; Song et al. 2019; Sussarellu et al. 2016; Wegner et al. 2012; Woods et al. 2018). Endpoints related to oxidative stress were the second most common endpoint, with 14 studies, 8 of which showing impacts on lipid peroxidation, formation of reactive oxygen species and total oxyradical scavenging capacity (Avio et al. 2015; Brandts et al. 2018b; Gonçalves et al. 2019; GonzálezFernández et al. 2018; Guilhermino et al. 2018; Magni et al. 2018; Oliveira et al. 2018; Paul-Pont et al. 2016; Revel et al. 2019; Ribeiro et al. 2017; Santana et al. 2018; Song et al. 2019; Sussarellu et al. 2016; von Moos et al. 2012). In combination with oxidative stress, alteration in enzymatic activity was also one of the main endpoints determined in molluscs (reported in 12 studies), with 10 studies showing alterations to antioxidant enzymes (Avio et al. 2015; Brandts et al. 2018b; Franzellitti et al. 2019; Gonçalves et al. 2019; Guilhermino et al. 2018; Magni et al. 2018; Oliveira et al. 2018; Paul-Pont et al. 2016; Pittura et al. 2018; Revel et al. 2019; Ribeiro et al. 2017; Song et al. 2019). Alterations in gene expression were also a common endpoint in most of the reviewed studies (12 studies), with 10 reporting up- and downregulation of genes involved in different metabolic pathways as detoxification, immunity, apoptosis, energy reserves, etc. (Avio et al. 2015; Balbi et al. 2017; Brandts et al. 2018a; Capolupo et al. 2018; Détrée and Gallardo-Escárate 2017, 2018; Franzellitti et al. 2019; Paul-Pont et al. 2016; Pittura et al. 2018; Revel 
et al. 2019; Rochman et al. 2017; Sussarellu et al. 2016). Histopathological alterations were also included in some of these studies to understand the effects of particle ingestion in different organs (total nine studies), with five studies reporting alterations in the gills and digestive glands of exposed organisms (Bråte et al. 2018; Gardon et al. 2018; Gonçalves et al. 2019; Guilhermino et al. 2018; Paul-Pont et al. 2016; Revel et al. 2019; Rochman et al. 2017; Song et al. 2019; von Moos et al. 2012). Five out of eight studies reported significant genotoxicity of the plastic particles used, expressed as DNA damage or micronuclei formation (Avio et al. 2015; Brandts et al. 2018a; Bråte et al. 2018; Magni et al. 2018; Pittura et al. 2018; Revel et al. 2019; Ribeiro et al. 2017; Santana et al. 2018). Seven studies also analysed the neurotoxicity of particles, with six reporting significant alterations in acetylcholinesterase activity (Avio et al. 2015; Brandts et al. 2018a; Guilhermino et al. 2018; Magni et al. 2018; Oliveira et al. 2018; Pittura et al. 2018; Ribeiro et al. 2017). Several endpoints related to population effects were determined in molluscs, most of which related to fecundity (six studies, Gardon et al. 2018; González-Fernández et al. 2018; Imhof and Laforsch 2016; Luan et al. 2019; Sussarellu et al. 2016; Tallec et al. 2018), offspring viability (one study, Capolupo et al. 2018), larval development (seven studies, Balbi et al. 2017; Beiras et al. 2018; Cole and Galloway 2015; Luan et al. 2019; Rist et al. 2019; Sussarellu et al. 2016; Tallec et al. 2018) and juvenile development (one study, Imhof and Laforsch 2016). Of these endpoints, only those related to fecundity (e.g. fertilization yield, gamete quality hatching rate, etc.) and larval development showed a significant effect. General health endpoints including growth (eight studies, Détrée and Gallardo-Escárate 2018; Gardon et al. 2018; Green 2016; Imhof and Laforsch 2016; Redondo-Hasselerharm et al. 2018; Rist et al. 2019; Santana et al. 2018; Song et al. 2019), energy reserves (five studies, Avio et al. 2015; Bour et al. 2018; Brandts et al. 2018a; Pittura et al. 2018; von Moos et al. 2012), condition index (six studies, Bour et al. 2018; Revel et al. 2019; Ribeiro et al. 2017; Santana et al. 2018; Sussarellu et al. 2016; von Moos et al. 2012), respiration rate (three studies, Gardon et al. 2018; Green 2016; Rist et al. 2016) and scope for growth (one study, Gardon et al. 2018) were also included in several studies; however, these were the less sensitive endpoints, where only one to two studies reported a significant effect.

Of the four freshwater species used in the studies reviewed, significant impacts were only recorded for $D$. polymorpha exposed to PS $(1-9 \mu \mathrm{m}$, LOEC 50000 particles/L) (Magni et al. 2018) and C. fluminea following exposure to a proprietary

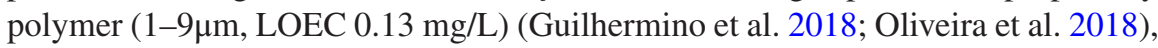
as well as PET, PE, PVC and PS fragments (Rochman et al. 2017). In the study by Rochman et al. (2017), C. fluminea was exposed to environmental concentrations and sizes of PET, PE, PVC and PS fragments (sizes range 50 to $>500 \mu \mathrm{m}$ ) for 28 days, after which histopathological alterations were recorded (LOEC $2.8 \mathrm{mg} / \mathrm{L}$ ). The authors highlight that the effects observed in exposed clams were specific to the polymer type used.

Several ecotoxicological effects across the different levels of biological organization were recorded for marine molluscs. Interestingly, mortality was one of the least sensitive endpoints in organisms exposed either via sediment or water, even at 
very high concentrations. Only Rist et al. (2016) reported substantial mortality in $P$. viridis exposed to PVC after 91 days of exposure (size range $1-49 \mu \mathrm{m}, 2160 \mathrm{mg} / \mathrm{L}$ ); however, no significant statistical differences were found compared to the control condition. Mussels belonging to the genus Mytilus were the most used marine species used in the reviewed studies, for which a wide range of biological endpoints were determined. The biological endpoints for which significant effects were recorded included byssus production and immunity deficiency (LOEC $0.025 \mathrm{mg} / \mathrm{L}$, PE fragments $>500 \mu \mathrm{m})$ (Green et al. 2019), mortality, concentration and phagocytic activity of circulation haemocytes, histopathological alterations, ROS production

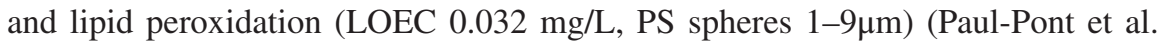
2016), antioxidant enzymatic activity and genotoxicity (LOECs of $0.000008 \mathrm{mg} / \mathrm{L}$ and $0.01 \mathrm{mg} / \mathrm{L}$, respectively, mixture PE and PP fragments, 200-500 $\mu \mathrm{m}$ ) (Revel et al. 2019), feeding behaviour (LOEC 3000 particles/L, PET fibres 200 to $>500 \mu \mathrm{m}$ ) (Woods et al. 2018), alterations in gene and protein expression, growth (LOEC $0.03 \mathrm{mg} / \mathrm{L}$, PE and PLA fragments 1 to $50 \mu \mathrm{m}$ ) (Détrée and Gallardo-Escárate 2018), larval malformations (LOEC $0.00042 \mathrm{mg} / \mathrm{L}$, PS spheres, 1-9 $\mu \mathrm{m}$ ) (Rist et al. 2019), lysosomal membrane stability (LOEC $1500 \mathrm{mg} / \mathrm{L}, \mathrm{PE}$ and PS fragments size range from $<0.05$ to $99 \mu \mathrm{m}$ ) (Avio et al. 2015) and neurotoxicity (LOEC $0.05 \mathrm{mg} / \mathrm{L}$, PS

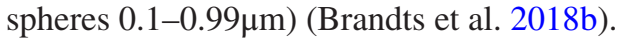

The gastropod A. fulica was the only terrestrial species in the ecotoxicological studies reviewed, for which effects were recorded following 28 days of exposure to PET fibres (length $1260 \mu \mathrm{m}$, diameter $76 \mu \mathrm{m}$ ) at concentrations ranging from 14 to $710 \mathrm{mg} / \mathrm{kg}$ sediment (Song et al. 2019). The authors reported alterations in feeding behaviour (LOEC $14 \mathrm{mg} / \mathrm{kg}$ sediment) upon exposure that resulted in histopathological alterations in the gastrointestinal tract (LOEC $140 \mathrm{mg} / \mathrm{kg}$ sediment) and oxidative stress in the liver (LOEC $710 \mathrm{mg} / \mathrm{L}$ ).

Mollusca was the taxonomical group for which a wider range of biological endpoints were determined. Overall, the reviewed data highlighted that acute and chronic toxicity of plastic particles in molluscs seem to be dependent not only on particle characteristics such as polymer type (Avio et al. 2015; Rochman et al. 2017), concentration range (Gardon et al. 2018; Rochman et al. 2017), particle size (Tallec et al. 2018) and surface chemistry (Cole and Galloway 2015; Luan et al. 2019), but also on organism-specific traits such as developmental stage (Balbi et al. 2017; Rist et al. 2019) and tissue analysed (Brandts et al. 2018b; Revel et al. 2019; Ribeiro et al. 2017). Furthermore, the reviewed findings further emphasize the need to conduct studies with freshwater and terrestrial species, especially when considering their higher risk of exposure to plastic particles. It is also worth mentioning that this taxonomical group includes many filter-feeding species with a high tendency for particle retention, thus representing a possible source of transfer across higher trophic levels and potentially to humans. 


\subsubsection{Echinodermata}

Echinoderms are exclusively marine invertebrate species that have a widespread distribution throughout the ocean. These organisms inhabit a diverse array of cold water and tropical ecosystems including habitats from coastal, intertidal zones to offshore, as well as deep water areas. Common echinoderms include sea cucumbers, starfish and sea urchins. Four microplastic ecotoxicology studies were reviewed for echinoderms representing the marine environment. Sea urchin species were used in all studies: Paracentrotus lividus was used in three studies (Beiras et al. 2018; Della Torre et al. 2014; Messinetti et al. 2018), while Tripneustes gratilla was used in one study (Kaposi et al. 2014). Early life stages of sea urchins were used for all studies (larvae/embryo (Beiras et al. 2018; Della Torre et al. 2014; Messinetti et al. 2018)). All studies with echinoderms were performed via water exposure. Reviewed studies used PS (two studies) and PE (two studies) microparticles. Experimental studies on echinoderms varied with PS with two different surface charges being used at the $40-50 \mathrm{~nm}$ size range and $10 \mu \mathrm{m}$ PS spherical microparticles. PE of similar size ranges similar as natural food of zooplankton organisms $(1-500 \mu \mathrm{m})$ were also used, as well commercial PE ranging from 10 to $45 \mu \mathrm{m}$.

The individual level was studied in all four studies and one study included endpoints at the cellular level (Della Torre et al. 2014). The effects of carboxylated PS (PS-COOH) and amine PS (PS-NH $\mathrm{N}_{2}$ ) nanoplastics were used to evaluate embryotoxicity in $P$. lividus, specifically disposition, embryo development and gene expression. No embryotoxicity was observed for PS-COOH which formed microaggregates and was anionic up to $50 \mu \mathrm{g} / \mathrm{mL}$. However, $\mathrm{PS}-\mathrm{NH}_{2}$, which was better dispersed and cationic, caused developmental defects $\left(\mathrm{EC}_{50} 3.85 \mu \mathrm{g} / \mathrm{mL} 24\right.$ hours post fertilization and $\mathrm{EC}_{50} 2.61 \mu \mathrm{g} / \mathrm{mL} 48$ hours post fertilization). These findings suggest that surface charge and particle aggregation dynamics in seawater influence embryotoxicity. Collectively, the findings of Della Torre et al. (2014) highlight the importance of different aggregation states and surface properties of nanoplastics and how they lead to differences in uptake, exposure and disposition routes and overall impacts.

The effects of ingesting microplastics in larval $T$. gratilla were proportionally related to the concentration of PE microspheres and ingestion was reduced in the presence of biological fouling and phytoplankton food. An unrealistically high concentration of PE microspheres (300 spheres $/ \mathrm{mL}$ ) affected larval growth with no significant effect on survival observed. Conversely, at environmentally realistic concentrations, there was little effect observed on growth or survival (Kaposi et al. 2014).

The planktotrophic larvae of $P$. lividus were utilized to evaluate the effects of PS microbeads on juvenile development. $P$. lividus larvae were able to ingest microplastics, albeit at a lower rate, in comparison to the sessile filter-feeding ascidian (Ciona robusta) juveniles. No effect of PS microbeads, at any concentration (control vs. $0.125,1.25,12.5$ and $25 \mu \mathrm{g} / \mathrm{mL}$ ), was observed on larval survival, whereas growth was negatively affected, with shorter larvae observed in the $25 \mu \mathrm{g} / \mathrm{mL}$ treatment (Messinetti et al. 2018). 


\subsubsection{Chordata: Fish}

Marine and freshwater environments are evenly represented in fish studies, with 19 and 20 studies, respectively. Overall, 18 different species were used in fish studies (Acanthochromis polyacanthus, Acanthurus triostegus, Bathygobius krefftii, Carassius carassius, Clarias gariepinus, Cyprinodon variegatus, Danio rerio, Dicentrarchus labrax, Lates calcarifer, Oncorhynchus mykiss, Oreochromis niloticus, Oryzias latipes, Oryzias melastigma, Pimephales promelas, Pomatoschistus microps, Sparus aurata, Symphysodon aequifasciatus). The most commonly studied species is the zebrafish $D$. rerio (12 studies, corresponding to $26 \%$ of studies). The European seabass (D. labrax) and the common goby ( . microps) are the most commonly studied marine species (six studies, $13 \%$ of studies each). Most studies were carried out on embryo/larvae (11 studies, $28 \%$ of studies) or juvenile (16 studies, $41 \%$ of studies) fish, while studies on adult fish only represent $18 \%$ of the studies ( 7 studies). Six studies did not report the developmental stage of the test species.

Fish exposure to microplastics was performed either directly via water (27 studies, $69 \%$ of studies) or via the trophic route (13 studies, $33 \%$ of studies). For the later, two main methods are found in the literature. The first method consists in exposing living prey to microplastics then feeding them to fish (Cedervall et al. 2012; Mattsson et al. 2015, 2017; Skjolding et al. 2017; Tosetto et al. 2017). The second method consists in spiking artificial food with known concentrations of microplastics and feed it to fish (Ašmonaitè et al. 2018a, b; Caruso et al. 2018; Granby et al. 2018; Jovanović et al. 2018; Mak et al. 2019; Mazurais et al. 2015; Rochman et al. 2013). While the first method is more representative of trophic interactions in the environment, microplastic ingestion by living prey is not a controlled parameter, and spiking artificial food therefore offers better control of exposure concentrations. The numbers of studies reporting adverse effects, as well those reporting an absence of effect, are similar for marine and freshwater environments and for the different exposure routes. This suggests that these parameters are not likely to influence the occurrence of effects in fish following exposure to microplastics.

More than $92 \%$ of studies conducted on fish species used PS (45\% = 18 studies) or PE $(47.5 \%=15$ studies) microplastics. Commercially available (micro)spheres are the most represented particle morphology and are used in 56\% of the studies (22 studies). Undetermined fragments are used in $46 \%$ of the studies (18 studies), and close to $13 \%$ of the studies ( 5 studies) did not disclose particle morphology. Four studies used microplastics produced by grinding larger plastic items (Caruso et al. 2018; Choi et al. 2018; Lei et al. 2018b). A broad range of particle sizes have been tested, with the vast majority of studies using microplastics comprised between 0.1 and $500 \mu \mathrm{m}$. Most studies investigating the effects of microplastics presenting different properties compared different particle sizes: 49\% (19 studies) studied microplastics presenting different sizes, while only one and two studies compared microplastic morphology and polymer type, respectively.

In fish studies, the subcellular level is the most frequently studied level of biological organization (23 studies, 59\% studies), followed by the individual, 
ecosystem, organ and population levels, respectively (16, 16, 13 and 8 studies, respectively, corresponding to $41 \%, 41 \%, 33 \%$ and $21 \%$ of studies). For each organization level, all the studied endpoints were listed and sorted as "impacted" or "not impacted" following exposure to microplastics. For most organization levels, the numbers of endpoints not impacted are very close to the numbers of impacted endpoints. At cellular and subcellular levels, oxidative stress is the main endpoint studied (Ašmonaitė et al. 2018a; Chen et al. 2017; Choi et al. 2018; Ding et al. 2018; Ferreira et al. 2016; Karami et al. 2017; LeMoine et al. 2018; Luís et al. 2015; Mak et al. 2019; Oliveira et al. 2013; Rochman et al. 2013; Wang et al. 2019c), as well as lipid peroxidation (Barboza et al. 2018; Ding et al. 2018; Ferreira et al. 2016; Fonte et al. 2016; Oliveira et al. 2013; Wen et al. 2018a), immune and/or inflammatory responses (Brandts et al. 2018a; Choi et al. 2018; Granby et al. 2018; Mazurais et al. 2015), neurotoxicity (Barboza et al. 2018; Ding et al. 2018; Ferreira et al. 2016; Fonte et al. 2016; Luís et al. 2015; Oliveira et al. 2013; Rainieri et al. 2018), energy production (Barboza et al. 2018; Oliveira et al. 2013; Wen et al. 2018a), endocrine disruption (Wang et al. 2019c) and gut tight junctions proteins, as well as active transport through gut (Ašmonaitè et al. 2018b). At the organ level, most studies focus on histological changes (Ašmonaitè et al. 2018b; Choi et al. 2018; Jovanović et al. 2018; Karami et al. 2016, 2017; Lei et al. 2018b; Mak et al. 2019; Rainieri et al. 2018; Rochman et al. 2013; Wang et al. 2019c), but other endpoints were also studied, such as intestine permeability (Ašmonaitė et al. 2018b; Jovanović et al. 2018), blood and plasma chemistry and metabolite concentrations (Jovanović et al. 2018; Mattsson et al. 2015, 2017), brain weight and water content (Mattsson et al. 2015, 2017), liver glycogen (Karami et al. 2016; Rochman et al. 2013), lipid metabolism (Cedervall et al. 2012) and gut microbiota (Caruso et al. 2018; Jin et al. 2018). Endpoints studied at the population level comprise fish fecundity (e.g. number of eggs laid and hatching rate) (Cong et al. 2019; LeMoine et al. 2018; Wang et al. 2019c), embryo survival and development (Batel et al. 2018; Pitt et al. 2018) and larval survival, development and behaviour (Chen et al. 2017; Choi et al. 2018; Malinich et al. 2018). Endpoints at the ecosystem levels relate to behaviour and include feeding behaviour (e.g. feeding time, foraging, predatory performance), environment exploration and fish locomotion (Cedervall et al. 2012; Choi et al. 2018; Critchell and Hoogenboom 2018; de Sá et al. 2015; Ferreira et al. 2016; Fonte et al. 2016; Guven et al. 2018; Jacob et al. 2019; Luís et al. 2015; Mak et al. 2019; Malinich et al. 2018; Mattsson et al. 2017; Pitt et al. 2018; Skjolding et al. 2017; Tosetto et al. 2017; Wen et al. 2018a). Contrary to the above-described levels of biological organization, for which the numbers of impacted and non-impacted endpoints are similar, at the individual level more studies report an absence of effects (11 studies) than the observation of adverse effects ( 3 studies) following microplastic exposure. Mortality was reported for medaka larvae exposed to PS sphere $(10 \mu \mathrm{m}$, 100,000 part./L) for 14 days (Cong et al. 2019) and for juvenile goby exposed to PE spheres $(1-5 \mu \mathrm{m}, 184 \mu \mathrm{g} / \mathrm{L})$ for 4 days (Fonte et al. 2016), and weight loss was observed in crucian carp exposed to PS nano-spheres via trophic chain for 42 days (Cedervall et al. 2012). Other studies investigating fish mortality, growth or body condition reported an absence of effect (Critchell and Hoogenboom 2018; Ding 
et al. 2018; Granby et al. 2018; Jovanović et al. 2018; Karami et al. 2017; Lei et al. 2018b; LeMoine et al. 2018; Mazurais et al. 2015; Oliveira et al. 2013; Wen et al. 2018a, b;), and in one case reported mortality only at the highest concentration test (PMMA nano-spheres, 20 mg/L) (Brandts et al. 2018a).

\subsubsection{Species Sensitivity Distributions}

Species sensitivity distributions (SSDs) are a common approach used in environmental protection, risk assessment and management practices to describe interspecies sensitivity and estimate community-level risks for a specific stressor. An SSD is derived by fitting a selected statistical model, in this case a lognormal distribution, to available ecotoxicity effect data for species from different taxonomical groups, after which predictions of the \% of species affected can be calculated (Posthuma et al. 2019). The SSD captures the interspecies variability, which can then be used to derive key risk assessment components, such as the concentration at which $5 \%$ of the species in an ecosystem can be affected. This key regulatory parameter is commonly known as the "hazardous concentration for $5 \%$ of the species" or $\mathrm{HC}_{5}$ and is normally used to derive environmental quality criteria standards (Besseling et al. 2019; Burns and Boxall 2018 and references therein). Even though this approach is commonly used to assess the risk of other environmental chemicals, only recently it has been applied to both microplastic and nanoplastic data (Adam et al. 2019; Besseling et al. 2019; Burns and Boxall 2018; Everaert et al. 2018; VKM 2019).

With the ecotoxicological data collected from the reviewed publications, three SSDs for microplastic were investigated for water, sediment/soil and food exposure routes, after which the $\mathrm{HC}_{5}$ corresponding to concentrations expressed in mass and particle number when available were estimated (Fig. 7.6). However, the lack of ecotoxicological data for species covering the different environmental compartments limited the applicability of SSDs in this case, thus decreasing the overall success of the hazard assessment of microplastics and nanoplastics. SSDs are as robust as the quality of their ecotoxicological data, and usually at least 12 different species are considered a minimum for fitting an SSD (Posthuma et al. 2019). Accordingly, even though a total of 107 species covering key taxonomical groups were comprehensibly assessed in the 175 publications reviewed, only 12-58 were used to build the SSDs. This represents a subset of the total data, depending on the availability of data for the exposure matrix (water or sediment/soil) and the exposure quantification (mass or particles).

As the total microplastic toxicity data on freshwater and marine environments is still limited, information collected on marine, freshwater and terrestrial species were combined according to exposure route (water, sediment/soil and food) to increase the number of feeding strategies and trophic levels included in the SSDs, thus increasing statistical power. No distinction was made between particle characteristics due to insufficient data within a certain particle size and polymer type. In 


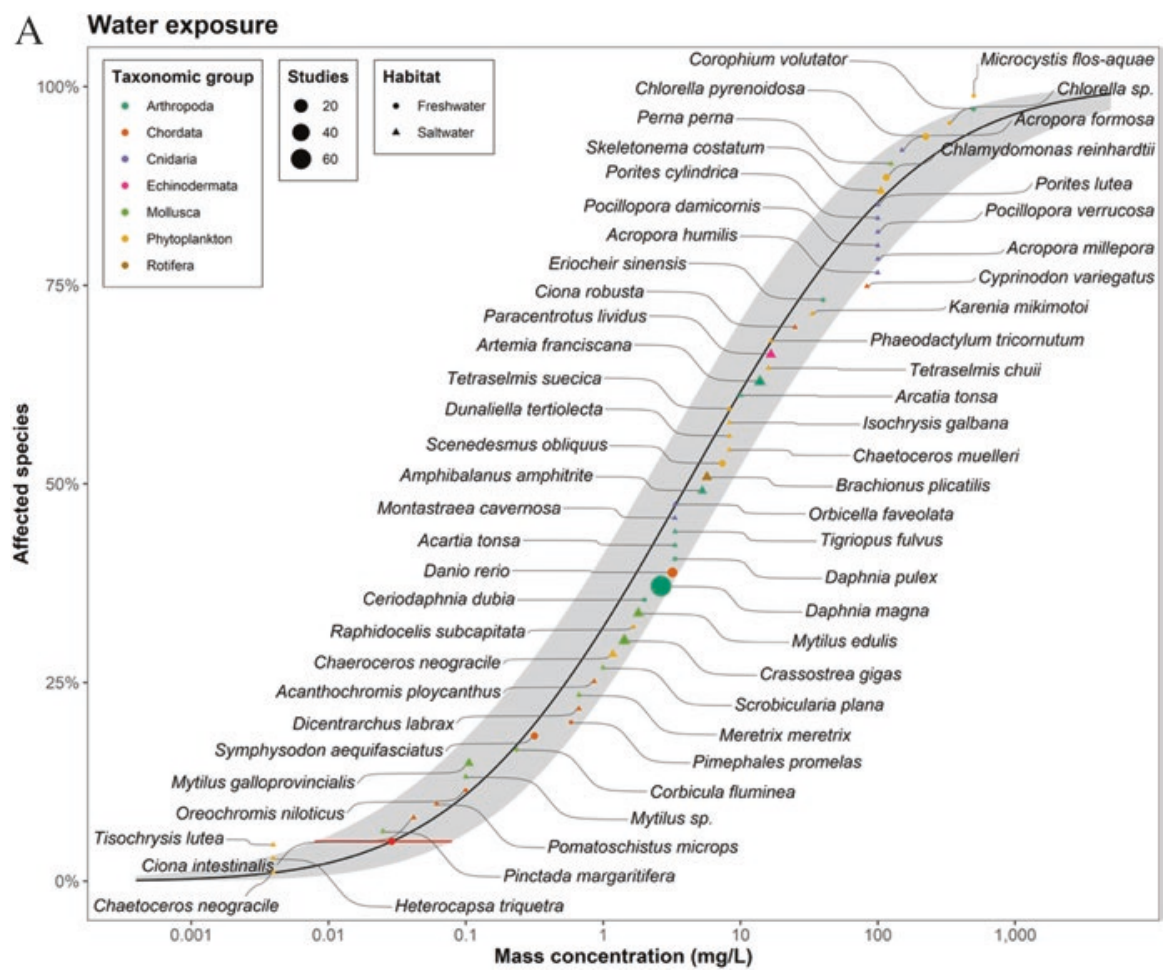

Fig. 7.6 Species sensitivity distributions (SSDs) for (a) species exposed via the water phase with data divided by particle concentration expressed as mass $(\mathrm{mg} / \mathrm{L})(n=58)$; (b) species exposed via the water phase with data divided by particle concentration expressed as particle number (million particles/L) $(n=31)$; and (c) species exposed via the sediment and soil phase with data shown only for particle concentration as mass number $(\mathrm{mg} / \mathrm{kg})(n=12)$. The average SSDs are plotted as solid black lines, and the $95 \%$ credible interval as grey ribbon. The $\mathrm{HC}_{5}$ (concentration at which $5 \%$ of the species are affected) is represented as a red point in combination with the $95 \%$ credible intervals. Taxonomic groups are represented in different colours, with the different habitats divided by shape and where size reflects the number of studies included

addition, only data pertaining to individual and population levels were considered (e.g. mortality, growth, reproduction), for which both $\mathrm{NOECs}$ and $\mathrm{EC}_{50} / \mathrm{LC}_{50}$ values were used.

The poor standardization in terms of reporting of experimental conditions was another factor influencing the construction of SSDs. For example, the lack of information on exposure concentrations expressed in mass and particle number further limited the usable data sets. Dose metrics were standardized to either mass- or particle-based concentrations. When it was not possible to perform this conversion, the studies were excluded from the SSD fitting. Most of the excluded studies were for exposure via food (e.g. fish), leaving insufficient data available to construct SSDs, as only 6 and 3 data points were available (for mass concentration and 


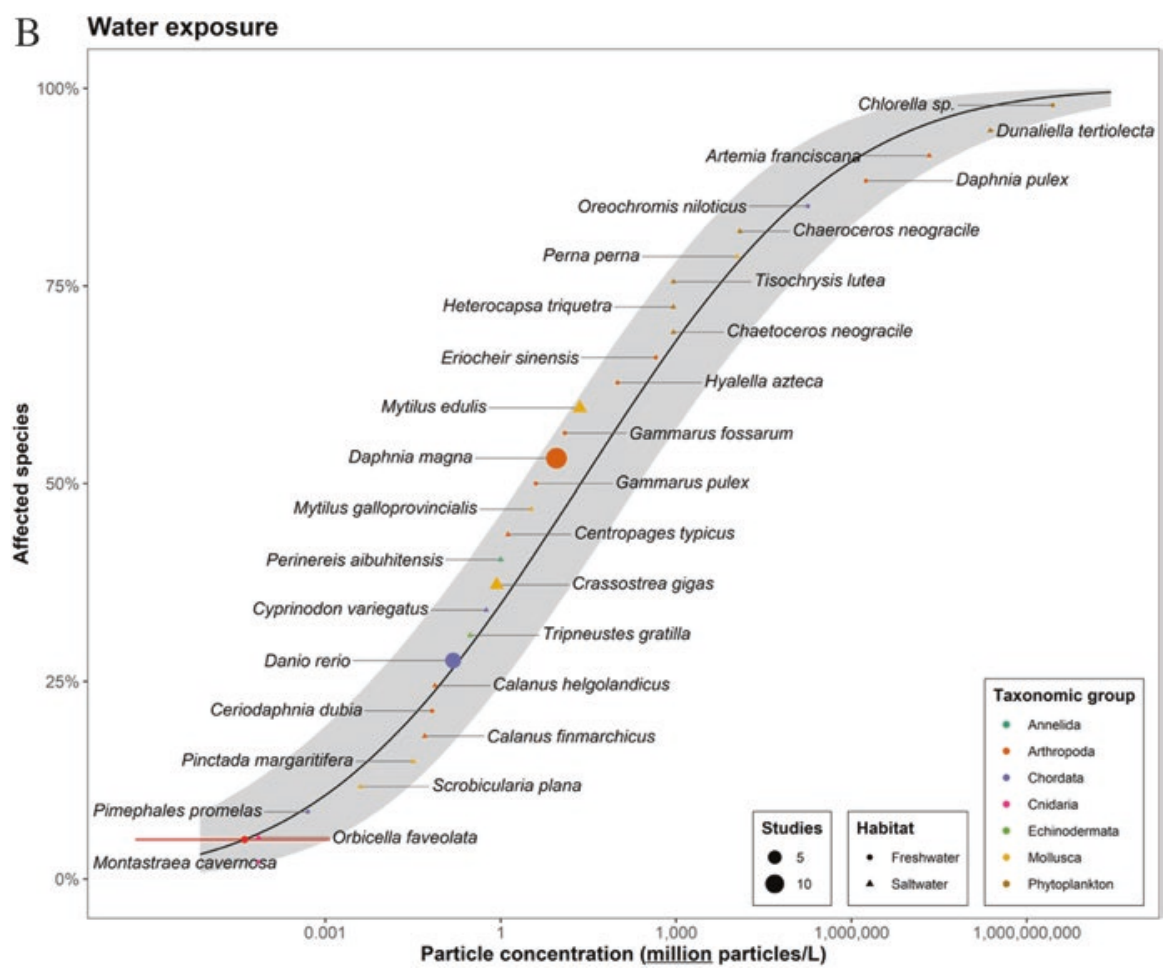

Fig. 7.6 (continued)

particle concentration, respectively). Overall, tentative SSDs reflecting the combined variability of species sensitivity, plastic properties and effect mechanisms were only constructed for water exposure as a function of particle dosage (both mass and number) and sediment/soil exposures as a function of particle dosage (mass only). Due to insufficient data, the particle-based sediment exposure route and the entire dietary exposure route were excluded from the SSD analyses. The SSD for mass-based water exposure was fitted to data from 101 studies, covering 58 species across 7 taxonomic groups and 2 habitats. Its particle-based counterpart was fitted to data from 39 studies, covering 31 species across 7 taxonomic groups and 2 habitats. For the mass-based sediment exposure route, the SSD was fitted to data from 17 studies, covering 12 species across 4 taxonomic groups and 3 habitats; note that in terms of species coverage, this is considered a minimum acceptable coverage.

The separately constructed SSDs for organisms exposed via water and sediment/ soil (expressed in mass and particle number) are shown in Fig. 7.6. Of the studies where concentrations were expressed by particle mass, microalgae species were the most and least sensitive species to exposure via the water phase (Fig. 7.6a). The most sensitive species was the marine microalgae $C$. neogracile ( $\mathrm{PS}-\mathrm{NH}_{2}$ spheres, $<1 \mu \mathrm{m}$ ), (González-Fernández et al. 2019), while the most sensitive freshwater species was the clam $C$. fluminea (proprietary polymer, 1-9 $\mu \mathrm{m})$ (Oliveira et al. 2018). 


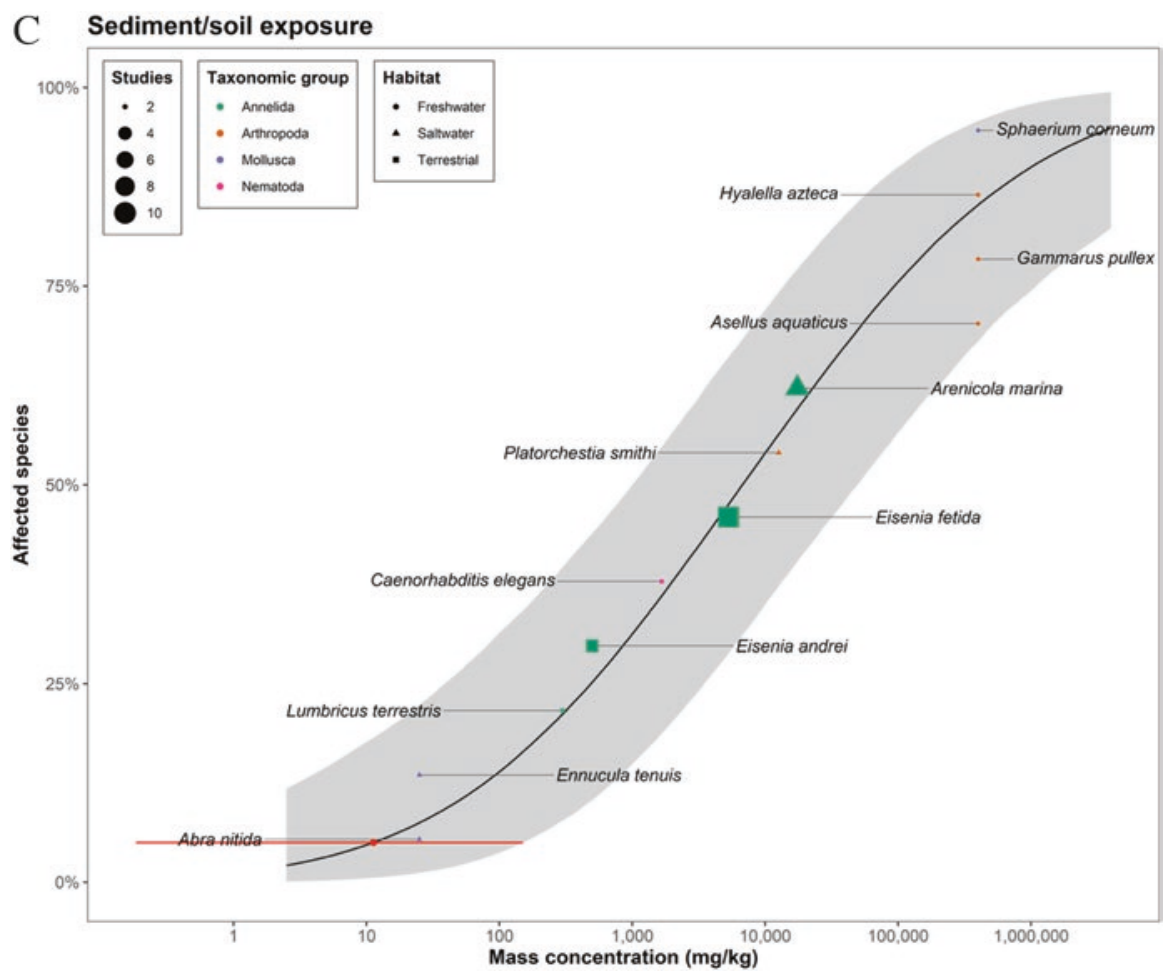

Fig. 7.6 (continued)

The least sensitive freshwater species was M. flos-aquae (PVC and PP, 100-199 $\mu \mathrm{m}$ ) (Wu et al. 2019b), while the cnidarian A. formosa was the least sensitive marine species (PE fragments, size range 50 to $500 \mu \mathrm{m}$ (Syakti et al. 2019). The derived $\mathrm{HC}_{5}$ for this SSD was $28.9 \mu \mathrm{g} / \mathrm{L}(95 \%$ CI $7.94-79.1 \mu \mathrm{g} / \mathrm{L})$. For the water exposure SSD built with data expressed in terms of particle number (Fig. 7.6b), the cnidarians M. cavernosa and $O$. faveolata were the most sensitive species (PE beads, $>50 \mu \mathrm{m}$ (Hankins et al. 2018)), while the least sensitive was the freshwater microalgae Chlorella sp. (Thiagarajan et al. 2019). The derived $\mathrm{HC}_{5}$ for this SSD was 41.6 particles/L (95\% CI 0.58-1176 particles/L). For exposures either via sediment or soil (Fig. 7.6c), the SSDs obtained for particle concentration in mass showed that the most sensitive species were the marine clams A. nitida and E. tenuis (PE fragments $>1 \mu \mathrm{m}$ ) (Bour et al. 2018), followed by the terrestrial annelid L. terrestris (PE spheres $<1$ to $>500 \mu \mathrm{m}$ ) (Huerta Lwanga et al. 2016). The least sensitive species were the freshwater snail S. corneum (PS fragments $>20 \mu \mathrm{m}$ (Redondo-Hasselerharm et al. 2018)) and the freshwater arthropod H. azteca (PE and PS fragments 10-500 $\mu \mathrm{m}$ ) (Au et al. 2015; Redondo-Hasselerharm et al. 2018). The derived $\mathrm{HC}_{5}$ for this SSD was $11.3 \mathrm{mg} / \mathrm{kg}$ (95\% CI $0.18-151 \mathrm{mg} / \mathrm{kg}$ ). As mentioned above, 
construction of an SSD for particle-based sediment exposure was not possible due to lack of sufficient data.

The mass-based water exposure $\mathrm{HC}_{5}$ value $(28.9 \mu \mathrm{g} / \mathrm{L})$ obtained in the present review is higher than that previously reported for microplastics $(0.08-5.4 \mu \mathrm{g} / \mathrm{L})$ (Table 7.2). The main reason for this difference is the inclusion of a higher number of species covering multiple taxonomical groups. On the other hand, the particle number-based $\mathrm{HC}_{5}$ value was 41.6 particles/L, which is within the range provided by the VKM (2019) assessment. Even though this estimate included a larger data set (31 species) than other assessments, the number of studies that provide particle concentrations in number is still quite limited. No other $\mathrm{HC}_{5}$ values expressed in $\mathrm{mg} / \mathrm{kg}$ exist in literature for comparison.

Even though the SSDs presented here are more robust as they are based on larger data sets and add to the existing SSDs in literature, several knowledge gaps still need to be addressed to reduce uncertainties and improve the robustness and relevance of the obtained results (Besseling et al. 2019; Burns and Boxall 2018). For this reason, ecotoxicity testing of relevant particle sizes, shapes and polymer types,

Table 7.2 $-\mathrm{HC}_{5}$ values obtained from species sensitivity distribution analysis collected from literature

\begin{tabular}{|c|c|c|c|c|}
\hline $\mathrm{HC}_{5}(\mu \mathrm{g} / \mathrm{L})$ & $\mathrm{HC}_{5}$ (particles/L) & $\begin{array}{l}\mathrm{HC}_{5} \\
(\mathrm{mg} / \mathrm{kg})\end{array}$ & Notes & References \\
\hline $\begin{array}{l}28.9 \\
(7.94-79.1)\end{array}$ & $\begin{array}{l}41.6 \\
(0.58-1176)\end{array}$ & $\begin{array}{l}11.3^{\mathrm{a}} \\
(0.18- \\
151)\end{array}$ & $\begin{array}{l}\text { Freshwater and marine species } \\
\text { exposed to micro- and } \\
\text { nanoplastics via water and } \\
\text { sediment/soil }\end{array}$ & Present review \\
\hline \begin{tabular}{l|}
0.14 \\
$(0.04-0.64)$
\end{tabular} & $\begin{array}{l}71.6 \\
(3.45-1991)\end{array}$ & - & $\begin{array}{l}\text { Freshwater and marine species } \\
\text { exposed to micro- and } \\
\text { nanoplastics }\end{array}$ & VKM (2019) \\
\hline \begin{tabular}{l|}
0.08 \\
$(0.04-0.11)$
\end{tabular} & $740(610-1300)$ & - & $\begin{array}{l}\text { Freshwater species exposed to } \\
\text { microplastics. } 25-75 \text { percentile } \\
\text { was used instead of confidence } \\
\text { interval }\end{array}$ & $\begin{array}{l}\text { Adam et al. } \\
(2019)\end{array}$ \\
\hline $\begin{array}{l}5.4 \\
(0.93- \\
31 \mathrm{mg} / \mathrm{L}) \\
\end{array}$ & $\begin{array}{l}5.97 \times 10^{10}(1.6 \\
\times 10^{10}-22 \times \\
\left.10^{10}\right)\end{array}$ & - & $\begin{array}{l}\text { Marine and freshwater species } \\
\text { exposed to nanoplastics }\end{array}$ & \multirow[t]{2}{*}{$\begin{array}{l}\text { Besseling et al. } \\
\text { (2019) }\end{array}$} \\
\hline $\begin{array}{l}1.67 \\
(0.086- \\
32.6)\end{array}$ & $\begin{array}{l}1015 \\
(101-10,223)\end{array}$ & - & $\begin{array}{l}\text { Marine and freshwater species } \\
\text { exposed to microplastics }\end{array}$ & \\
\hline - & 64,000 & - & $\begin{array}{l}\text { Marine and freshwater species } \\
\text { exposed to microplastics (10 to } \\
5000 \mathrm{~mm} \text { ) }\end{array}$ & $\begin{array}{l}\text { Burns and Boxall } \\
\text { (2018) }\end{array}$ \\
\hline- & \begin{tabular}{|l|}
33.3 \\
$(0.36-13,943)$ \\
\end{tabular} & - & $\begin{array}{l}\text { Marine species exposed to } \\
\text { microplastics }\end{array}$ & $\begin{array}{l}\text { Everaert et al. } \\
(2018)\end{array}$ \\
\hline- & $\begin{array}{l}3214 \\
(3.3900-84,261)\end{array}$ & - & $\begin{array}{l}\text { Marine species exposed via water } \\
\text { and sediment to microplastics }\end{array}$ & $\begin{array}{l}\text { Van } \\
\text { Cauwenberghe } \\
(2016)\end{array}$ \\
\hline
\end{tabular}

${ }^{a}$ Note that the $\mathrm{HC}_{5}$ value for mass-based sediment exposure is derived from a minimum of necessary data and needs to be interpreted with caution 
standardized testing, improved reporting of experimental designs, methods and results, as well as a higher focus on freshwater and terrestrial compartments, need to be prioritized in order to enable a sound risk assessment of plastic particles in the environment.

\subsubsection{Direct and Indirect Effects at the Ecosystem/ Community Level}

Cascading effects through different levels of biological organization is a central paradigm of ecotoxicology: contaminant-induced subcellular changes, such as enzymatic activity or gene expression, can impact higher levels of organization and affect organism's performance (e.g. locomotion, feeding, reproduction). These alterations might impact an entire population and could ultimately have consequences at the ecosystem level. With that said, directly linking effects at the lowest levels of biological organization to impacts on ecosystems is extremely challenging for any environmental contaminant (Galloway et al. 2017). The data currently available on nano- and microplastic ecotoxicity does not allow firm conclusions to be drawn about such links. However, certain endpoints observed at the individual level are indicators of potential indirect effects on other species and/or on the functioning of ecosystems. Such endpoints are therefore categorized as endpoints relevant at the ecosystem level. For example, behavioural changes at the individual level can affect prey-predator interactions (Fonte et al. 2016; Wen et al. 2018a) and impact entire trophic webs, or impaired burrowing activity of dwelling organisms can alter bioturbation and soil/sediment oxygenation (Green et al. 2016). Changes in microbial activity can also result in altered essential ecosystem processes, such as nutrient cycling (e.g. nitrogen and carbon cycles) (Green et al. 2017).

Among the studies reviewed in this chapter, endpoints relevant at the ecosystem level were most studied on three taxonomical groups: Annelida, Arthropoda and Chordata. The recorded endpoints were related to behaviour: feeding activity (Besseling et al. 2013, 2017; Browne et al. 2013; Cedervall et al. 2012; Green et al. 2016; Guven et al. 2018; Malinich et al. 2018; Mattsson et al. 2017; Wright et al. 2013), burial and burrow formation (Booth et al. 2016; Huerta Lwanga et al. 2016), cast production (Green et al. 2016; Prendergast-Miller et al. 2019), locomotion (Chae et al. 2018; Choi et al. 2018; Critchell and Hoogenboom 2018; de Felice et al. 2019; Frydkjær et al. 2017; Gambardella et al. 2017; Kim and An 2019; Lin et al. 2019b; Mattsson et al. 2017; Pitt et al. 2018; Skjolding et al. 2017; Tosetto et al. 2016, 2017; Ziajahromi et al. 2017), prey-predator interactions (de Sá et al. 2015; Ferreira et al. 2016; Fonte et al. 2016; Jacob et al. 2019; Luís et al. 2015; Mattsson et al. 2017; Wen et al. 2018a) and aggression (Critchell and Hoogenboom 2018). Studies focusing on such ecologically relevant endpoints are currently underrepresented (16\% of the reviewed studies), although the available data shows that these endpoints can be impacted by plastic particles, especially locomotion (Cedervall 
et al. 2012; Choi et al. 2018; de Felice et al. 2019; Frydkjær et al. 2017; Kim and An 2019; Lin et al. 2019b; Mattsson et al. 2017), feeding activity (Besseling et al. 2013, 2017; Green et al. 2016; Guven et al. 2018; Mattsson et al. 2017; Wright et al. 2013) and prey-predator interactions (Fonte et al. 2016; Wen et al. 2018a).

Only a single study looked at the ecosystem-level effects on Cnidaria, more specifically on P. damicornis (Tang et al. 2018). The results obtained in this study suggest that acute exposure to PS particles can activate stress responses at the individual level, repressing detoxification and immune systems, which in turn can compromise the anti-stress capacity of exposed organisms. However, this study found a minimal impact in community shifts (symbiont density and chlorophyll content) in the short term. In a similar study, Reichert et al. (2018) suggested that species-specific effects might promote community shifts in coral reefs. For example, if growth, health and photosynthesis are affected, this might amplify the coral's susceptibility to other stressors such as increased seawater temperatures, contributing to shifts in coral reef assemblages. Like cnidarians, only one study considered the effects of nanoplastics at the ecosystem level in phytoplankton (González-Fernández et al. 2019). This study analysed the impact of $\mathrm{PS}-\mathrm{NH}_{2}(50 \mathrm{~nm})$ on a diatom $(C$. neogracile $)$, which led to changes of the concentration of associated bacterial communities. It is important to study effects following exposure to plastic particles in phytoplankton not only due to their susceptibility (as seen in the SSD) but also due to their importance in the ecosystem. As already stated, these organisms are at the base of the aquatic food web, and changes in their communities may disturb the productivity of an entire ecosystem (Prata et al. 2019). Moreover, particles may end up higher in the food web due to algae-particle interaction as the first step in the biomagnification (Nolte et al. 2017), as previously shown in other studies with suspension-feeding bivalves (Ward and Kach 2009). Finally, one study addressed the impacts of microplastics on the health and biological functioning of oysters (O. edulis) and on the structure of associated macrofaunal assemblages using an outdoor mesocosm experiment (Green 2016). The author found that exposure to high concentrations of microplastic resulted in alterations of assemblage structure, diversity, abundances and biomasses of several taxa in vegetated oyster habitats, whose cascade effects can lead to significant impacts in marine ecosystems.

Indirect, secondary effects are effects occurring on species not necessarily exposed to plastic particles but which are impacted by changes resulting from their direct exposure. In their mesocosm study, Green et al. (2016) exposed the lugworm A. marina to microplastics and observed a decrease in cast production, as well as decreased microbial biomass with increasing concentrations. One of the hypotheses discussed by the authors to explain the decreased microbial biomass was that reduced sand reworking by the worms would have resulted in less nutrients available in the sand to support primary productivity. No firm conclusion about indirect effects of microplastics could be drawn from this study, as microplastics could have directly affected microbial communities, but this scenario is one of the potential examples of indirect microplastic effects. In another recent study, reduced survival and reproduction were observed for the terrestrial invertebrate Enchytraeus crypticus following exposure to synthetic fibres (Selonen et al. 2020). However, fibre 
ingestion could not be confirmed, and the authors hypothesized that the observed effects could be due to changes in environmental conditions, such as microbial activity and physicochemical properties of the soil, resulting from microplastic exposure. In both cases, the authors (Green et al. 2016; Selonen et al. 2020) present indirect effects of microplastics as a hypothesis, but investigating microplastic indirect effects was not the main purpose of the study. Although highly ecologically relevant, studies on nano- and microplastic indirect effects are currently almost nonexistent. Such studies are needed to help link effects at the organism level to impacts on the ecosystem level. Future studies should consider potential direct and indirect nano- and microplastic effects at the ecosystem level, to fill these major gaps in the field of plastic ecotoxicology.

\subsubsection{Interaction of Plastic Particles with Chemicals}

The challenge of assessing the impact of plastic particles in the environment is further complicated by the presence of chemicals, which can potentially pose additional hazards towards organisms. These chemicals comprise polymerization catalysts and additives, which are incorporated during production to endow plastics with specific characteristics (e.g. flame retardants, plasticizers, antioxidants, UV stabilizers and pigments) (Gallo et al. 2018) and non-intentionally added substances (NIAS). Furthermore, chemicals already present in the environment (e.g. polycyclic aromatic hydrocarbons (PAHs) and metals) may also be incorporated/adsorbed by plastic surfaces depending on the polymer physico-chemical properties (e.g. Teuten et al. 2009).

Few studies have identified nano- and microplastics as vectors for other contaminants (Trojan horse effect), and even fewer have focused on the presence and leaching of chemical additives. Of the 175 references reviewed, 48 addressed these combined effects, with a focus on chemicals present in the environment, such as PAHs (e.g. benzo(a)pyrene (BaP), phenanthrene, fluoranthene, pyrene), polychlorinated biphenyls (PCBs), organophosphates (e.g. chlorpyrifos), metals (e.g. gold, mercury, cadmium, chromium and copper), metal nanomaterials (gold and titanium nanoparticles) and pharmaceuticals (roxithromycin, cefalexin, carbamazepine, florfenicol, doxycycline and procainamide). Only a small percentage of these studies $(12.5 \%)$ focused on chemicals known to be used as plastic additives (e.g. benzophenone, polybrominated diphenyl ethers (PBDEs), perfluorooctane sulfonates (PFOs), bisphenol A (BPA), triclosan), surfactants (e.g. nonylphenol), as well as chemical leachates extracted from plastic particles. In addition, the combined effects of plastic particles with natural acidic organic polymers (e.g. palmitic acid, humic acid and fulvic acid) were also considered in some of the reviewed publications.

Most of these studies were conducted in arthropods (28\%), followed by fish (20\%), molluscs (17\%), phytoplankton (15\% studies), annelids (9\%), echinoderms (2\%), nematodes $(2 \%)$ and rotifers $(2 \%)$. No studies on the combined effects of plastic particles and other contaminants were reported for cnidarians. Of the 57 
studies reviewed for arthropods, 15 addressed the interaction between plastic particles and chemicals. These chemicals included benzophenone (Beiras et al. 2018), fluoranthene (Bergami et al. 2016, 2017; Horton et al. 2018; Vicentini et al. 2019), humic acid (Fadare et al. 2019; Wu et al. 2019a), PCBs (Gerdes et al. 2019; Lin et al. 2019a; Watts et al. 2015), phenanthrene (Ma et al. 2016), gold (Pacheco et al. 2018), BPA (Rehse et al. 2018), PAHs (Tosetto et al. 2016), palmitic acid (Vicentini et al. 2019) and roxithromycin (Zhang et al. 2019). Several effects at the subcellular, individual and population levels were seen in arthropods upon exposure to nano- or microplastics combined with these chemicals. The most reported effects where impacts on reproduction, mortality, development and growth. Eleven studies conducted on fish used microplastics sorbed with chemicals. In seven of those, the tested microplastics were purposely spiked with chemicals, such as BaP (Batel et al. 2018); antibiotics (Fonte et al. 2016); heavy metals such as mercury (Barboza et al. 2018), cadmium (Lu et al. 2018) and chromium (Luís et al. 2015); gold nanoparticles (Ferreira et al. 2016); and a cocktail of environmental contaminants comprising PCBs, PBDEs, PFOs and metals (Granby et al. 2018). Additionally, in four studies, the tested microplastics were deployed in environmental matrices (i.e. harbour, sewage effluent, urban bay), and further analyses confirmed the presence of environmental contaminants, such as surfactants and PAHs (Ašmonaite et al. 2018a, b; Rochman et al. 2013; Tosetto et al. 2017). Interestingly, for every level of biological organization covered in these fish studies, the presence of chemicals sorbed on microplastics does not change the occurrence of adverse effects, indicating that microplastic-associated chemicals would play a minor role in microplastic effects. Studies on combined effects of micro- and nanoplastics and chemical exposure using molluscs included pyrene (Avio et al. 2015), carbamazepine (Brandts et al. 2018b), florfenicol (Guilhermino et al. 2018), mercury (Oliveira et al. 2018), fluoranthene (Paul-Pont et al. 2016; Rist et al. 2016), BaP (Pittura et al. 2018) and PCBs (Rochman et al. 2017). Effects at the cellular and subcellular levels were often reported for this taxonomical group, followed by impacts at the organ and individual level. Additionally, in one of the studies reviewed, no effects were reported for M. galloprovincialis exposed to benzophenone (Beiras et al. 2018). In the eight studies reported for phytoplankton, adverse effects of micro- and nanoplastics in combination with other contaminants were reported for metal mixtures (Baudrimont et al. 2020), copper (Bellingeri et al. 2019), titanium nanoparticles (Thiagarajan et al. 2019), fulvic and humic acid (Liu et al. 2019), chlorpyrifos (Garrido et al. 2019), doxycycline and procainamide (Prata et al. 2018), triclosan (Zhu et al. 2019) as well as leachate mixtures (Luo et al. 2019). Overall, the documented effects in these studies included reduction in growth, oxidative stress, membrane stability and reduction in protein content and natural pigments. From the 16 studies conducted with annelids, five included co-exposure with contaminants, namely, PCBs (Besseling et al. 2013, 2017), chlorpyrifos (sprayed to the surface of PE spheres (Rodríguez-Seijo et al. 2018b)), BaP (Gomiero et al. 2018), nonylphenol, phenanthrene, triclosan and PBDE-47 (sorbed to microplastics (Browne et al. 2013)). Of the effects found in annelids, alterations in behaviour (i.e. reduced feeding) were most commonly reported associated with exposure to PCBs (Besseling et al. 2013, 
2017). Reduction in growth was also observed at lower concentrations when plastic particles were sprayed with chlorpyrifos (Rodríguez-Seijo et al. 2018b) or coexposed with PCBs (Besseling et al. 2013). Of the reviewed studies for Echinodermata, only Beiras et al. (2018) utilized microplastics spiked with benzophenone-3, an organic, hydrophobic chemical found in cosmetic products, using P. lividus as a test organism. Even though ingestion of virgin and BP-3 spiked PE microplastics was observed at 1 and $10 \mathrm{mg} / \mathrm{L}$, no acute toxicity was observed above concentrations considered environmentally relevant (low treatment $=20 \mu \mathrm{g} / \mathrm{L}$ and high concentration treatment $=200 \mathrm{ng} / \mathrm{L}$ ) (Beiras et al. 2018). When it comes to nematodes, in the study by Judy et al. (2019), microplastics were added to soil amended with municipal waste compost. The presence of trace metals was assessed in amended soils and in microplastics (PE, PET, PVC), and GC-MS analysis revealed the presence of phthalates in PVC, which could have accounted for the effects observed in exposed organisms. Only one study looked at combined effects of PE spheres and benzophenone using the rotifer B. plicatilis, for which no effects were reported (Beiras et al. 2018).

Overall, the studies reviewed on the joint toxicity of plastic particles and chemicals (either adsorbed to particles or additives) showed that their interaction can elicit a wide range of biological responses in exposed organisms. In addition, chemicals associated to plastic particles can also influence their bioavailability and potential transfer through food chains, possibly causing effects at the ecosystem level. Nonetheless, these findings need to be interpreted with caution as most of these studies differ in how they approach vectoral transfer kinetics and exposure mechanisms for chemicals under realistic natural conditions and thus overestimate the role of plastic particles as the delivery system of chemicals to organisms. The majority of these laboratory experiments use simplified exposure settings, in which clean organisms placed in clean media/sediment/soil are exposed to plastic particles pretreated with chemicals. These controlled exposure settings create conditions that promote rapid dissolution of the chemicals from the plastic particles into the surrounding environmental compartment, which then become easily bioavailable to organisms through a more conventional exposure route (Diepens and Koelmans 2018; Booth and Sørensen 2020). Under more environmentally relevant exposure scenarios, currently available data suggests that chemicals accumulated in organisms are derived to a very small extent from ingested plastic particles, especially when compared to natural pathways of bioaccumulation as water, sediment and food (Koelmans et al. 2016; Besseling et al. 2017). For this reason, it is important to consider the relative importance of plastic particles as an exposure route for chemicals in the context of other uptake pathways that may be more relevant under realistic natural conditions (Lohmann 2017; Diepens and Koelmans 2018). To understand how plastic particles can act as vectors for other chemicals and what is the contribution that additives make to overall exposures, a thorough control of exposure mechanisms is therefore necessary. This will ensure that any observed biological effects are a consequence of exposure to the chemicals adsorbed and/or incorporated in the particles and not derived from their leaching, desorption and dissolution into environmental compartments (Booth and Sørensen 2020; Gallo et al. 2018; 
Hermabessiere et al. 2017). In addition, there is a pressing need for studies addressing synergistic/antagonist effects following short- and long-term exposure to plastic particles in combination with contaminants of high concern, as well as studies on their cumulative effects in both terrestrial and aquatic species and potential biomagnification throughout food chains. For further information on the impacts of environmental contaminants and plastic additives in terrestrial and aquatic organisms, see reviews by Gallo et al. (2018) and Hermabessiere et al. (2017). For additional studies on the importance of exposure pathways for a range of chemicals present in plastic particles under natural conditions, the readers may refer to Koelmans et al. (2016), Lohmann (2017) and Diepens and Koelmans (2018).

\subsection{Challenges and Future Directions}

Exposure experiments focusing on the ecotoxicological effects of plastic particles in a wide range of organisms have increased exponentially over the past few years. A consensus from the reviewed literature is that plastic particles can impact organisms across successive levels of biological organization, covering effects from the subcellular level up to the ecosystem level (Galloway et al. 2017; VKM 2019). Nonetheless, our understanding on the mechanisms behind any toxic effects recorded is still minimal, partially due to a lack of attempt to link the physical and chemical properties of the particles being tested with the recorded toxic effects. Many of the reviewed studies relate to common chemical exposure endpoints rather than particle related endpoints, including how particles directly interact with the cellular environment and organisms, their uptake mechanisms, tissue distribution and subsequent impacts (e.g. tissue alterations due to inflammation or other physical impacts). Accordingly, understanding and distinguishing the potential physical and chemical effects of plastic particles across the whole spectrum of biological levels is needed to improve environmental risk assessment of plastic pollution, as a means to ensure a better protection and mitigation of its impacts in the different environmental compartments.

The comparability of existing ecotoxicological data is being hampered by numerous factors such as the use of wide array of experimental testing approaches, unrealistic environmental concentrations, lack of relevance in terms of particle characteristics (polymer type, shape or size), use of appropriate controls, incomplete/inadequate particle characterization (physico-chemical properties and chemical additives), variability in reporting units (e.g. in mass and/or particle number, \% particles in food or sediment) and experimental conditions (e.g. exposure duration). Many of these limitations were found during the evaluation of data quality in the reviewed references, in which the use of appropriate controls, confirmation of exposure concentration and polymer type as well as presence of chemical leachates and particle size distributions were the most common issues. The ubiquitous nature of microplastic contamination, widespread geographical distribution, abundance and small size have also raised significant concerns regarding their interactive effects 
with chemicals, not only by increasing the bioavailability of contaminants in organisms but also by eliciting common toxic effects. This is especially true when considering the potential risk of chemical accumulation in higher trophic levels including humans, as well modifications in population structure and ecosystem dynamics (e.g. negative effects at lower trophic levels) that may potentially result in a reduced productivity of the whole ecosystem. However, the role of plastic particles as the delivery system of chemicals to organisms is currently overestimated and additional data is required to understand the relative importance of exposure to chemicals (either adsorbed or additives) from particles compared to other exposure pathways (e.g. water and natural diet).

This overview is consistent with the tendencies observed by other authors, calling into question the environmental relevance and proposed risks caused by nanoplastic and microplastic exposure (e.g. Burns and Boxall 2018; de Ruijter et al. 2020; Kögel et al. 2020; VKM 2019). To determine if these plastic particles are in fact posing significant risks to organisms, future work needs to focus on the development of reporting guidelines to improve the reproducibility and comparability of plastic-related research, as highlighted by Connors et al. (2017) and Cowger et al. (2020). Several research priorities are thus recommended to better understand the ecological risks of plastic particles in the terrestrial and aquatic environments:

1. Standardization. It is fundamental for ecotoxicological investigations to be comparable. A standardized approach from experimental design to reporting is required. To this end, quality assessments should be conducted throughout the whole duration of any laboratory studies (including concentrations and exposure conditions with quality assessment) to obtain reliable and comparable data.

2. Environmental relevance. Researchers should endeavour to conduct experiments which have relevance to current and future scenarios of plastic concentrations and characteristics in the different environmental compartments. These include partially degraded and irregularly shaped particles commonly found in the environment, with varying polymer types, sizes and surface properties. As fibres and fragments are prevalent in environmental samples, these should be prioritized in future studies.

3. Particle vs. chemical effect. The combination of particle and associated additives must be considered in ecotoxicological studies, such that it is possible to discriminate between effects derived from particles from those resulting from additive chemicals. Therefore, it is paramount that a thorough characterization of exposure materials is carried out, including the chemical profiles of organic and metal additives. To really understand whether plastic particles are relevant carriers for chemicals, environmentally realistic exposure settings also need to be taken into account when looking at particle-chemical interactions, more specifically leaching/desorption kinetics, chemical bioaccumulation from water/sediment/soil, natural diet and percentage of ingested particles.

4. Ecosystem compartments. As highlighted throughout this chapter, there is a disproportion between the number of studies conducted on marine, freshwater and terrestrial biota. Moving forward, it is important to direct attention towards 
freshwater and terrestrial ecosystems, as these are considered the main sources and transport pathways of plastic particles to the marine environment.

5. Test species. Species utilized for ecotoxicological testing are generally focused on model organisms used for standard ecotoxicological testing. This originates a significant knowledge gap on the effects of plastic particles in other species that have critical roles in ecosystem balance. Species considered at highest risk of exposure due to their feeding strategies and position in the water column need to be prioritized in terms of ecotoxicity testing, e.g. planktonic species not included in ISO and OECD guidelines. Species ecology and time spent in various environmental compartments are also important considerations for choice of test species, with particular emphasis on early developmental stages that have been shown to be highly susceptible to the impacts of plastic particles. Moreover, given that soil/sediment is considered the ultimate sink for plastic particles and other conventional contaminants, increased testing with suspension and deposit feeders is also warranted.

6. Physiological perspective. Currently there is a lack of mechanistic understanding of the effects of microplastics and nanoplastics on biota. Additional efforts are needed to understand the differences in physical and chemical behaviour of plastic particles compared to conventional contaminants. The direct and indirect interaction of nano- and microplastics within the cellular environment and organisms, uptake mechanisms (size dependency), tissue distribution and impacts must therefore be comprehensibly assessed and linked to the physical and chemical properties of the particles being used. Modifications in experimental design and proper characterization of the particles (e.g. presence of additives) can also assist to explain the underlying mechanisms responsible for the observed responses and help distinguish physical from chemical toxicological effects.

7. Integrated and multi-level approaches. Long-term experiments with multiple species (e.g. model ecosystems) are required to examine effects with higher ecological relevance. Therefore, small- and large-scale mesocosm experiments mimicking environmentally relevant scenarios and covering links from primary producers (e.g. microalgae) to top predators (e.g. fish) are encouraged.

Acknowledgments This work was supported by the Research Council of Norway-funded projects MicroLEACH (Grant 295174) and REVEAL (Grant 656879). Handelens Miljøfond, the Norwegian Retailers Association, also supported this work through the project MicroOPT, in addition to the Norwegian Institute for Water Research (NIVA) strategic research programme.

\section{References}

Adam V, Yang T, Nowack B (2019) Toward an ecotoxicological risk assessment of microplastics: comparison of available hazard and exposure data in freshwaters: environmental risk assessment of microplastics. Environ Toxicol Chem 38(2):436-447. https://doi.org/10.1002/etc.4323

Anbumani S, Kakkar P (2018) Ecotoxicological effects of microplastics on biota: a review. Environ Sci Pollut Res 25(15):14373-14396. https://doi.org/10.1007/s11356-018-1999-x 
Ašmonaitė G, Larsson K, Undeland I, Sturve J, Carney Almroth BM (2018a) Size matters: ingestion of relatively large microplastics contaminated with environmental pollutants posed little risk for fish health and fillet quality. Environ Sci Technol 52(24):14381-14391. https://doi. org/10.1021/acs.est.8b04849

Ašmonaite G, Sundh H, Asker N, Carney Almroth BM (2018b) Rainbow trout maintain intestinal transport and barrier functions following exposure to polystyrene microplastics. Environ Sci Technol 52(24):14392-14401. https://doi.org/10.1021/acs.est.8b04848

Au SY, Bruce TF, Bridges WC, Klaine SJ (2015) Responses of Hyalella azteca to acute and chronic microplastic exposures. Environ Toxicol Chem 34(11):2564-2572. https://doi.org/10.1002/ etc.3093

Avio CG, Gorbi S, Milan M, Benedetti M, Fattorini D, d'Errico G, Pauletto M, Bargelloni L, Regoli F (2015) Pollutants bioavailability and toxicological risk from microplastics to marine mussels. Environ Pollut 198:211-222. https://doi.org/10.1016/j.envpol.2014.12.021

Balbi T, Camisassi G, Montagna M, Fabbri R, Franzellitti S, Carbone C, Dawson K, Canesi L (2017) Impact of cationic polystyrene nanoparticles $\left(\mathrm{PS}_{\mathrm{N}} \mathrm{NH}_{2}\right)$ on early embryo development of Mytilus galloprovincialis: effects on shell formation. Chemosphere 186:1-9. https://doi. org/10.1016/j.chemosphere.2017.07.120

Bank MS, Hansson SV (2019) The plastic cycle: a novel and holistic paradigm for the Anthropocene. Environ Sci Technol 53(13):7177-7179. https://doi.org/10.1021/acs.est.9b02942

Bank MS, Hansson SV (2021) The microplastic cycle: An introduction to a complex issue. In: Bank MS (ed) Microplastic in the environment: pattern and process. Springer, Amsterdam

Barboza LGA, Vieira LR, Branco V, Figueiredo N, Carvalho F, Carvalho C, Guilhermino L (2018) Microplastics cause neurotoxicity, oxidative damage and energy-related changes and interact with the bioaccumulation of mercury in the European seabass, Dicentrarchus labrax (Linnaeus, 1758). Aquat Toxicol 195:49-57. https://doi.org/10.1016/j.aquatox.2017.12.008

Batel A, Borchert F, Reinwald H, Erdinger L, Braunbeck T (2018) Microplastic accumulation patterns and transfer of benzo[a]pyrene to adult zebrafish (Danio rerio) gills and zebrafish embryos. Environ Pollut 235:918-930. https://doi.org/10.1016/j.envpol.2018.01.028

Baudrimont M, Arini A, Guégan C, Venel Z, Gigault J, Pedrono B, Prunier J, Maurice L, Ter Halle A, Feurtet-Mazel A (2020) Ecotoxicity of polyethylene nanoplastics from the North Atlantic oceanic gyre on freshwater and marine organisms (microalgae and filter-feeding bivalves). Environ Sci Pollut Res 27(4):3746-3755. https://doi.org/10.1007/s11356-019-04668-3

Beiras R, Bellas J, Cachot J, Cormier B, Cousin X, Engwall M, Gambardella C, Garaventa F, Keiter S, Le Bihanic F, López-Ibáñez S, Piazza V, Rial D, Tato T, Vidal-Liñán L (2018) Ingestion and contact with polyethylene microplastics does not cause acute toxicity on marine zooplankton. J Hazard Mater 360:452-460. https://doi.org/10.1016/j.jhazmat.2018.07.101

Bellingeri A, Bergami E, Grassi G, Faleri C, Redondo-Hasselerharm P, Koelmans AA, Corsi I (2019) Combined effects of nanoplastics and copper on the freshwater alga Raphidocelis subcapitata. Aquat Toxicol 210:179-187. https://doi.org/10.1016/j.aquatox.2019.02.022

Bergami E, Bocci E, Vannuccini ML, Monopoli M, Salvati A, Dawson KA, Corsi I (2016) Nanosized polystyrene affects feeding, behavior and physiology of brine shrimp Artemia franciscana larvae. Ecotoxicol Environ Saf 123:18-25. https://doi.org/10.1016/j.ecoenv.2015.09.021

Bergami E, Pugnalini S, Vannuccini ML, Manfra L, Faleri C, Savorelli F, Dawson KA, Corsi I (2017) Long-term toxicity of surface-charged polystyrene nanoplastics to marine planktonic species Dunaliella tertiolecta and Artemia franciscana. Aquat Toxicol 189:159-169. https:// doi.org/10.1016/j.aquatox.2017.06.008

Besseling E, Wegner A, Foekema EM, van den Heuvel-Greve MJ, Koelmans AA (2013) Effects of microplastic on fitness and PCB bioaccumulation by the lugworm Arenicola marina (L.). Environ Sci Technol 47(1):593-600. https://doi.org/10.1021/es302763x

Besseling E, Wang B, Lürling M, Koelmans AA (2014) Nanoplastic affects growth of S. obliquus and reproduction of D. magna. Environ Sci Technol 48(20):12336-12343. https://doi. org/10.1021/es503001d 
Besseling E, Foekema EM, van den Heuvel-Greve MJ, Koelmans AA (2017) The effect of microplastic on the uptake of chemicals by the lugworm Arenicola marina (L.) under environmentally relevant exposure conditions. Environ Sci Technol 51(15):8795-8804. https://doi. org/10.1021/acs.est.7b02286

Besseling E, Redondo-Hasselerharm P, Foekema EM, Koelmans AA (2019) Quantifying ecological risks of aquatic micro- and nanoplastic. Crit Rev Environ Sci Technol 49(1):32-80. https:// doi.org/10.1080/10643389.2018.1531688

Bhargava S, Chen Lee SS, Min Ying LS, Neo ML, Lay-Ming Teo S, Valiyaveettil S (2018) Fate of nanoplastics in marine larvae: a case study using barnacles, Amphibalanus amphitrite. ACS Sustain Chem Eng 6(5):6932-6940. https://doi.org/10.1021/acssuschemeng.8b00766

Blarer P, Burkhardt-Holm P (2016) Microplastics affect assimilation efficiency in the freshwater amphipod Gammarus fossarum. Environ Sci Pollut Res 23(23):23522-23532. https://doi. org/10.1007/s11356-016-7584-2

Booth AM, Sørensen L (2020) Microplastic fate and impacts in the environment. In: Rocha-Santos T, Costa M, Mouneyrac C (eds) Handbook of microplastics in the environment. Springer, pp 1-24. https://doi.org/10.1007/978-3-030-10618-8_29-1

Booth AM, Hansen BH, Frenzel M, Johnsen H, Altin D (2016) Uptake and toxicity of methylmethacrylate-based nanoplastic particles in aquatic organisms: ecotoxicity and uptake of nanoplastic particles. Environ Toxicol Chem 35(7):1641-1649. https://doi.org/10.1002/ etc. 3076

Bosker T, Olthof G, Vijver MG, Baas J, Barmentlo SH (2019) Significant decline of Daphnia magna population biomass due to microplastic exposure. Environ Pollut 250:669-675. https:// doi.org/10.1016/j.envpol.2019.04.067

Botterell ZLR, Beaumont N, Dorrington T, Steinke M, Thompson RC, Lindeque PK (2018) Bioavailability and effects of microplastics on marine zooplankton: a review. Environ Pollut. https://doi.org/10.1016/j.envpol.2018.10.065

Bour A, Haarr A, Keiter S, Hylland K (2018) Environmentally relevant microplastic exposure affects sediment-dwelling bivalves. Environ Pollut 236:652-660. https://doi.org/10.1016/j. envpol.2018.02.006

Brandts I, Teles M, Tvarijonaviciute A, Pereira ML, Martins MA, Tort L, Oliveira M (2018a) Effects of polymethylmethacrylate nanoplastics on Dicentrarchus labrax. Genomics 110(6):435-441. https://doi.org/10.1016/j.ygeno.2018.10.006

Brandts I, Teles M, Gonçalves AP, Barreto A, Franco-Martinez L, Tvarijonaviciute A, Martins MA, Soares AMVM, Tort L, Oliveira M (2018b) Effects of nanoplastics on Mytilus galloprovincialis after individual and combined exposure with carbamazepine. Sci Total Environ 643:775-784. https://doi.org/10.1016/j.scitotenv.2018.06.257

Bråte ILN, Blázquez M, Brooks SJ, Thomas KV (2018) Weathering impacts the uptake of polyethylene microparticles from toothpaste in Mediterranean mussels (M. galloprovincialis). Sci Total Environ 626:1310-1318. https://doi.org/10.1016/j.scitotenv.2018.01.141

Browne MA, Niven SJ, Galloway TS, Rowland SJ, Thompson RC (2013) Microplastic moves pollutants and additives to worms, reducing functions linked to health and biodiversity. Curr Biol 23(23):2388-2392. https://doi.org/10.1016/j.cub.2013.10.012

Bruck S, Ford AT (2018) Chronic ingestion of polystyrene microparticles in low doses has no effect on food consumption and growth to the intertidal amphipod, Echinogammarus marinus? Environmental Pollution (Barking Essex: 1987) 233:1125-1130. https://doi.org/10.1016/j. envpol.2017.10.015

Bürkner P-C (2017) Brms: An R package for Bayesian multilevel models using Stan. J Stat Softw 80(1):1-28. https://doi.org/10.18637/jss.v080.i01

Bürkner P-C (2018) Advanced Bayesian multilevel modeling with the R package brms. R J 10(1):395-411

Burns EE, Boxall ABA (2018) Microplastics in the aquatic environment: evidence for or against adverse impacts and major knowledge gaps: microplastics in the environment. Environ Toxicol Chem 37(11):2776-2796. https://doi.org/10.1002/etc.4268 
Canniff PM, Hoang TC (2018) Microplastic ingestion by Daphnia magna and its enhancement on algal growth. Sci Total Environ 633:500-507. https://doi.org/10.1016/j.scitotenv.2018.03.176

Cao D, Wang X, Luo X, Liu G, Zheng H (2017) Effects of polystyrene microplastics on the fitness of earthworms in an agricultural soil. IOP Conf Ser Earth Environ Sci 61:012148. https://doi. org/10.1088/1755-1315/61/1/012148

Capolupo M, Franzellitti S, Valbonesi P, Lanzas CS, Fabbri E (2018) Uptake and transcriptional effects of polystyrene microplastics in larval stages of the Mediterranean mussel Mytilus galloprovincialis. Environ Pollut 241:1038-1047. https://doi.org/10.1016/j.envpol.2018.06.035

Caruso G, Pedà C, Cappello S, Leonardi M, La Ferla R, Lo Giudice A, Maricchiolo G, Rizzo C, Maimone G, Rappazzo AC, Genovese L, Romeo T (2018) Effects of microplastics on trophic parameters, abundance and metabolic activities of seawater and fish gut bacteria in mesocosm conditions. Environ Sci Pollut Res 25(30):30067-30083. https://doi.org/10.1007/ s11356-018-2926-x

Casado MP, Macken A, Byrne HJ (2013) Ecotoxicological assessment of silica and polystyrene nanoparticles assessed by a multitrophic test battery. Environ Int 51:97-105. https://doi. org/10.1016/j.envint.2012.11.001

Cedervall T, Hansson L-A, Lard M, Frohm B, Linse S (2012) Food chain transport of nanoparticles affects behaviour and fat metabolism in fish. PLoS One 7(2):e32254. https://doi.org/10.1371/ journal.pone. 0032254

Chae Y, Kim D, Kim SW, An Y-J (2018) Trophic transfer and individual impact of nano-sized polystyrene in a four-species freshwater food chain. Sci Rep 8(1):284. https://doi.org/10.1038/ s41598-017-18849-y

Chen Q, Gundlach M, Yang S, Jiang J, Velki M, Yin D, Hollert H (2017) Quantitative investigation of the mechanisms of microplastics and nanoplastics toward zebrafish larvae locomotor activity. Sci Total Environ 584-585:1022-1031. https://doi.org/10.1016/j.scitotenv.2017.01.156

Choi JS, Jung Y-J, Hong N-H, Hong SH, Park J-W (2018) Toxicological effects of irregularly shaped and spherical microplastics in a marine teleost, the sheepshead minnow (Cyprinodon variegatus). Mar Pollut Bull 129(1):231-240. https://doi.org/10.1016/j.marpolbul.2018.02.039

Cole M, Galloway TS (2015) Ingestion of nanoplastics and microplastics by Pacific oyster larvae. Environ Sci Technol 49(24):14625-14632. https://doi.org/10.1021/acs.est.5b04099

Cole M, Lindeque P, Halsband C, Galloway TS (2011) Microplastics as contaminants in the marine environment: a review. Mar Pollut Bull 62(12):2588-2597. https://doi.org/10.1016/j. marpolbul.2011.09.025

Cole M, Lindeque P, Fileman E, Halsband C, Goodhead R, Moger J, Galloway TS (2013) Microplastic ingestion by zooplankton. Environ Sci Technol 47(12):6646-6655. https://doi. org/10.1021/es400663f

Cole M, Lindeque P, Fileman E, Halsband C, Galloway TS (2015) The impact of polystyrene microplastics on feeding, function and fecundity in the marine copepod Calanus helgolandicus. Environ Sci Technol 49(2):1130-1137. https://doi.org/10.1021/es504525u

Cole M, Coppock R, Lindeque PK, Altin D, Reed S, Pond DW, Sørensen L, Galloway TS, Booth AM (2019) Effects of nylon microplastic on feeding, lipid accumulation, and moulting in a coldwater copepod. Environ Sci Technol 53(12):7075-7082. https://doi.org/10.1021/acs. est.9b01853

Collard F, Gasperi J, Gabrielsen GW, Tassin B (2019) Plastic particle ingestion by wild freshwater fish: a critical review. Environ Sci Technol 53(22):12974-12988. https://doi.org/10.1021/acs. est.9b03083

Cong Y, Jin F, Tian M, Wang J, Shi H, Wang Y, Mu J (2019) Ingestion, egestion and post-exposure effects of polystyrene microspheres on marine medaka (Oryzias melastigma). Chemosphere 228:93-100. https://doi.org/10.1016/j.chemosphere.2019.04.098

Connors KA, Dyer SD, Belanger SE (2017) Advancing the quality of environmental microplastic research: advancing the quality of environmental microplastic research. Environ Toxicol Chem 36(7):1697-1703. https://doi.org/10.1002/etc.3829 
Cowger W, Booth AM, Hamilton BM, Thaysen C, Primpke S, Munno K, Lusher AL, Dehaut A, Vaz VP, Liboiron M, Devriese LI, Hermabessiere L, Rochman C, Athey SN, Lynch JM, De Frond H, Gray A, Jones OAH, Brander S et al (2020) Reporting guidelines to increase the reproducibility and comparability of research on microplastics. Appl Spectrosc 74(9):1066-1077. https://doi.org/10.1177/0003702820930292

Critchell K, Hoogenboom MO (2018) Effects of microplastic exposure on the body condition and behaviour of planktivorous reef fish (Acanthochromis polyacanthus). PLoS One 13(3):e0193308. https://doi.org/10.1371/journal.pone.0193308

Cui R, Kim SW, An Y-J (2017) Polystyrene nanoplastics inhibit reproduction and induce abnormal embryonic development in the freshwater crustacean Daphnia galeata. Sci Rep 7(1):1-10. https://doi.org/10.1038/s41598-017-12299-2

de Felice B, Sabatini V, Antenucci S, Gattoni G, Santo N, Bacchetta R, Ortenzi MA, Parolini M (2019) Polystyrene microplastics ingestion induced behavioral effects to the cladoceran Daphnia magna. Chemosphere 231:423-431. https://doi.org/10.1016/j.chemosphere.2019.05.115

de Ruijter VN, Redondo-Hasselerharm PE, Gouin T, Koelmans AA (2020) Quality criteria for microplastic effect studies in the context of risk assessment: a critical review. Environ Sci Technol 54(19):11692-11705. https://doi.org/10.1021/acs.est.0c03057

de Sá LC, Luís LG, Guilhermino L (2015) Effects of microplastics on juveniles of the common goby (Pomatoschistus microps): confusion with prey, reduction of the predatory performance and efficiency, and possible influence of developmental conditions. Environ Pollut 196:359-362. https://doi.org/10.1016/j.envpol.2014.10.026

de Sá LC, Oliveira M, Ribeiro F, Rocha TL, Futter MN (2018) Studies of the effects of microplastics on aquatic organisms: what do we know and where should we focus our efforts in the future? Sci Total Environ 645:1029-1039. https://doi.org/10.1016/j.scitotenv.2018.07.207

Della Torre C, Bergami E, Salvati A, Faleri C, Cirino P, Dawson KA, Corsi I (2014) Accumulation and embryotoxicity of polystyrene nanoparticles at early stage of development of sea urchin embryos Paracentrotus lividus. Environ Sci Technol 48(20):12302-12311. https://doi. org/10.1021/es502569w

Détrée C, Gallardo-Escárate C (2017) Polyethylene microbeads induce transcriptional responses with tissue-dependent patterns in the mussel Mytilus galloprovincialis. J Molluscan Stud 83(2):220-225. https://doi.org/10.1093/mollus/eyx005

Détrée C, Gallardo-Escárate C (2018) Single and repetitive microplastics exposures induce immune system modulation and homeostasis alteration in the edible mussel Mytilus galloprovincialis. Fish Shellfish Immunol 83:52-60. https://doi.org/10.1016/j.fsi.2018.09.018

Diepens NJ, Koelmans AA (2018) Accumulation of plastic debris and associated contaminants in aquatic food webs. Environ Sci Technol 52(15):8510-8520. https://doi.org/10.1021/acs. est.8b02515

Ding J, Zhang S, Razanajatovo RM, Zou H, Zhu W (2018) Accumulation, tissue distribution, and biochemical effects of polystyrene microplastics in the freshwater fish red tilapia (Oreochromis niloticus). Environ Pollut 238:1-9. https://doi.org/10.1016/j.envpol.2018.03.001

EFSA CONTAM Panel (EFSA Panel on Contaminants in the Food Chain) (2016) Statement on the presence of microplastics and nanoplastics in food, with particular focus on seafood. EFSA J 14(6):4501. $30 \mathrm{pp}$

Everaert G, Van Cauwenberghe L, De Rijcke M, Koelmans AA, Mees J, Vandegehuchte M, Janssen CR (2018) Risk assessment of microplastics in the ocean: modelling approach and first conclusions. Environ Pollut 242:1930-1938. https://doi.org/10.1016/j.envpol.2018.07.069

Fadare OO, Wan B, Guo L-H, Xin Y, Qin W, Yang Y (2019) Humic acid alleviates the toxicity of polystyrene nanoplastic particles to Daphnia magna. Environ Sci Nano 6(5):1466-1477. https://doi.org/10.1039/C8EN01457D

Farkas J, Booth AM (2017) Are fluorescence-based chlorophyll quantification methods suitable for algae toxicity assessment of carbon nanomaterials? Nanotoxicology 11(4):569-577. https:// doi.org/10.1080/17435390.2017.1329953 
Ferreira P, Fonte E, Soares ME, Carvalho F, Guilhermino L (2016) Effects of multi-stressors on juveniles of the marine fish Pomatoschistus microps: gold nanoparticles, microplastics and temperature. Aquat Toxicol 170:89-103. https://doi.org/10.1016/j.aquatox.2015.11.011

Fonte E, Ferreira P, Guilhermino L (2016) Temperature rise and microplastics interact with the toxicity of the antibiotic cefalexin to juveniles of the common goby (Pomatoschistus microps): post-exposure predatory behaviour, acetylcholinesterase activity and lipid peroxidation. Aquat Toxicol 180:173-185. https://doi.org/10.1016/j.aquatox.2016.09.015

Franzellitti S, Capolupo M, Wathsala RHGR, Valbonesi P, Fabbri E (2019) The multixenobiotic resistance system as a possible protective response triggered by microplastic ingestion in Mediterranean mussels (Mytilus galloprovincialis): larvae and adult stages. Comp Biochem Physiol C Toxicol Pharmacol 219:50-58. https://doi.org/10.1016/j.cbpc.2019.02.005

Frydkjær CK, Iversen N, Roslev P (2017) Ingestion and egestion of microplastics by the cladoceran Daphnia magna: effects of regular and irregular shaped plastic and sorbed phenanthrene. Bull Environ Contam Toxicol 99(6):655-661. https://doi.org/10.1007/s00128-017-2186-3

Gallo F, Fossi C, Weber R, Santillo D, Sousa J, Ingram I, Nadal A, Romano D (2018) Marine litter plastics and microplastics and their toxic chemicals components: the need for urgent preventive measures. Environ Sci Eur 30(1):13. https://doi.org/10.1186/s12302-018-0139-z

Galloway TS, Cole M, Lewis C (2017) Interactions of microplastic debris throughout the marine ecosystem. Nat Ecol Evol 1(5). https://doi.org/10.1038/s41559-017-0116

Gambardella C, Morgana S, Ferrando S, Bramini M, Piazza V, Costa E, Garaventa F, Faimali M (2017) Effects of polystyrene microbeads in marine planktonic crustaceans. Ecotoxicol Environ Saf 145:250-257. https://doi.org/10.1016/j.ecoenv.2017.07.036

Gambardella C, Morgana S, Bramini M, Rotini A, Manfra L, Migliore L, Piazza V, Garaventa F, Faimali M (2018) Ecotoxicological effects of polystyrene microbeads in a battery of marine organisms belonging to different trophic levels. Mar Environ Res 141:313-321. https://doi. org/10.1016/j.marenvres.2018.09.023

Gardon T, Reisser C, Soyez C, Quillien V, Le Moullac G (2018) Microplastics affect energy balance and gametogenesis in the pearl oyster Pinctada margaritifera. Environ Sci Technol 52(9):5277-5286. https://doi.org/10.1021/acs.est.8b00168

Garrido S, Linares M, Campillo JA, Albentosa M (2019) Effect of microplastics on the toxicity of chlorpyrifos to the microalgae Isochrysis galbana, clone t-ISO. Ecotoxicol Environ Saf 173:103-109. https://doi.org/10.1016/j.ecoenv.2019.02.020

Gerdes Z, Ogonowski M, Nybom I, Ek C, Adolfsson-Erici M, Barth A, Gorokhova E (2019) Microplastic-mediated transport of PCBs? A depuration study with Daphnia magna. PLoS One 14(2). https://doi.org/10.1371/journal.pone.0205378

GESAMP (2019) Guidelines for the monitoring and assessment of plastic litter and microplastics in the ocean. In: Kershaw PJ, Turra A, Galgani F (eds) IMO/FAO/UNESCO-IOC/UNIDO/ WMO/IAEA/UN/UNEP/UNDP/ISA Joint Group of Experts on the Scientific Aspects of Marine Environmental Protection, Rep. Stud. GESAMP No. 99, 130p

GESAMP (2020) Proceedings of the GESAMP International Workshop on assessing the risks associated with plastics and microplastics in the marine environment. In: Kershaw PJ, Carney Almroth B, Villarrubia-Gómez P, Koelmans AA, Gouin T (eds) IMO/FAO/UNESCO-IOC/ UNIDO/WMO/IAEA/UN/UNEP/UNDP/ISA Joint Group of Experts on the Scientific Aspects of Marine Environmental Protection, Reports to GESAMP No. 103, 68 pp

Gomiero A, Strafella P, Pellini G, Salvalaggio V, Fabi G (2018) Comparative effects of ingested PVC micro particles with and without adsorbed benzo(a)pyrene vs. spiked sediments on the cellular and sub cellular processes of the benthic organism Hediste diversicolor. Front Mar Sci 5:99. https://doi.org/10.3389/fmars.2018.00099

Gonçalves C, Martins M, Sobral P, Costa PM, Costa MH (2019) An assessment of the ability to ingest and excrete microplastics by filter-feeders: a case study with the Mediterranean mussel. Environ Pollut 245:600-606. https://doi.org/10.1016/j.envpol.2018.11.038

González-Fernández C, Tallec K, Le Goïc N, Lambert C, Soudant P, Huvet A, Suquet M, Berchel M, Paul-Pont I (2018) Cellular responses of Pacific oyster (Crassostrea gigas) gametes exposed 
in vitro to polystyrene nanoparticles. Chemosphere 208:764-772. https://doi.org/10.1016/j. chemosphere.2018.06.039

González-Fernández C, Toullec J, Lambert C, Le Goïc N, Seoane M, Moriceau B, Huvet A, Berchel M, Vincent D, Courcot L, Soudant P, Paul-Pont I (2019) Do transparent exopolymeric particles (TEP) affect the toxicity of nanoplastics on Chaetoceros neogracile? Environ Pollut 250:873-882. https://doi.org/10.1016/j.envpol.2019.04.093

Granby K, Rainieri S, Rasmussen RR, Kotterman MJJ, Sloth JJ, Cederberg TL, Barranco A, Marques A, Larsen BK (2018) The influence of microplastics and halogenated contaminants in feed on toxicokinetics and gene expression in European seabass (Dicentrarchus labrax). Environ Res 164:430-443. https://doi.org/10.1016/j.envres.2018.02.035

Gray AD, Weinstein JE (2017) Size- and shape-dependent effects of microplastic particles on adult daggerblade grass shrimp (Palaemonetes pugio): uptake and retention of microplastics in grass shrimp. Environ Toxicol Chem. https://doi.org/10.1002/etc.3881

Green DS (2016) Effects of microplastics on European flat oysters, Ostrea edulis and their associated benthic communities. Environ Pollut (Barking, Essex: 1987) 216:95-103. https://doi. org/10.1016/j.envpol.2016.05.043

Green DS, Boots B, Sigwart J, Jiang S, Rocha C (2016) Effects of conventional and biodegradable microplastics on a marine ecosystem engineer (Arenicola marina) and sediment nutrient cycling. Environ Pollut 208(Part B):426-434. https://doi.org/10.1016/j.envpol.2015.10.010

Green DS, Boots B, O'Connor NE, Thompson R (2017) Microplastics affect the ecological functioning of an important biogenic habitat. Environ Sci Technol 51(1):68-77. https://doi. org/10.1021/acs.est.6b04496

Green DS, Colgan TJ, Thompson RC, Carolan JC (2019) Exposure to microplastics reduces attachment strength and alters the haemolymph proteome of blue mussels (Mytilus edulis). Environ Pollut 246:423-434. https://doi.org/10.1016/j.envpol.2018.12.017

Guilhermino L, Vieira LR, Ribeiro D, Tavares AS, Cardoso V, Alves A, Almeida JM (2018) Uptake and effects of the antimicrobial florfenicol, microplastics and their mixtures on freshwater exotic invasive bivalve Corbicula fluminea. Sci Total Environ 622-623:1131-1142. https://doi. org/10.1016/j.scitotenv.2017.12.020

Guven O, Bach L, Munk P, Dinh KV, Mariani P, Nielsen TG (2018) Microplastic does not magnify the acute effect of PAH pyrene on predatory performance of a tropical fish (Lates calcarifer). Aquat Toxicol 198:287-293. https://doi.org/10.1016/j.aquatox.2018.03.011

Haegerbaeumer A, Mueller M-T, Fueser H, Traunspurger W (2019) Impacts of micro- and nanosized plastic particles on benthic invertebrates: a literature review and gap analysis. Front Environ Sci:7. https://doi.org/10.3389/fenvs.2019.00017

Hämer J, Gutow L, Köhler A, Saborowski R (2014) Fate of microplastics in the marine isopod Idotea emarginata. Environ Sci Technol 48(22):13451-13458. https://doi.org/10.1021/ es501385y

Handy RD, van den Brink N, Chappell M, Mühling M, Behra R, Dušinská M, Simpson P, Ahtiainen J, Jha AN, Seiter J, Bednar A, Kennedy A, Fernandes TF, Riediker M (2012) Practical considerations for conducting ecotoxicity test methods with manufactured nanomaterials: what have we learnt so far? Ecotoxicology (London, England) 21(4):933-972. https://doi.org/10.1007/ s10646-012-0862-y

Hankins C, Duffy A, Drisco K (2018) Scleractinian coral microplastic ingestion: potential calcification effects, size limits, and retention. Mar Pollut Bull 135:587-593. https://doi.org/10.1016/j. marpolbul.2018.07.067

Hartmann NB, Hüffer T, Thompson RC, Hassellöv M, Verschoor A, Daugaard AE, Rist S, Karlsson T, Brennholt N, Cole M, Herrling MP, Hess MC, Ivleva NP, Lusher AL, Wagner M (2019) Are we speaking the same language? Recommendations for a definition and categorization framework for plastic debris. Environ Sci Technol 53(3):1039-1047. https://doi.org/10.1021/ acs.est.8b05297

Heindler FM, Alajmi F, Huerlimann R, Zeng C, Newman SJ, Vamvounis G, van Herwerden L (2017) Toxic effects of polyethylene terephthalate microparticles and $\mathrm{Di}$ (2-ethylhexyl)phthal- 
ate on the calanoid copepod, Parvocalanus crassirostris. Ecotoxicol Environ Saf 141:298-305. https://doi.org/10.1016/j.ecoenv.2017.03.029

Hermabessiere L, Dehaut A, Paul-Pont I, Lacroix C, Jezequel R, Soudant P, Duflos G (2017) Occurrence and effects of plastic additives on marine environments and organisms: a review. Chemosphere 182:781-793. https://doi.org/10.1016/j.chemosphere.2017.05.096

Hermsen E, Mintenig SM, Besseling E, Koelmans AA (2018) Quality criteria for the analysis of microplastic in biota samples: a critical review. Environ Sci Technol 52(18):10230-10240. https://doi.org/10.1021/acs.est.8b01611

Horton AA, Svendsen C, Williams RJ, Spurgeon DJ, Lahive E (2017) Large microplastic particles in sediments of tributaries of the River Thames, UK - abundance, sources and methods for effective quantification. Mar Pollut Bull 114(1):218-226. https://doi.org/10.1016/j. marpolbul.2016.09.004

Horton AA, Jürgens MD, Lahive E, van Bodegom PM, Vijver MG (2018) The influence of exposure and physiology on microplastic ingestion by the freshwater fish Rutilus rutilus (roach) in the river Thames, UK. Environ Pollut 236:188-194. https://doi.org/10.1016/j.envpol.2018.01.044

Huerta Lwanga E, Gertsen H, Gooren H, Peters P, Salánki T, van der Ploeg M, Besseling E, Koelmans AA, Geissen V (2016) Microplastics in the terrestrial ecosystem: implications for Lumbricus terrestris (Oligochaeta, Lumbricidae). Environ Sci Technol 50(5):2685-2691. https://doi.org/10.1021/acs.est.5b05478

Imhof HK, Laforsch C (2016) Hazardous or not - are adult and juvenile individuals of Potamopyrgus antipodarum affected by non-buoyant microplastic particles? Environ Pollut 218:383-391. https://doi.org/10.1016/j.envpol.2016.07.017

Imhof HK, Rusek J, Thiel M, Wolinska J, Laforsch C (2017) Do microplastic particles affect Daphnia magna at the morphological, life history and molecular level? PLoS One 12(11). https://doi.org/10.1371/journal.pone.0187590

Jacob H, Gilson A, Lanctôt C, Besson M, Metian M, Lecchini D (2019) No effect of polystyrene microplastics on foraging activity and survival in a post-larvae coral-reef fish, Acanthurus triostegus. Bull Environ Contam Toxicol 102(4):457-461. https://doi.org/10.1007/ s00128-019-02587-0

Jemec A, Horvat P, Kunej U, Bele M, Kržan A (2016) Uptake and effects of microplastic textile fibers on freshwater crustacean Daphnia magna. Environ Pollut 219:201-209. https://doi. org/10.1016/j.envpol.2016.10.037

Jeong C-B, Won E-J, Kang H-M, Lee M-C, Hwang D-S, Hwang U-K, Zhou B, Souissi S, Lee S-J, Lee J-S (2016) Microplastic size-dependent toxicity, oxidative stress induction, and p-JNK and p-p38 activation in the monogonont rotifer (Brachionus koreanus). Environ Sci Technol 50(16):8849-8857. https://doi.org/10.1021/acs.est.6b01441

Jeong C-B, Kang H-M, Lee M-C, Kim D-H, Han J, Hwang D-S, Souissi S, Lee S-J, Shin K-H, Park HG, Lee J-S (2017) Adverse effects of microplastics and oxidative stress-induced MAPK/ Nrf2 pathway-mediated defense mechanisms in the marine copepod Paracyclopina nana. Sci Rep 7. https://doi.org/10.1038/srep41323

Jin Y, Xia J, Pan Z, Yang J, Wang W, Fu Z (2018) Polystyrene microplastics induce microbiota dysbiosis and inflammation in the gut of adult zebrafish. Environ Pollut 235:322-329. https:// doi.org/10.1016/j.envpol.2017.12.088

Jovanović B, Gökdağ K, Güven O, Emre Y, Whitley EM, Kideys AE (2018) Virgin microplastics are not causing imminent harm to fish after dietary exposure. Mar Pollut Bull 130:123-131. https://doi.org/10.1016/j.marpolbul.2018.03.016

Judy JD, Williams M, Gregg A, Oliver D, Kumar A, Kookana R, Kirby JK (2019) Microplastics in municipal mixed-waste organic outputs induce minimal short to long-term toxicity in key terrestrial biota. Environ Pollut 252:522-531. https://doi.org/10.1016/j.envpol.2019.05.027

Kallenbach EMF, Rødland ES, Buenaventura NT, Hurley R (2021) Microplastics in terrestrial and freshwater environments. In: Bank MS (ed) Microplastic in the environment: pattern and process. Springer, Amsterdam 
Kaposi KL, Mos B, Kelaher BP, Dworjanyn SA (2014) Ingestion of microplastic has limited impact on a marine larva. Environ Sci Technol 48(3):1638-1645. https://doi.org/10.1021/es404295e

Karami A, Romano N, Galloway T, Hamzah H (2016) Virgin microplastics cause toxicity and modulate the impacts of phenanthrene on biomarker responses in African catfish (Clarias gariеріnus). Environ Res 151:58-70. https://doi.org/10.1016/j.envres.2016.07.024

Karami A, Groman DB, Wilson SP, Ismail P, Neela VK (2017) Biomarker responses in zebrafish (Danio rerio) larvae exposed to pristine low-density polyethylene fragments. Environ Pollut 223:466-475. https://doi.org/10.1016/j.envpol.2017.01.047

Kim SW, An Y-J (2019) Soil microplastics inhibit the movement of springtail species. Environ Int 126:699-706. https://doi.org/10.1016/j.envint.2019.02.067

Kim D, Chae Y, An Y-J (2017) Mixture toxicity of nickel and microplastics with different functional groups on Daphnia magna. Environ Sci Technol 51(21):12852-12858. https://doi. org/10.1021/acs.est.7b03732

Koelmans AA, Bakir A, Burton GA, Janssen CR (2016) Microplastic as a vector for chemicals in the aquatic environment: critical review and model-supported reinterpretation of empirical studies. Environ Sci Technol 50(7):3315-3326. https://doi.org/10.1021/acs.est.5b06069

Koelmans AA, Mohamed Nor NH, Hermsen E, Kooi M, Mintenig SM, De France J (2019) Microplastics in freshwaters and drinking water: critical review and assessment of data quality. Water Res 155:410-422. https://doi.org/10.1016/j.watres.2019.02.054

Kögel T, Bjorøy $\varnothing$, Toto B, Bienfait AM, Sanden M (2020) Micro- and nanoplastic toxicity on aquatic life: determining factors. Sci Total Environ 709:136050. https://doi.org/10.1016/j. scitotenv.2019.136050

Kokalj AJ, Kunej U, Skalar T (2018) Screening study of four environmentally relevant microplastic pollutants: uptake and effects on Daphnia magna and Artemia franciscana. Chemosphere 208:522-529. https://doi.org/10.1016/j.chemosphere.2018.05.172

Kooi M, Koelmans AA (2019) Simplifying microplastic via continuous probability distributions for size, shape, and density. Environ Sci Technol Lett 6(9):551-557. https://doi.org/10.1021/ acs.estlett.9b00379

Kühn S, Bravo Rebolledo EL, van Franeker JA (2015) Deleterious effects of litter on marine life. In: Bergmann M, Gutow L, Klages M (eds) Marine anthropogenic litter. Springer, Berlin, pp 75-116. https://doi.org/10.1007/978-3-319-16510-3_4

Lagarde F, Olivier O, Zanella M, Daniel P, Hiard S, Caruso A (2016) Microplastic interactions with freshwater microalgae: hetero-aggregation and changes in plastic density appear strongly dependent on polymer type. Environ Pollut 215:331-339. https://doi.org/10.1016/j. envpol.2016.05.006

Lambert S, Wagner M (2016) Characterisation of nanoplastics during the degradation of polystyrene. Chemosphere 145:265-268. https://doi.org/10.1016/j.chemosphere.2015.11.078

Law KL, Thompson RC (2014) Microplastics in the seas. Science 345(6193):144-145. https://doi. org/10.1126/science. 1254065

Lee K-W, Shim WJ, Kwon OY, Kang J-H (2013) Size-dependent effects of micro polystyrene particles in the marine copepod Tigriopus japonicus. Environ Sci Technol 47(19):11278-11283. https://doi.org/10.1021/es401932b

Lei L, Liu M, Song Y, Lu S, Hu J, Cao C, Xie B, Shi H, He D (2018a) Polystyrene (nano)microplastics cause size-dependent neurotoxicity, oxidative damage and other adverse effects in Caenorhabditis elegans. Environ Sci Nano 5(8):2009-2020. https://doi.org/10.1039/ C8EN00412A

Lei L, Wu S, Lu S, Liu M, Song Y, Fu Z, Shi H, Raley-Susman KM, He D (2018b) Microplastic particles cause intestinal damage and other adverse effects in zebrafish Danio rerio and nematode Caenorhabditis elegans. Sci Total Environ 619-620:1-8. https://doi.org/10.1016/j. scitotenv.2017.11.103

LeMoine CMR, Kelleher BM, Lagarde R, Northam C, Elebute OO, Cassone BJ (2018) Transcriptional effects of polyethylene microplastics ingestion in developing zebrafish (Danio rerio). Environ Pollut 243:591-600. https://doi.org/10.1016/j.envpol.2018.08.084 
Leung J, Chan KYK (2018) Microplastics reduced posterior segment regeneration rate of the polychaete Perinereis aibuhitensis. Mar Pollut Bull 129(2):782-786. https://doi.org/10.1016/j. marpolbul.2017.10.072

Lin W, Jiang R, Xiong Y, Wu J, Xu J, Zheng J, Zhu F, Ouyang G (2019a) Quantification of the combined toxic effect of polychlorinated biphenyls and nano-sized polystyrene on Daphnia magna. J Hazard Mater 364:531-536. https://doi.org/10.1016/j.jhazmat.2018.10.056

Lin W, Jiang R, Hu S, Xiao X, Wu J, Wei S, Xiong Y, Ouyang G (2019b) Investigating the toxicities of different functionalized polystyrene nanoplastics on Daphnia magna. Ecotoxicol Environ Saf 180:509-516. https://doi.org/10.1016/j.ecoenv.2019.05.036

Liu Z, Cai M, Yu P, Chen M, Wu D, Zhang M, Zhao Y (2018) Age-dependent survival, stress defense, and AMPK in Daphnia pulex after short-term exposure to a polystyrene nanoplastic. Aquat Toxicol (Amsterdam, Netherlands) 204:1-8. https://doi.org/10.1016/j.aquatox.2018.08.017

Liu Z, Yu P, Cai M, Wu D, Zhang M, Huang Y, Zhao Y (2019) Polystyrene nanoplastic exposure induces immobilization, reproduction, and stress defense in the freshwater cladoceran Daphnia pulex. Chemosphere 215:74-81. https://doi.org/10.1016/j.chemosphere.2018.09.176

Lohmann R (2017) Microplastics are not important for the cycling and bioaccumulation of organic pollutants in the oceans-but should microplastics be considered POPs themselves? Integr Environ Assess Manag 13(3):460-465. https://doi.org/10.1002/ieam.1914

Long M, Paul-Pont I, Hégaret H, Moriceau B, Lambert C, Huvet A, Soudant P (2017) Interactions between polystyrene microplastics and marine phytoplankton lead to species-specific heteroaggregation. Environ Pollut 228:454-463. https://doi.org/10.1016/j.envpol.2017.05.047

Lowry GV, Espinasse BP, Badireddy AR, Richardson CJ, Reinsch BC, Bryant LD, Bone AJ, Deonarine A, Chae S, Therezien M, Colman BP, Hsu-Kim H, Bernhardt ES, Matson CW, Wiesner MR (2012) Long-term transformation and fate of manufactured Ag nanoparticles in a simulated large scale freshwater emergent wetland. Environ Sci Technol 46(13):7027-7036. https://doi.org/10.1021/es204608d

Lu K, Qiao R, An H, Zhang Y (2018) Influence of microplastics on the accumulation and chronic toxic effects of cadmium in zebrafish (Danio rerio). Chemosphere 202:514-520. https://doi. org/10.1016/j.chemosphere.2018.03.145

Luan L, Wang X, Zheng H, Liu L, Luo X, Li F (2019) Differential toxicity of functionalized polystyrene microplastics to clams (Meretrix meretrix) at three key development stages of life history. Mar Pollut Bull 139:346-354. https://doi.org/10.1016/j.marpolbul.2019.01.003

Luís LG, Ferreira P, Fonte E, Oliveira M, Guilhermino L (2015) Does the presence of microplastics influence the acute toxicity of chromium(VI) to early juveniles of the common goby (Pomatoschistus microps)? A study with juveniles from two wild estuarine populations. Aquat Toxicol 164:163-174. https://doi.org/10.1016/j.aquatox.2015.04.018

Lundebye A-K, Lusher AL, Bank MS (2021) Microplastics in the ocean and seafood: implications for food security. In: Bank MS (ed) Microplastic in the environment: pattern and process. Springer, Amsterdam, pp xx- $\mathrm{xx}$

Luo H, Xiang Y, He D, Li Y, Zhao Y, Wang S, Pan X (2019) Leaching behavior of fluorescent additives from microplastics and the toxicity of leachate to Chlorella vulgaris. Sci Total Environ 678:1-9. https://doi.org/10.1016/j.scitotenv.2019.04.401

Lusher A, Hollman P, Mendoza-Hill J (2017) Microplastics in fisheries and aquaculture: status of knowledge on their occurrence and implications for aquatic organisms and food safety. FAO

Ma Y, Huang A, Cao S, Sun F, Wang L, Guo H, Ji R (2016) Effects of nanoplastics and microplastics on toxicity, bioaccumulation, and environmental fate of phenanthrene in fresh water. Environ Pollut (Barking Essex: 1987) 219:166-173. https://doi.org/10.1016/j. envpol.2016.10.061

Magni S, Gagné F, André C, Della Torre C, Auclair J, Hanana H, Parenti CC, Bonasoro F, Binelli A (2018) Evaluation of uptake and chronic toxicity of virgin polystyrene microbeads in freshwater zebra mussel Dreissena polymorpha (Mollusca: Bivalvia). Sci Total Environ 631-632:778-788. https://doi.org/10.1016/j.scitotenv.2018.03.075 
Mak CW, Ching-Fong Yeung K, Chan KM (2019) Acute toxic effects of polyethylene microplastic on adult zebrafish. Ecotoxicol Environ Saf 182:109442. https://doi.org/10.1016/j. ecoenv.2019.109442

Malinich TD, Chou N, Sepúlveda MS, Höök TO (2018) No evidence of microplastic impacts on consumption or growth of larval Pimephales promelas: no microplastic impacts on consumption or growth of larvae. Environ Toxicol Chem 37(11):2912-2918. https://doi.org/10.1002/ etc. 4257

Manfra L, Rotini A, Bergami E, Grassi G, Faleri C, Corsi I (2017) Comparative ecotoxicity of polystyrene nanoparticles in natural seawater and reconstituted seawater using the rotifer Brachionus plicatilis. Ecotoxicol Environ Saf 145:557-563. https://doi.org/10.1016/j. ecoenv.2017.07.068

Mao Y, Ai H, Chen Y, Zhang Z, Zeng P, Kang L, Li W, Gu W, He Q, Li H (2018) Phytoplankton response to polystyrene microplastics: perspective from an entire growth period. Chemosphere 208:59-68. https://doi.org/10.1016/j.chemosphere.2018.05.170

Mattsson K, Ekvall MT, Hansson L-A, Linse S, Malmendal A, Cedervall T (2015) Altered behavior, physiology, and metabolism in fish exposed to polystyrene nanoparticles. Environ Sci Technol 49(1):553-561. https://doi.org/10.1021/es5053655

Mattsson K, Johnson EV, Malmendal A, Linse S, Hansson L-A, Cedervall T (2017) Brain damage and behavioural disorders in fish induced by plastic nanoparticles delivered through the food chain. Sci Rep 7(1):11452. https://doi.org/10.1038/s41598-017-10813-0

Mazurais D, Ernande B, Quazuguel P, Severe A, Huelvan C, Madec L, Mouchel O, Soudant P, Robbens J, Huvet A, Zambonino-Infante J (2015) Evaluation of the impact of polyethylene microbeads ingestion in European sea bass (Dicentrarchus labrax) larvae. Mar Environ Res 112:78-85. https://doi.org/10.1016/j.marenvres.2015.09.009

Messinetti S, Mercurio S, Parolini M, Sugni M, Pennati R (2018) Effects of polystyrene microplastics on early stages of two marine invertebrates with different feeding strategies. Environ Pollut 237:1080-1087. https://doi.org/10.1016/j.envpol.2017.11.030

Mudunkotuwa A, Grassian H (2011) The devil is in the details (or the surface): impact of surface structure and surface energetics on understanding the behavior of nanomaterials in the environment. J Environ Monit 13(5):1135-1144. https://doi.org/10.1039/C1EM00002K

Nasser F, Lynch I (2016) Secreted protein eco-corona mediates uptake and impacts of polystyrene nanoparticles on Daphnia magna. J Proteome 137:45-51. https://doi.org/10.1016/j. jprot.2015.09.005

Nel AE, Mädler L, Velegol D, Xia T, Hoek EMV, Somasundaran P, Klaessig F, Castranova V, Thompson M (2009) Understanding biophysicochemical interactions at the nano-bio interface. Nat Mater 8(7):543-557. https://doi.org/10.1038/nmat2442

Nolte TM, Hartmann NB, Kleijn JM, Garnæs J, van de Meent D, Jan Hendriks A, Baun A (2017) The toxicity of plastic nanoparticles to green algae as influenced by surface modification, medium hardness and cellular adsorption. Aquat Toxicol 183:11-20. https://doi.org/10.1016/j. aquatox.2016.12.005

Ogonowski M, Schür C, Jarsén Å, Gorokhova E (2016) The effects of natural and anthropogenic microparticles on individual fitness in Daphnia magna. PLoS One 11(5):e0155063. https://doi. org/10.1371/journal.pone. 0155063

Oliveira M, Ribeiro A, Hylland K, Guilhermino L (2013) Single and combined effects of microplastics and pyrene on juveniles (0+ group) of the common goby Pomatoschistus microps (Teleostei, Gobiidae). Ecol Indic 34:641-647. https://doi.org/10.1016/j.ecolind.2013.06.019

Oliveira P, Barboza LGA, Branco V, Figueiredo N, Carvalho C, Guilhermino L (2018) Effects of microplastics and mercury in the freshwater bivalve Corbicula fluminea (Müller, 1774): filtration rate, biochemical biomarkers and mercury bioconcentration. Ecotoxicol Environ Saf 164:155-163. https://doi.org/10.1016/j.ecoenv.2018.07.062

Ott WR (1990) A physical explanation of the lognormality of pollutant concentrations. J Air Waste Manage Assoc 40(10):1378-1383. https://doi.org/10.1080/10473289.1990.10466789

Pacheco A, Martins A, Guilhermino L (2018) Toxicological interactions induced by chronic exposure to gold nanoparticles and microplastics mixtures in Daphnia magna. Sci Total Environ 628-629:474-483. https://doi.org/10.1016/j.scitotenv.2018.02.081 
Paul-Pont I, Lacroix C, González Fernández C, Hégaret H, Lambert C, Le Goïc N, Frère L, Cassone A-L, Sussarellu R, Fabioux C, Guyomarch J, Albentosa M, Huvet A, Soudant P (2016) Exposure of marine mussels Mytilus spp. to polystyrene microplastics: toxicity and influence on fluoranthene bioaccumulation. Environ Pollut 216:724-737. https://doi.org/10.1016/j. envpol.2016.06.039

Paul-Pont I, Tallec K, Gonzalez-Fernandez C, Lambert C, Vincent D, Mazurais D, ZamboninoInfante J-L, Brotons G, Lagarde F, Fabioux C, Soudant P, Huvet A (2018) Constraints and priorities for conducting experimental exposures of marine organisms to microplastics. Front Mar Sci 5. https://doi.org/10.3389/fmars.2018.00252

Phuong NN, Zalouk-Vergnoux A, Poirier L, Kamari A, Châtel A, Mouneyrac C, Lagarde F (2016) Is there any consistency between the microplastics found in the field and those used in laboratory experiments? Environ Pollut 211:111-123. https://doi.org/10.1016/j.envpol.2015.12.035

Pitt JA, Kozal JS, Jayasundara N, Massarsky A, Trevisan R, Geitner N, Wiesner M, Levin ED, Di Giulio RT (2018) Uptake, tissue distribution, and toxicity of polystyrene nanoparticles in developing zebrafish (Danio rerio). Aquat Toxicol 194:185-194. https://doi.org/10.1016/j. aquatox.2017.11.017

Pittura L, Avio CG, GiulianiME, d'Errico G, Keiter SH, Cormier B, Gorbi S, Regoli F (2018) Microplastics as vehicles of environmental PAHs to marine organisms: Combined chemical and physical hazards to the mediterranean mussels, Mytilus galloprovincialis. Front Marine Sci 5. https://doi.org/10.3389/fmars.2018.00103

PlasticsEurope (2019) PlasticsEurope-plastics—the facts 2019. An analysis of European plastics production, demand and waste data

Posthuma L, van Gils J, Zijp MC, van de Meent D, de Zwart D (2019) Species sensitivity distributions for use in environmental protection, assessment, and management of aquatic ecosystems for 12386 chemicals. Environ Toxicol Chem 38(4):905-917. https://doi.org/10.1002/etc.4373

Prakash V, Dwivedi S, Gautam K, Seth M, Anbumani S (2020) Occurrence and ecotoxicological effects of microplastics on aquatic and terrestrial ecosystems. In: He D, Luo Y (eds) Microplastics in terrestrial environments: emerging contaminants and major challenges. Springer, Switzerland, pp 223-243. https://doi.org/10.1007/698_2020_456

Prata JC, Lavorante BRBO, Montenegro M d CBSM, Guilhermino L (2018) Influence of microplastics on the toxicity of the pharmaceuticals procainamide and doxycycline on the marine microalgae Tetraselmis chuii. Aquat Toxicol 197:143-152. https://doi.org/10.1016/j. aquatox.2018.02.015

Prata JC, da Costa JP, Lopes I, Duarte AC, Rocha-Santos T (2019) Effects of microplastics on microalgae populations: a critical review. Sci Total Environ 665:400-405. https://doi. org/10.1016/j.scitotenv.2019.02.132

Prata JC, Reis V, da Costa JP, Mouneyrac C, Duarte AC, Rocha-Santos T (2021) Contamination issues as a challenge in quality control and quality assurance in microplastics analytics. $\mathrm{J}$ Hazard Mater 403:123660. https://doi.org/10.1016/j.jhazmat.2020.123660

Prendergast-Miller MT, Katsiamides A, Abbass M, Sturzenbaum SR, Thorpe KL, Hodson ME (2019) Polyester-derived microfibre impacts on the soil-dwelling earthworm Lumbricus terrestris. Environ Pollut 251:453-459. https://doi.org/10.1016/j.envpol.2019.05.037

R Core Team (2020) R: A language and environment for statistical computing. R Foundation for Statistical Computing, Vienna, Austria. URL https://www.R-project.org/

Rainieri S, Conlledo N, Larsen BK, Granby K, Barranco A (2018) Combined effects of microplastics and chemical contaminants on the organ toxicity of zebrafish (Danio rerio). Environ Res 162:135-143. https://doi.org/10.1016/j.envres.2017.12.019

Redondo-Hasselerharm PE, Falahudin D, Peeters ETHM, Koelmans AA (2018) Microplastic effect thresholds for freshwater benthic macroinvertebrates. Environ Sci Technol 52(4):2278-2286. https://doi.org/10.1021/acs.est.7b05367

Rehse S, Kloas W, Zarfl C (2016) Short-term exposure with high concentrations of pristine microplastic particles leads to immobilisation of Daphnia magna. Chemosphere 153:91-99. https:// doi.org/10.1016/j.chemosphere.2016.02.133 
Rehse S, Kloas W, Zarfl C (2018) Microplastics reduce short-term effects of environmental contaminants. Part I: Effects of bisphenol A on freshwater zooplankton are lower in presence of polyamide particles. Int J Environ Res Public Health 15(2). https://doi.org/10.3390/ ijerph 15020280

Reichert J, Schellenberg J, Schubert P, Wilke T (2018) Responses of reef building corals to microplastic exposure. Environ Pollut 237:955-960. https://doi.org/10.1016/j.envpol.2017.11.006

Revel M, Lagarde F, Perrein-Ettajani H, Bruneau M, Akcha F, Sussarellu R, Rouxel J, Costil K, Decottignies P, Cognie B, Châtel A, Mouneyrac C (2019) Tissue-specific biomarker responses in the blue mussel mytilus spp. exposed to a mixture of microplastics at environmentally relevant concentrations. Front Environ Sci:7. https://doi.org/10.3389/fenvs.2019.00033

Ribeiro F, Garcia AR, Pereira BP, Fonseca M, Mestre NC, Fonseca TG, Ilharco LM, Bebianno MJ (2017) Microplastics effects in Scrobicularia plana. Mar Pollut Bull 122(1-2):379-391. https://doi.org/10.1016/j.marpolbul.2017.06.078

Rillig MC, Ziersch L, Hempel S (2017) Microplastic transport in soil by earthworms. Sci Rep 7(1):1-6. https://doi.org/10.1038/s41598-017-01594-7

Rist S, Assidqi K, Zamani NP, Appel D, Perschke M, Huhn M, Lenz M (2016) Suspended micro-sized PVC particles impair the performance and decrease survival in the Asian green mussel Perna viridis. Mar Pollut Bull 111(1):213-220. https://doi.org/10.1016/j.marpolbul.2016.07.006

Rist S, Baun A, Hartmann NB (2017) Ingestion of micro- and nanoplastics in Daphnia magna quantification of body burdens and assessment of feeding rates and reproduction. Environ Pollut 228:398-407. https://doi.org/10.1016/j.envpol.2017.05.048

Rist S, Baun A, Almeda R, Hartmann NB (2019) Ingestion and effects of micro- and nanoplastics in blue mussel (Mytilus edulis) larvae. Mar Pollut Bull 140:423-430. https://doi.org/10.1016/j. marpolbul.2019.01.069

Rochman CM (2015) The complex mixture, fate and toxicity of chemicals associated with plastic debris in the marine environment. In: Bergmann M, Gutow L, Klages M (eds) Marine anthropogenic litter. Springer, Switzerland, pp 117-140. https://doi.org/10.1007/978-3-319-16510-3_5

Rochman CM, Hoh E, Kurobe T, Teh SJ (2013) Ingested plastic transfers hazardous chemicals to fish and induces hepatic stress. Sci Rep 3. https://doi.org/10.1038/srep03263

Rochman CM, Parnis JM, Browne MA, Serrato S, Reiner EJ, Robson M, Young T, Diamond ML, Teh SJ (2017) Direct and indirect effects of different types of microplastics on freshwater prey (Corbicula fluminea) and their predator (Acipenser transmontanus). PLoS One 12(11):e0187664. https://doi.org/10.1371/journal.pone.0187664

Rochman CM, Brookson C, Bikker J, Djuric N, Earn A, Bucci K, Athey S, Huntington A, McIlwraith H, Munno K, Frond HD, Kolomijeca A, Erdle L, Grbic J, Bayoumi M, Borrelle SB, Wu T, Santoro S, Werbowski LM et al (2019) Rethinking microplastics as a diverse contaminant suite. Environ Toxicol Chem 38(4):703-711. https://doi.org/10.1002/etc.4371

Rodríguez-Seijo A, Lourenço J, Rocha-Santos TAP, da Costa J, Duarte AC, Vala H, Pereira R (2017) Histopathological and molecular effects of microplastics in Eisenia andrei Bouché. Environ Pollut 220:495-503. https://doi.org/10.1016/j.envpol.2016.09.092

Rodríguez-Seijo A, da Costa JP, Rocha-Santos T, Duarte AC, Pereira R (2018a) Oxidative stress, energy metabolism and molecular responses of earthworms (Eisenia fetida) exposed to lowdensity polyethylene microplastics. Environ Sci Pollut Res Int 25(33):33599-33610. https:// doi.org/10.1007/s11356-018-3317-z

Rodríguez-Seijo A, Santos B, da Silva EF, Cachada A, Pereira R (2018b) Low-density polyethylene microplastics as a source and carriers of agrochemicals to soil and earthworms. Environ Chem 16(1):8-17. https://doi.org/10.1071/EN18162

Santana MFM, Moreira FT, Pereira CDS, Abessa DMS, Turra A (2018) Continuous exposure to microplastics does not cause physiological effects in the cultivated mussel Perna perna. Arch Environ Contam Toxicol 74(4):594-604. https://doi.org/10.1007/s00244-018-0504-3

SAPEA (2019) A scientific perspective on microplastics in nature and society (Evidence Review Report No. 4). EU 
Selonen S, Dolar A, Jemec Kokalj A, Skalar T, Parramon Dolcet L, Hurley R, van Gestel CAM (2020) Exploring the impacts of plastics in soil - the effects of polyester textile fibers on soil invertebrates. Sci Total Environ 700:134451. https://doi.org/10.1016/j.scitotenv.2019.134451

Sendra M, Staffieri E, Yeste MP, Moreno-Garrido I, Gatica JM, Corsi I, Blasco J (2019) Are the primary characteristics of polystyrene nanoplastics responsible for toxicity and ad/absorption in the marine diatom Phaeodactylum tricornutum? Environ Pollut (Barking, Essex: 1987) 249:610-619. https://doi.org/10.1016/j.envpol.2019.03.047

Seoane M, González-Fernández C, Soudant P, Huvet A, Esperanza M, Cid Á, Paul-Pont I (2019) Polystyrene microbeads modulate the energy metabolism of the marine diatom Chaetoceros neogracile. Environ Pollut (Barking, Essex: 1987) 251:363-371. https://doi.org/10.1016/j. envpol.2019.04.142

Skjolding LM, Ašmonaitė G, Jølck RI, Andresen TL, Selck H, Baun A, Sturve J (2017) An assessment of the importance of exposure routes to the uptake and internal localisation of fluorescent nanoparticles in zebrafish (Danio rerio), using light sheet microscopy. Nanotoxicology 11(3):351-359. https://doi.org/10.1080/17435390.2017.1306128

Snell TW, Hicks DG (2011) Assessing toxicity of nanoparticles using Brachionus manjavacas (Rotifera). Environ Toxicol 26(2):146-152. https://doi.org/10.1002/tox.20538

Song Y, Cao C, Qiu R, Hu J, Liu M, Lu S, Shi H, Raley-Susman KM, He D (2019) Uptake and adverse effects of polyethylene terephthalate microplastics fibers on terrestrial snails (Achatina fulica) after soil exposure. Environ Pollut 250:447-455. https://doi.org/10.1016/j. envpol.2019.04.066

Straub S, Hirsch PE, Burkhardt-Holm P (2017) Biodegradable and petroleum-based microplastics do not differ in their ingestion and excretion but in their biological effects in a freshwater invertebrate Gammarus fossarum. Int J Environ Res Public Health 14(7). https://doi.org/10.3390/ ijerph 14070774

Strungaru S-A, Jijie R, Nicoara M, Plavan G, Faggio C (2019) Micro- (nano) plastics in freshwater ecosystems: abundance, toxicological impact and quantification methodology. TrAC Trends Anal Chem 110:116-128. https://doi.org/10.1016/j.trac.2018.10.025

Sussarellu R, Suquet M, Thomas Y, Lambert C, Fabioux C, Pernet MEJ, Goïc NL, Quillien V, Mingant C, Epelboin Y, Corporeau C, Guyomarch J, Robbens J, Paul-Pont I, Soudant P, Huvet A (2016) Oyster reproduction is affected by exposure to polystyrene microplastics. Proc Natl Acad Sci 113(9):2430-2435. https://doi.org/10.1073/pnas.1519019113

Syakti AD, Jaya JV, Rahman A, Hidayati NV, Raza'i TS, Idris F, Trenggono M, Doumenq P, Chou LM (2019) Bleaching and necrosis of staghorn coral (Acropora formosa) in laboratory assays: immediate impact of LDPE microplastics. Chemosphere 228:528-535. https://doi. org/10.1016/j.chemosphere.2019.04.156

Tallec K, Huvet A, Di Poi C, González-Fernández C, Lambert C, Petton B, Le Goïc N, Berchel M, Soudant P, Paul-Pont I (2018) Nanoplastics impaired oyster free living stages, gametes and embryos. Environ Pollut 242:1226-1235. https://doi.org/10.1016/j.envpol.2018.08.020

Tang J, Ni X, Zhou Z, Wang L, Lin S (2018) Acute microplastic exposure raises stress response and suppresses detoxification and immune capacities in the scleractinian coral Pocillopora damicornis. Environ Pollut 243:66-74. https://doi.org/10.1016/j.envpol.2018.08.045

Tang J, Wang X, Yin J, Han Y, Yang J, Lu X, Xie T, Akbar S, Lyu K, Yang Z (2019) Molecular characterization of thioredoxin reductase in waterflea Daphnia magna and its expression regulation by polystyrene microplastics. Aquat Toxicol 208:90-97. https://doi.org/10.1016/j. aquatox.2019.01.001

Ter Halle A, Jeanneau L, Martignac M, Jardé E, Pedrono B, Brach L, Gigault J (2017) Nanoplastic in the North Atlantic subtropical gyre. Environ Sci Technol 51(23):13689-13697. https://doi. org/10.1021/acs.est.7b03667

Teuten EL, Saquing JM, Knappe DRU, Barlaz MA, Jonsson S, Björn A, Rowland SJ, Thompson RC, Galloway TS, Yamashita R, Ochi D, Watanuki Y, Moore C, Viet PH, Tana TS, Prudente M, Boonyatumanond R, Zakaria MP, Akkhavong K et al (2009) Transport and release of chemi- 
cals from plastics to the environment and to wildlife. Philos Trans R Soc Lond B Biol Sci 364(1526):2027-2045. https://doi.org/10.1098/rstb.2008.0284

Thiagarajan V, Natarajan L, Seenivasan R, Chandrasekaran N, Mukherjee A (2019) Influence of differently functionalized polystyrene microplastics on the toxic effects of P25 TiO2 NPs towards marine algae Chlorella sp. Aquat Toxicol 207:208-216. https://doi.org/10.1016/j. aquatox.2018.12.014

Thompson RC, Olsen Y, Mitchell RP, Davis A, Rowland SJ, John AWG, McGonigle D, Russell AE (2004) Lost at sea: where is all the plastic? Science (New York, NY) 304(5672):838. https:// doi.org/10.1126/science.1094559

Tosetto L, Brown C, Williamson JE (2016) Microplastics on beaches: ingestion and behavioural consequences for beachhoppers. Mar Biol 163(10):199. https://doi.org/10.1007/ s00227-016-2973-0

Tosetto L, Williamson JE, Brown C (2017) Trophic transfer of microplastics does not affect fish personality. Anim Behav 123:159-167. https://doi.org/10.1016/j.anbehav.2016.10.035

Ugolini A, Ungherese G, Ciofini M, Lapucci A, Camaiti M (2013) Microplastic debris in sandhoppers. Estuar Coast Shelf Sci 129:19-22. https://doi.org/10.1016/j.ecss.2013.05.026

Van Cauwenberghe L (2016) Occurrence, effects and risks of marine microplastics [Thesis submitted in fulfilment of the requirements for the degree of Doctor $(\mathrm{PhD})$ in Applied Biological Sciences]. http://hdl.handle.net/1854/LU-7097647

Van Cauwenberghe L, Janssen CR (2014) Microplastics in bivalves cultured for human consumption. Environ Pollut (Barking, Essex: 1987) 193:65-70. https://doi.org/10.1016/j. envpol.2014.06.010

Van Cauwenberghe L, Claessens M, Vandegehuchte MB, Janssen CR (2015) Microplastics are taken up by mussels (Mytilus edulis) and lugworms (Arenicola marina) living in natural habitats. Environ Pollut 199:10-17. https://doi.org/10.1016/j.envpol.2015.01.008

Vicentini DS, Nogueira DJ, Melegari SP, Arl M, Köerich JS, Cruz L, Justino NM, Oscar BV, Puerari RC, da Silva MLN, Simioni C, Ouriques LC, Matias MS, de Castilhos Junior AB, Matias WG (2019) Toxicological evaluation and quantification of ingested metal-core nanoplastic by Daphnia magna through fluorescence and inductively coupled plasma-mass spectrometric methods. Environ Toxicol Chem 38(10):2101-2110. https://doi.org/10.1002/etc.4528

Vince J, Hardesty BD (2017) Plastic pollution challenges in marine and coastal environments: from local to global governance. Restor Ecol 25(1):123-128. https://doi.org/10.1111/rec.12388

VKM (2019) Microplastics; occurrence, levels and implications for environment and human health related to food.. Scientific Opinion of the Scientific Steering Committee of the Norwegian Scientific Committee for Food and Environment

von Moos N, Burkhardt-Holm P, Köhler A (2012) Uptake and effects of microplastics on cells and tissue of the blue mussel Mytilus edulis L. after an experimental exposure. Environ Sci Technol 46(20):11327-11335. https://doi.org/10.1021/es302332w

Wang J, Coffin S, Sun C, Schlenk D, Gan J (2019a) Negligible effects of microplastics on animal fitness and HOC bioaccumulation in earthworm Eisenia fetida in soil. Environ Pollut 249:776-784. https://doi.org/10.1016/j.envpol.2019.03.102

Wang W, Gao H, Jin S, Li R, Na G (2019b) The ecotoxicological effects of microplastics on aquatic food web, from primary producer to human: a review. Ecotoxicol Environ Saf 173:110-117. https://doi.org/10.1016/j.ecoenv.2019.01.113

Wang J, Li Y, Lu L, Zheng M, Zhang X, Tian H, Wang W, Ru S (2019c) Polystyrene microplastics cause tissue damages, sex-specific reproductive disruption and transgenerational effects in marine medaka (Oryzias melastigma). Environ Pollut 254:113024. https://doi.org/10.1016/j. envpol.2019.113024

Wang W, Ge J, Yu X (2020) Bioavailability and toxicity of microplastics to fish species: a review. Ecotoxicol Environ Saf 189:109913. https://doi.org/10.1016/j.ecoenv.2019.109913

Ward JE, Kach DJ (2009) Marine aggregates facilitate ingestion of nanoparticles by suspension-feeding bivalves. Mar Environ Res 68(3):137-142. https://doi.org/10.1016/j. marenvres.2009.05.002 
Ward JE, Zhao S, Holohan BA, Mladinich KM, Griffin TW, Wozniak J, Shumway SE (2019) Selective ingestion and egestion of plastic particles by the blue mussel (Mytilus edulis) and eastern oyster (Crassostrea virginica): implications for using bivalves as bioindicators of microplastic pollution. Environ Sci Technol 53(15):8776-8784. https://doi.org/10.1021/acs. est.9b02073

Watts AJR, Urbina MA, Corr S, Lewis C, Galloway TS (2015) Ingestion of plastic microfibers by the crab Carcinus maenas and its effect on food consumption and energy balance. Environ Sci Technol 49(24):14597-14604. https://doi.org/10.1021/acs.est.5b04026

Weber A, Scherer C, Brennholt N, Reifferscheid G, Wagner M (2018) PET microplastics do not negatively affect the survival, development, metabolism and feeding activity of the freshwater invertebrate Gammarus pulex. Environ Pollut 234:181-189. https://doi.org/10.1016/j. envpol.2017.11.014

Wegner A, Besseling E, Foekema EM, Kamermans P, Koelmans AA (2012) Effects of nanopolystyrene on the feeding behavior of the blue mussel (Mytilus edulis L.). Environ Toxicol Chem/ SETAC 31(11):2490-2497. https://doi.org/10.1002/etc.1984

Welden NAC, Cowie PR (2016) Long-term microplastic retention causes reduced body condition in the langoustine, Nephrops norvegicus. Environ Pollut 218:895-900. https://doi.org/10.1016/j. envpol.2016.08.020

Wen B, Zhang N, Jin S-R, Chen Z-Z, Gao J-Z, Liu Y, Liu H-P, Xu Z (2018a) Microplastics have a more profound impact than elevated temperatures on the predatory performance, digestion and energy metabolism of an Amazonian cichlid. Aquat Toxicol 195:67-76. https://doi. org/10.1016/j.aquatox.2017.12.010

Wen B, Jin S-R, Chen Z-Z, Gao J-Z, Liu Y-N, Liu J-H, Feng X-S (2018b) Single and combined effects of microplastics and cadmium on the cadmium accumulation, antioxidant defence and innate immunity of the discus fish (Symphysodon aequifasciatus). Environ Pollut 243:462-471. https://doi.org/10.1016/j.envpol.2018.09.029

Windsor FM, Durance I, Horton AA, Thompson RC, Tyler CR, Ormerod SJ (2019) A catchmentscale perspective of plastic pollution. Glob Chang Biol 25(4):1207-1221. https://doi. org/10.1111/gcb.14572

Woods MN, Stack ME, Fields DM, Shaw SD, Matrai PA (2018) Microplastic fiber uptake, ingestion, and egestion rates in the blue mussel (Mytilus edulis). Mar Pollut Bull 137:638-645. https://doi.org/10.1016/j.marpolbul.2018.10.061

Wright SL, Rowe D, Thompson RC, Galloway TS (2013) Microplastic ingestion decreases energy reserves in marine worms. Curr Biol 23(23):R1031-R1033. https://doi.org/10.1016/j. cub.2013.10.068

Wu J, Jiang R, Lin W, Ouyang G (2019a) Effect of salinity and humic acid on the aggregation and toxicity of polystyrene nanoplastics with different functional groups and charges. Environ Pollut 245:836-843. https://doi.org/10.1016/j.envpol.2018.11.055

Wu Y, Guo P, Zhang X, Zhang Y, Xie S, Deng J (2019b) Effect of microplastics exposure on the photosynthesis system of freshwater algae. J Hazard Mater 374:219-227. https://doi. org/10.1016/j.jhazmat.2019.04.039

Yu P, Liu Z, Wu D, Chen M, Lv W, Zhao Y (2018) Accumulation of polystyrene microplastics in juvenile Eriocheir sinensis and oxidative stress effects in the liver. Aquat Toxicol 200:28-36. https://doi.org/10.1016/j.aquatox.2018.04.015

Zhang C, Chen X, Wang J, Tan L (2017) Toxic effects of microplastic on marine microalgae Skeletonema costatum: interactions between microplastic and algae. Environ Pollut 220:1282-1288. https://doi.org/10.1016/j.envpol.2016.11.005

Zhang P, Yan Z, Lu G, Ji Y (2019) Single and combined effects of microplastics and roxithromycin on Daphnia magna. Environ Sci Pollut Res Int 26(17):17010-17020. https://doi.org/10.1007/ s11356-019-05031-2

Zhao S, Zhu L, Li D (2015) Microplastic in three urban estuaries, China. Environ Pollut (Barking, Essex: 1987) 206:597-604. https://doi.org/10.1016/j.envpol.2015.08.027 
Zhao T, Tan L, Huang W, Wang J (2019) The interactions between micro polyvinyl chloride $(\mathrm{mPVC})$ and marine dinoflagellate Karenia mikimotoi: the inhibition of growth, chlorophyll and photosynthetic efficiency. Environ Pollut (Barking, Essex: 1987) 247:883-889. https://doi. org/10.1016/j.envpol.2019.01.114

Zhu D, Chen Q-L, An X-L, Yang X-R, Christie P, Ke X, Wu L-H, Zhu Y-G (2018) Exposure of soil collembolans to microplastics perturbs their gut microbiota and alters their isotopic composition. Soil Biol Biochem 116:302-310. https://doi.org/10.1016/j.soilbio.2017.10.027

Zhu Z, Wang S, Zhao F, Wang S, Liu F, Liu G (2019) Joint toxicity of microplastics with triclosan to marine microalgae Skeletonema costatum. Environ Pollut 246:509-517. https://doi. org/10.1016/j.envpol.2018.12.044

Ziajahromi S, Kumar A, Neale PA, Leusch FDL (2017) Impact of microplastic beads and fibers on waterflea (Ceriodaphnia dubia) survival, growth, and reproduction: implications of single and mixture exposures. Environ Sci Technol 10

Ziajahromi S, Kumar A, Neale PA, Leusch FDL (2018) Environmentally relevant concentrations of polyethylene microplastics negatively impact the survival, growth and emergence of sediment-dwelling invertebrates. Environ Pollut 236:425-431. https://doi.org/10.1016/j. envpol.2018.01.094

Open Access This chapter is licensed under the terms of the Creative Commons Attribution 4.0 International License (http://creativecommons.org/licenses/by/4.0/), which permits use, sharing, adaptation, distribution and reproduction in any medium or format, as long as you give appropriate credit to the original author(s) and the source, provide a link to the Creative Commons license and indicate if changes were made.

The images or other third party material in this chapter are included in the chapter's Creative Commons license, unless indicated otherwise in a credit line to the material. If material is not included in the chapter's Creative Commons license and your intended use is not permitted by statutory regulation or exceeds the permitted use, you will need to obtain permission directly from the copyright holder. 